Review

\title{
Crosslinkers for polysaccharides and proteins: Synthesis conditions, mechanisms, and crosslinking efficiency, a review
}

\author{
Alex Carvalho Alavarse a, Emilli Caroline Garcia Frachini ${ }^{\text {a }}$, \\ Rafael Leonardo Cruz Gomes da Silva ${ }^{a}$, Vitoria Hashimoto Lima ${ }^{a}$, Amin Shavandi ${ }^{b}$, \\ Denise Freitas Siqueira Petri ${ }^{\text {a, }}$ *
}

${ }^{a}$ Fundamental Chemistry Department, Institute of Chemistry, University of São Paulo, Av. Prof. Lineu Prestes 748, 05508-000 São Paulo, Brazil

${ }^{\mathrm{b}}$ BioMatter Unit, École polytechnique de Bruxelles, Université Libre de Bruxelles (ULB), 1050 Brussels, Belgium

\section{A R T I C L E I N F O}

\section{Keywords:}

Crosslinkers

Hydrogels

Polysaccharides

Proteins

\begin{abstract}
A B S T R A C T
Polysaccharides and proteins are important macromolecules for developing hydrogels devoted to biomedical applications. Chemical hydrogels offer chemical, mechanical, and dimensional stability than physical hydrogels due to the chemical bonds among the chains mediated by crosslinkers. There are many crosslinkers to synthesize polysaccharides and proteins based on hydrogels. In this review, we revisited the crosslinking reaction mechanisms between synthetic or natural crosslinkers and polysaccharides or proteins. The selected synthetic crosslinkers were glutaraldehyde, carbodiimide, boric acid, sodium trimetaphosphate, $N, N^{\prime}$-methylene bisacrylamide, and polycarboxylic acid, whereas the selected natural crosslinkers included transglutaminase, tyrosinase, horseradish peroxidase, laccase, sortase A, genipin, vanillin, tannic acid, and phytic acid. No less important are the reactions involving click chemistry and the macromolecular crosslinkers for polysaccharides and proteins. Literature examples of polysaccharides or proteins crosslinked by the different strategies were presented along with the corresponding highlights. The general mechanism involved in chemical crosslinking mediated by gamma and UV radiation was discussed, with particular attention to materials commonly used in digital light processing. The evaluation of crosslinking efficiency by gravimetric measurements, rheology, and spectroscopic techniques was presented. Finally, we presented the challenges and opportunities to create safe chemical hydrogels for biomedical applications.
\end{abstract}

\section{Introduction}

IUPAC defines hydrogels as non-fluid colloidal networks or polymer networks where the swelling agent is water [1]. The polymer chains in the network swell, but they do not dissolve in water [2] because the polymer chains are held in a tridimensional structure by joint points. The joint points might be physical interactions or chemical bonds. Phys- ical interactions provide physical hydrogels, which might be susceptible to changes in temperature, $\mathrm{pH}$ and ionic strength, making the solgel transition reversible. Such stimuli-responsive hydrogels are relevant as drug delivery systems; upon changing the $\mathrm{pH}$, temperature and ionic strength to the physiological conditions, the physical interactions that hold the polymer chains in the hydrogel are weakened, allowing the release of the drug to the medium [3]. Hydrogen bonds, hydrophobic or

Abbreviations: AAc, acrylic acid; AC, aminated collagen; ACL, acrylamide; AIBN, Azobisisobutyronitrila; APS, ammonium persulfate; BA, Boric acid; BGP, betaglycerophosphate; BMI, bismaleimide; BTCA, 1,2,3,4-butanetetracarboxylic acid; CDH, carbohydrazide; Chi, Chitosan; CMC, carboxymethyl cellulose; CPCs,

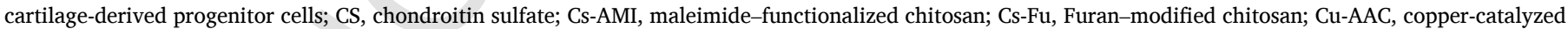

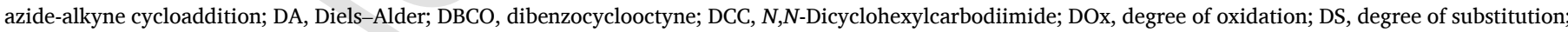
EDC, (1-ethyl-3-(3-dimethylaminopropyl) carbodiimide hydrochloride); E, Elastic Modulus; FGE, furfuryl glycidyl ether; GA, glutaraldehyde; GelMa, Gelatin methacrylamide; HA, hyaluronic acid; HMW, high molecular weight; HPMC, hydroxypropyl methylcellulose; HRP, Horseradish peroxidase; KPS, potassium

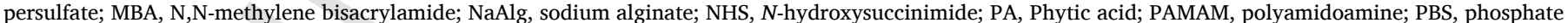
buffered saline; PEG, Poly(ethylene glycol); PNIPAM, poly( $N$-isopropylacrylamide); PVA, poly(vinyl alcohol); SA, Sortase A; SD, swelling degree; SF, Silk fibroin;

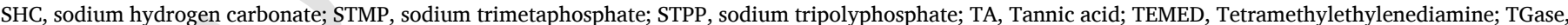
transglutaminase; TNBS, 2,4,6-trinitrobenzenesulfonic acid; TPs, transpeptidases; $\beta$ CD, $\beta$-cyclodextrin

* Corresponding author.

E-mail address: dfsp@iq.usp.br (D.F.S. Petri). 
van der Waals forces are physical intermolecular forces that keep the macromolecules together [4]. The chemical bonds among the polymer chains in chemical hydrogels are generally mediated by a crosslinker agent, making the chemical hydrogels more stable than the physical hydrogels. Changes in temperature, $\mathrm{pH}$ and ionic strength to the physiological conditions might cause changes in the swelling behavior of chemical hydrogels, but they do not disrupt the tridimensional structure. Such stability is advantageous for biomedical applications as scaffolds for cell proliferation and differentiation, implants, bioprinting [5].

Hydrogels based on polysaccharides and proteins are interesting for biomedical applications due to their renewability, biodegradability, biocompatibility, and versatility [6]. However, the hydrogels should present mechanical and chemical stability under physiological conditions [7]. Chemical and physical crosslinking are feasible strategies to connect the biopolymer chains, improving the chemical and mechanical stability of the hydrogel $[8,9]$.

Figs. $1 \mathrm{a}$ and $1 \mathrm{~b}$ show the most common synthetic and natural crosslinkers applied for polysaccharides and proteins, respectively, according to a survey at the PubMed database over the last 20 years [10]. Glutaraldehyde (GA) is the most frequently used crosslinker, although toxicity might be an issue [11]. Carbodiimide, phosphate groups, boric acid (BA), acrylamides, aldehydes, and epoxy compounds have also been often used to prepare biomedical materials. Crosslinking with carbodiimides compounds is advantageous because the resulting matrices have high mechanical stability [12,13], are less toxic than GA, and by-products are water-soluble [14]. Noteworthy, the number of publications reporting sodium trimetaphosphate (STMP) or BA as crosslinking agents has increased considerably in recent years. STMP is a safe and non-toxic crosslinking agent suitable for polysaccharides. BA is commonly used as a crosslinker for polysaccharides such as scleroglucan [15], sodium alginate[16], galactomannan [17], guar gum [18], and starch[19]. The borate-diol linkages contribute to the increase of the self-healing and viscoelastic properties. Furthermore, BA-mediated crosslinking reactions can be conducted at room temperature [20-22].

The unreacted crosslinkers might remain inside the scaffolds, causing biocompatibility issues. For this reason, crosslinking with natural crosslinkers is an increasing trend. The most frequently used natural crosslinkers are genipin, enzymes, citric acid and tannic acid due to their low toxicity. Genipin is the most frequently applied natural crosslinker (Fig. 1), despite its high cost. Some of the main advantages of polycarboxylic acids, such as citric acid, are the low cytotoxicity and low cost [23]. Tannic acid is a plant-derived phenolic compound with antioxidant properties [24], stimulating its application as crosslinkers. Phytic acid (PA) and vanillin also have antioxidant activities and they can be promising candidates for bio-based crosslinkers [25,26].

Although there are many chemically crosslinked hydrogels reported in the literature, comprehensive studies about the different mechanisms involved in the crosslinking reactions under different experimental conditions aiming at biomedical applications are scarce. This review discusses the main reaction mechanisms between the most frequently used synthetic and natural crosslinkers and polysaccharides or proteins, and the reaction conditions. A session was dedicated to the main techniques used for determining the crosslinking degree. Finally, some strategies for selecting the ideal crosslinker will be discussed.

\section{Synthetic crosslinkers}

Fig. 1 shows the large variety of crosslinkers for polysaccharides and proteins. Although dihydrazides and epoxy-based compounds are reported as efficient crosslinkers, this review focuses on the reaction mechanisms involved in the crosslinking with glutaraldehyde, carbodiimide, boric acid, sodium trimetaphosphate, $N, N^{\prime}$-methylene bisacrylamide and polycarboxylic acids. Except for glutaraldehyde, the other synthetic crosslinkers present moderate or low toxicity.

\subsection{Glutaraldehyde}

Glutaraldehyde (GA) is undoubtedly one of the most widely used crosslinkers for proteins or polysaccharides (chitosan) $[27,28]$. In the 1960s, Sabatini and co-workers were the first to report GA applications [29]. They used the GA for cell preservation and tissue fixation. Since then, several applications have been developed, mainly in preparing biomaterials based on proteins and polysaccharides for drug delivery and tissue engineering.

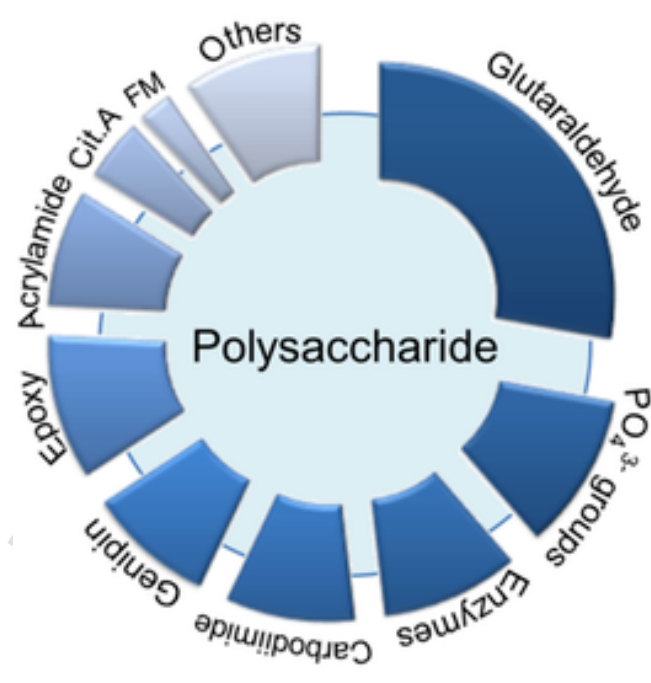

(a)

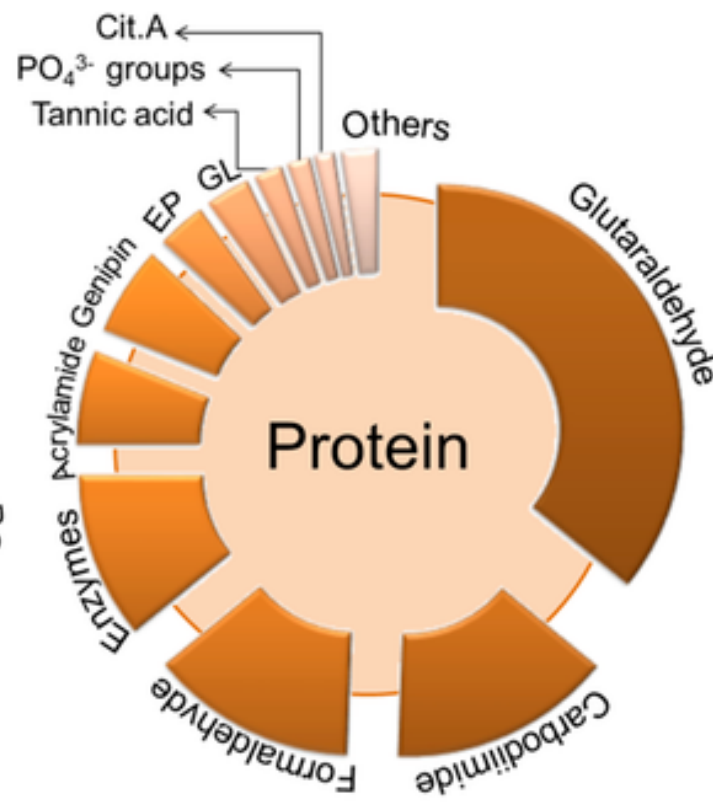

(b)

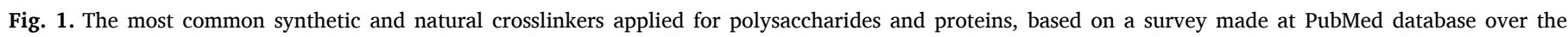
last 20 years [10]. Cit.A: Citric acid; FM:formaldehyde; EP:epoxy; GL:glyoxal. Accessed on July 30 2021. 
GA is a bifunctional aldehyde with low molecular weight, a colorless liquid with a pungent odor, soluble in water, alcohol, and organic solvents [30]. It is generally sold as an aqueous solution with a $\mathrm{pH}$ of $\sim 3-4$. The structure of GA in an aqueous solution has already been the subject of debate and controversy because GA can exist as monomeric dialdehyde, dimer, trimer, and polymer according to $\mathrm{pH}$ conditions. Hardy et al. [31] indicated that the structures I, II, III, and IV coexist in equilibrium (Fig. 2) in the GA solution due to the hydration of structure I after dissolution in water. On the other hand, Whipple and Ruta [32] reported that aqueous GA is mainly formed by cyclic hemiacetal (structure II), distributed between two geometrical isomeric forms (cis and trans). Korn and co-workers also found an equilibrium between free GA (I), cyclic hemiacetal (IV), and their oligomers (V) by $\mathrm{H}^{1}$-NMR analysis [33]. Therefore, in a commercial aqueous GA solution, the structures I, II, III, and IV can coexist under acid conditions. It's worth mentioning that an aldol condensation of GA chains may occur spontaneously in an aqueous solution under basic conditions, favoring structures VI and VII. Richards and Knowles [34] reported significant amounts of $\alpha, \beta$ unsaturated aldehydes (structure VI) that were able to form rings (structure VII). The structures VIII, IX and X also can exist in the aqueous solution of GA in alkaline media, due to polymerization by intramolecular-intermolecular mechanism (VIII) [35] and dimolecular aldol condensation (IX and X) [36,37].

Crosslinking with GA has proved to be a convenient and effective method of improving the physical and chemical properties of hydrogels because it has a high binding affinity with amine, imidazole, and thiol functional groups [38]. Some researchers reported that hydroxyl groups also can undergo crosslinking with GA in acidic conditions because the acid can catalyze the acetalization among hydroxyl and GA's aldehyde groups [38-40].
The covalent bonds formed between GA and primary amines result in a color change to yellow. Two reactions may occur, both involving the amino groups of the polysaccharide or protein, Michael addition or Schiff's base formation. In addition, ring structures can also be formed from dimeric cyclic glutaraldehyde and hemiacetal species [41]. The reactions of GA with amino groups under acidic conditions are shown in Fig. 3. Fig. 3A shows a nucleophilic attack that takes place by the amino group of the proteins to glutaraldehyde. The primary amine should not be protonated because it is a nucleophile attack to the electrophilic carbon. Although the protonated amine groups lose the ability to attack the carbonyl carbon, dehydration is fast under acidic conditions. In contrast, the last step of $\mathrm{C}-\mathrm{O}$ binding cleavage and dehydration is unfavoured under basic conditions [42,43]. The Schiff's base is unstable under very acidic conditions; the imine bond can undergo hydrolysis and regenerate GA and amine groups [44]. Ruijgrok et al [45] showed that heating or ultrasonic radiation can dissolve polymers crosslinked with GA under neutral and acidic $\mathrm{pH}$. Some researchers have added a final reduction step by $\mathrm{NaBH}_{4}$ or $\mathrm{NaBCNH}_{3}$ to stabilize the Schiff's base [46], as shown in Fig. 3B. According to Barbosa et al. [44], the mechanism of glutaraldehyde with amino groups could be mediated by hemiacetal cyclic conformations (structures II and V in Fig. 2), yielding the structures presented in Fig. 3C and Fig. 3D; the reactions can occur by nucleophilic substitution of the amino groups with the hydroxyl group of GA.

Two mechanisms of GA linkage with amino groups under basic conditions have been proposed from $\alpha, \beta$ unsaturated aldehyde (structure VI): Schiff's base and Michael's addition, schematically represented in Fig. 4, mechanisms (1) and (2), respectively [44,47]. In mechanism (1), the reaction among the internal aldehyde groups with primary amino groups yields imine linkages. The second mechanism involves Michael's addition to double $\mathrm{C}=\mathrm{C}$ linkage. Wine et al. [47] were the first to study

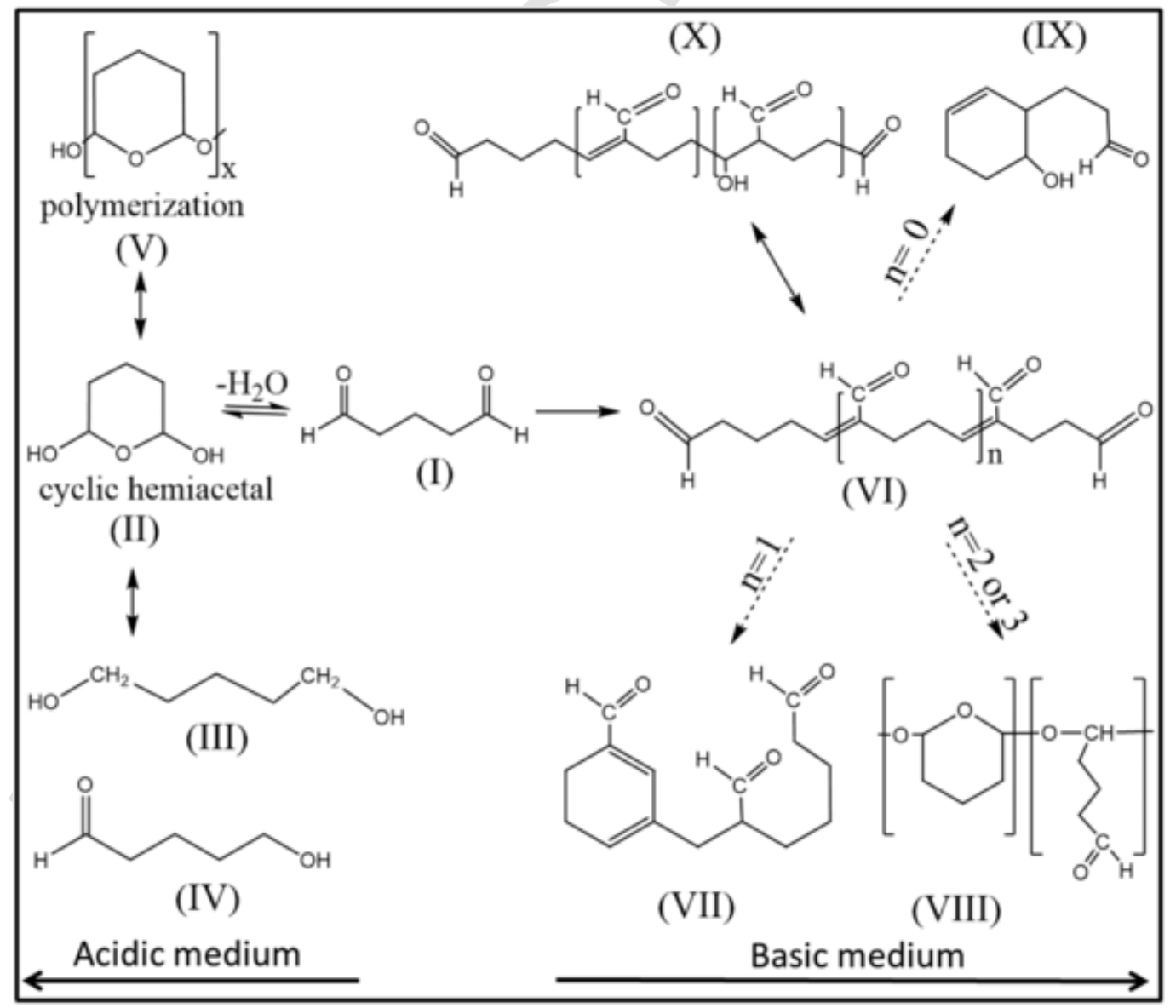

Fig 2. Overview of possible equilibrium structures of GA in aqueous solution, according to the medium pH. Adapted from Ref. [27]. 
(A)

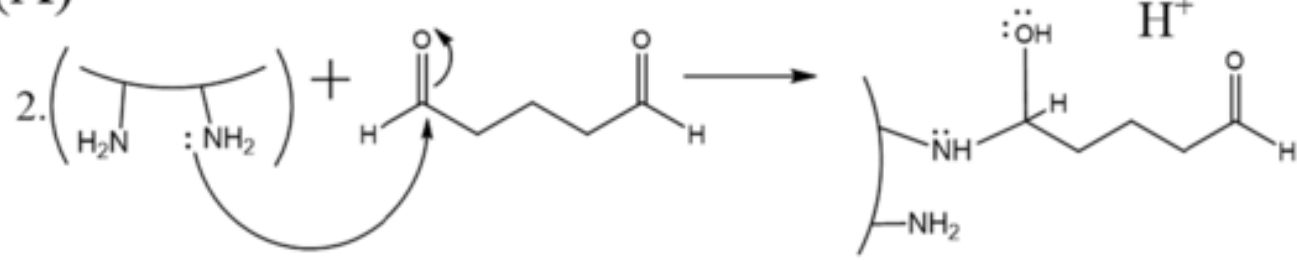<smiles>CC(CCCCC=NC(C)C(C)N)N=CC=O</smiles>

\section{(B) stabilization with reducing agents}<smiles>CC(N)CCCCC=NC(C)C(C)N</smiles><smiles>CC(N)C(C)NCCCCCNC(C)C(C)N</smiles>

(C)<smiles>CC(C)C(C)C(C)NC(C)C(C)NOC1CCCC(O)O1</smiles>

(D)

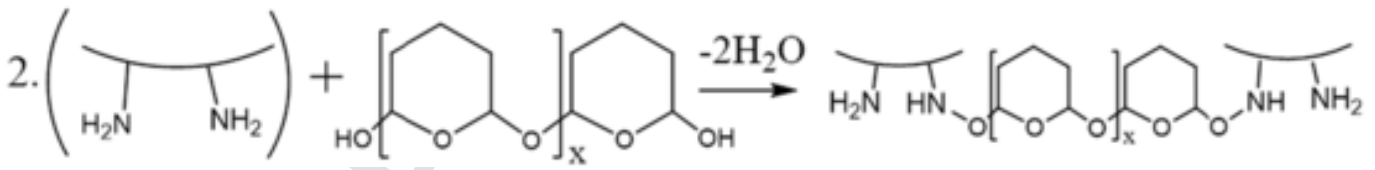

Fig. 3. Reactions mechanism of GA with primary amino groups under acidic conditions.

the GA crosslinking by high-resolution X-ray diffraction. Their findings agree with other reviews, indicating that the product formed under alkaline media results from Schiff's base formation and Michael addition, simultaneously. It also proposes an additional mechanism for crosslinking under acid conditions, namely, the Schiff's base formation and the $\mathrm{C}-\mathrm{N}$ bond by Anti-Markovnikov addition in the neighboring carbon of $\mathrm{C}=\mathrm{N}$. The low stability on the end product obtained via Michael's addition may be justified because breaking the double $\mathrm{C}=\mathrm{C}$ linkage causes instability in the structure [44]. On the other hand, no reduction agent is required to stabilize the adducts when Michael's addition occurs $[27,36]$.

The literature provides excellent reports about the use of GA as crosslinkers for materials based on chitosan [48], chitosan/nano-silica [49], carboxymethyl chitosan/poloxamer [50], hydroxyapatite/chitosan [46], collagen/chitosan [51], chitosan/polyacrylonitrile [52], collagen [53], k-carrageenan [54], gelatin [55,56], gelatin/carrageenan [57], silk fibroin/gelatin [58], and enzymes [44]. Table 1 presents some examples of biomaterials crosslinked with GA, the synthesis conditions and final applications.
GA chemical crosslinking can be performed by in situ or ex-situ processes (Fig. 5). The In situ process is a one-step procedure, in which the crosslinking occurs by blending (mixing) the biopolymer solution with an aqueous GA solution (Fig. 5A). Briefly, glutaraldehyde solution is added to a homogeneous polymer solution and mixed under magnetic stirring. Then, the solution can be cast [46], frozen [59], or kept at room temperature at rest [50] to produce the biomaterials. The ex-situ method refers to immersing the physical hydrogel into an aqueous GA solution [57] or exposing the physical hydrogel to GA vapor [58] (Fig. 5B). Vapor exposition methods are widely described for crosslinking of gelatin nanofibrous matrices [60]. However, both methods can produce stable materials $[54,56,61]$.

Despite commercial availability, low cost, and short reaction time, GA is cytotoxic and should not be released to the medium. Some strategies are proposed to reduce the cytotoxic effects, such as decreasing the GA concentration, extensively rinsing with water or adding molecules able to bind to the unreacted GA molecules. However, there is a growing demand for biocompatible crosslinkers that do not present cytotoxicity. Alternative crosslinking approaches have also been explored, in- 

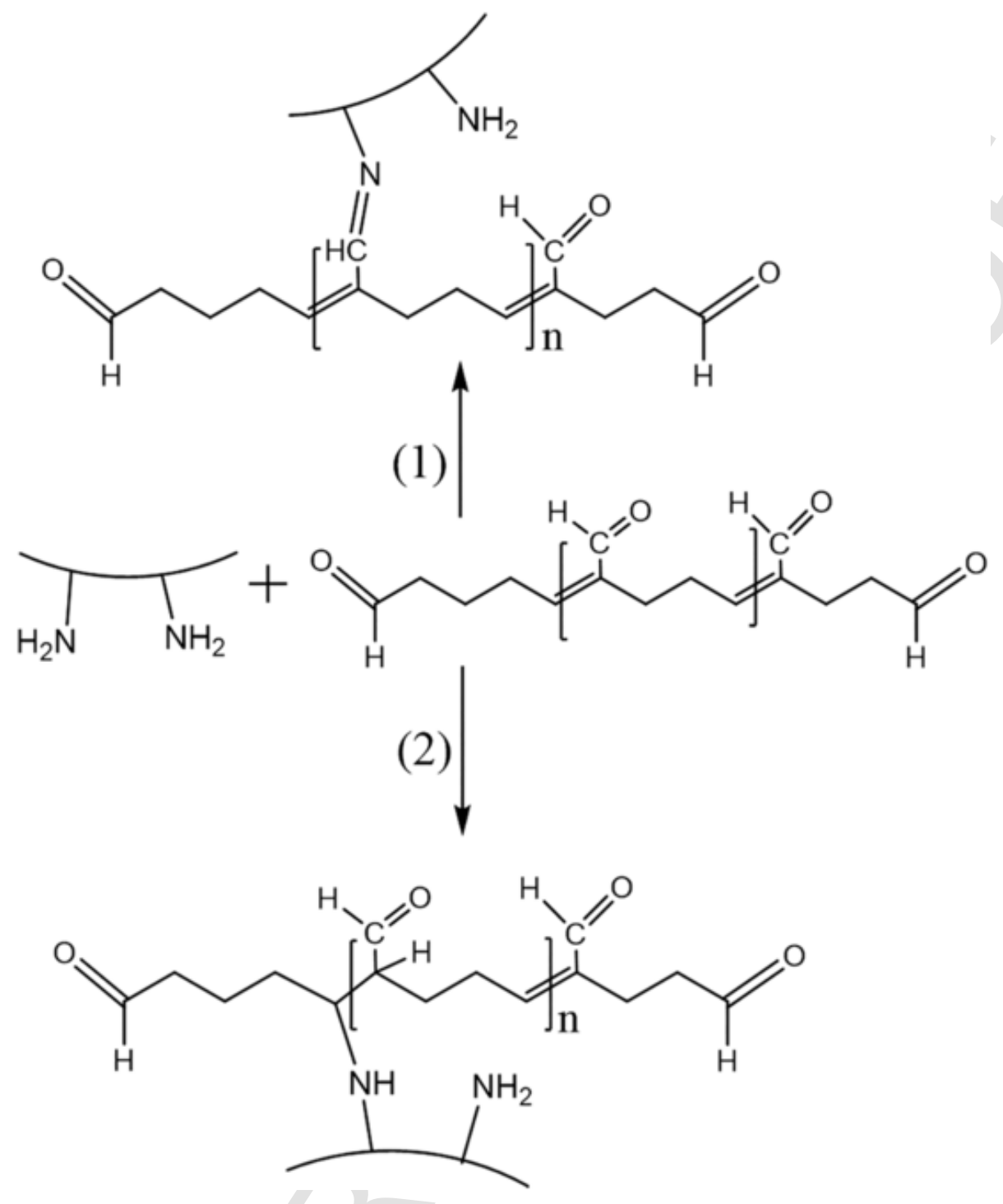

Fig 4. Reactions mechanism of GA with primary amino groups under basic conditions: (1) Schiff base reaction (2) Michael addition.

cluding sodium trimetaphosphate (STMP), enzymatic reactions, and carbodiimide methods. Although GA is one of the most widely used synthetic crosslinkers, the reaction mechanisms with proteins and polysaccharides might be complex due to the many equilibrium structures of GA in aqueous solution (Fig. 2).

\subsection{Carbodiimide}

Carbodiimide compounds are well-known to be non-toxic, biocompatible, and provide "zero-length" amide linkages between carboxylic and amine groups $[62,63]$. Although scaffolds crosslinked via carbodiimide tend to have poorer mechanical properties, softer surface, and lower degradation time compared to GA-crosslinked scaffolds [14,64], they offer the advantage of lower cytotoxicity than GA [13,62,64,65], and the crosslinker excess is easily removed by washing with water or by dialysis.

The most widely used carbodiimides are 1-ethyl-3-(-3-dimethyl aminopropyl) carbodiimide (EDC) and $N, N$-Dicyclohexylcarbodiimide (DCC). EDC is a water-soluble crosslinker capable of activating carboxyl groups to produce the $O$-acylisourea under acidic conditions, indicated as (1) in Fig. 6. Then, in (2), the nucleophilic attack on the $O$ acylisourea by amine or hydroxyl groups occurs to yield a stable linkage of amide or ester [66-71]. DCC also crosslinks carboxylic acids with amine groups in the same way as EDC does, but DCC is used primarily in organic synthesis because it is water-insoluble [41,72].

The $O$-acylisourea can react with primary amino groups, yielding an amide bond according to (2) in Fig. 6. However, this compound can undergo hydrolysis, regenerating the carboxyl group and forming urea as a byproduct, as shown in (3). N-hydroxysuccinimide (NHS) or $\mathrm{N}$ hydroxysulfosuccinimide (sulfo-NHS) can be used with the EDC to improve crosslinking reactivity because it provides intermediates more stable than the $O$-acylisourea, suppresses possible side reactions, and extends the lifetime of the intermediate. Using NHS or Sulfo-NHS makes it feasible to carry out a two-step reaction, as shown in (4) in Fig. 6 [41,72-74].

The optimum $\mathrm{pH}$ to activate the carboxyl groups with EDC is under slightly acidic conditions $[75,76]$. At $\mathrm{pH}<7$, EDC protonation and ionization of carboxyl groups occur. The protonation of nitrogen (in the EDC molecule) reduces the electronic density of carbon and facilitates the nucleophilic attack by carboxylate groups. NHS mediatedcrosslinking, (4) (Fig. 6), is also more efficient under neutral or slightly alkaline conditions. In an acidic environment, primary amines would be protonated and unreactive for nucleophilic attack. A mismatch of optimal $\mathrm{pH}$ conditions occurs in the crosslinking via carbodiimide. Therefore, a pH range between 5 to 8 is recommended [77]. Furthermore, synthesis in a buffered system is required. The 4- 


\section{Table 1}

Examples of biopolymers (polysaccharides or proteins) crosslinked with GA, the corresponding synthesis conditions, and final applications. The blending method refers to the mixture of reactants. The immersion method stands for the immersion of the solid biopolymer material into GA solution. In some cases, the solid materials were exposed to GA vapor. ENV, DD and TE stand for environmental remediation, drug delivery and tissue engineering, respectively.

\begin{tabular}{|c|c|c|c|c|}
\hline Biomaterial & Concentration & $\begin{array}{l}\text { Synthesis } \\
\text { conditions }\end{array}$ & Applications & Ref \\
\hline $\begin{array}{l}\text { Amino- } \\
\text { hydroxyapatite/ } \\
\text { Chitosan }\end{array}$ & $\begin{array}{l}\text { Hpa-NH }{ }_{2} 10 \mathrm{~g} / \mathrm{L} \\
\text { Chitosan } 2 \mathrm{~g} / \mathrm{L} \\
\text { GA } 2.5 \%\end{array}$ & $\begin{array}{l}\text { Blending method: } \\
\mathrm{pH} 3,4,5 \text { or } 6 \text {; } \\
\text { dried at } 60^{\circ} \mathrm{C}\end{array}$ & $\begin{array}{l}\text { ENV- Removal } \\
\text { of diclofenac } \\
\text { sodium }\end{array}$ & [46] \\
\hline Chitosan & $\begin{array}{l}\text { Chitosan } 7.5 \% \\
\text { (w/v) } \\
\text { GA } 0.1 \%\end{array}$ & $\begin{array}{l}\text { Blending method; } \\
\text { Casting method: } \\
\text { dried } 45^{\circ} \mathrm{C}-12 \mathrm{~h}\end{array}$ & - & [48] \\
\hline $\begin{array}{l}\text { Chitosan/ } \\
\text { Nanosilica }\end{array}$ & $\begin{array}{l}\text { Chitosan } 1.5 \% \\
\text { (w/w) } \\
\text { Nanosilica } 0.5 \% \\
\text { (w/v) } \\
\text { GA } 0.1-2 \text { g/L }\end{array}$ & $\begin{array}{l}\text { Immersion } \\
\text { method: GA } \\
\text { solution -pH 10; }\end{array}$ & - & [49] \\
\hline CMC/F127 & $\begin{array}{l}\text { CMC } 1.5-2.5 \% \\
(w / v) \\
\text { F127 } 1.5-20 \% \\
(w / v) \\
\text { GA } 1 \%\end{array}$ & Blending method & $\begin{array}{l}\text { DD-nepafenac } \\
\text { TE-HCECs cells }\end{array}$ & [50] \\
\hline $\begin{array}{l}\text { Chitosan/ } \\
\text { polyacrylonitrile }\end{array}$ & $\begin{array}{l}\text { Chitosan 2\% } \\
\text { (wt) } \\
\text { Polyacryl. } 2 \% \\
\text { (wt) } \\
\text { GA 25\% }\end{array}$ & $\begin{array}{l}\text { Casting method; } \\
\text { GA vapor at room } \\
\text { temperature for } \\
24,48 \text {, and } 96 \mathrm{~h}\end{array}$ & $\begin{array}{l}\text { ENV - Removal } \\
\text { of Rhodamine B } \\
\text { dye }\end{array}$ & [52] \\
\hline Gelatin type B & $\begin{array}{l}\text { Gelatin } 10 \% \\
\text { GA } 2-20 \%\end{array}$ & $\begin{array}{l}\text { Blending method: } \\
\text { for } 24 \mathrm{~h} \text { at room } \\
\text { temperature; } \\
\text { Dried at } 37^{\circ} \mathrm{C}\end{array}$ & $\begin{array}{l}\text { Immobilization } \\
\text { of lipase }\end{array}$ & [55] \\
\hline Gelatin type B & $\begin{array}{l}\text { Gelatin } 6 \%(w / \\
\text { v) } \\
\text { GA } 50 \%(w / t)\end{array}$ & $\begin{array}{l}\text { Blending method } \\
\text { GA solution: } \mathrm{pH} \\
4.5,6.5,11\end{array}$ & - & [56] \\
\hline $\begin{array}{l}\text { Gelatin/ } \\
\text { Carrageenan }\end{array}$ & $\begin{array}{l}\text { Gelatin 1\%(w/ } \\
\text { w) } \\
\text { Carrag. 1-3\% } \\
\text { (w/w) } \\
\text { GA } 5 \%\end{array}$ & $\begin{array}{l}\text { Casting method; } \\
\text { Immersion } \\
\text { method }\end{array}$ & $\begin{array}{l}\text { Microbial } \\
\text { impermeability- } \\
\text { wound dressing }\end{array}$ & [57] \\
\hline $\begin{array}{l}\text { Silk fibroin/ } \\
\text { gelatin }\end{array}$ & $\begin{array}{l}\text { SK/Gelatin } \\
\text { weight ratio: } \\
\text { 100/0, 90/10, } \\
70 / 30 \text { ) } \\
\text { Gelatin } 13 \% \\
\text { (wt) } \\
\text { GA } 20 \%(v / v)\end{array}$ & $\begin{array}{l}\text { Electrospinning } \\
\text { process; } \\
\text { GA vapor at room } \\
\text { temperature for } \\
6 \mathrm{~h}\end{array}$ & $\begin{array}{l}\text { TE-Mouse } \\
\text { fibroblast cells } \\
\text { line } 3 \mathrm{~T} 3\end{array}$ & [58] \\
\hline
\end{tabular}

morpholinoethanesulfonic acid (MES) buffer is the most used in EDC/ NHS crosslinking reactions because it does not carry amino groups, and the crosslinking reaction is fast [76]. Phosphate buffer is also used, but the crosslinking reaction has lower efficiency [76].

The high reactivity and instability of $O$-acylisourea can also induce undesirable side reactions that might be triggered from the carbodiimide activation step. The anhydride formation can occur, if a carboxylate group is close to the $O$-acylisourea, as shown in (5) Fig. 6. Fortunately, the anhydride is reactive with amino groups and the amide linkage still can be formed [41]. Another side reaction is the spontaneous conversion of $\mathrm{O}$-acylisourea intermediate to $\mathrm{N}$-acylurea; the rearrangement is shown in (6) Fig. 6 . These side reactions induce a decreased reaction yield and challenge on product purification. Some authors have reported that a decrease in temperature can suppress $N$-acylurea formation, while the increase in the solvent polarity and EDC excess enhance the formation of $N$-acylurea [66,78,79].

Cammarata et al. [76] reported that carbodiimide excess under alkaline medium is undesirable for amide bond formation, and JafariSabet et al. [80] showed that the excess of EDC worsens the mechanical properties of the scaffolds. On the other hand, Lai [81] reported that to obtain gelatin/chondroitin sulfate (CS) scaffolds providing high cell ad- hesion and proliferation, the optimum NHS/EDC molar ratio was 0.5. Crosslinking via carbodiimide can occur under distinct experimental conditions; some are displayed in Table 2 . The crosslinking via carbodiimide seems to be completed after $12 \mathrm{~h} \mathrm{[82],} \mathrm{but} \mathrm{the} \mathrm{reaction} \mathrm{time} \mathrm{re-}$ ported in the literature range from $0.5 \mathrm{~h}$ to $48 \mathrm{~h}$ [64,83-86]. The crosslinking might take place at $4{ }^{\circ} \mathrm{C}[84,87,88]$, at room temperature $[36,65][90]$, or $37{ }^{\circ} \mathrm{C}[91,92]$, but syntheses at higher temperatures have not been found. Thereby, selecting the suitable reaction conditions, such as EDC/NHS molar ratio, $\mathrm{pH}$ of the medium, reaction time, is important to achieve efficient crosslinking reactions via carbodiimide.

\subsection{Boric acid}

Boric acid $\left(\mathrm{H}_{3} \mathrm{BO}_{3}\right.$ - BA) is a water-soluble weak Lewis acid. Its occurrence is mainly from minerals such as boracite, colemanite, ulexite, borax, and others [93]. Volcanic and geothermal activity, hot springs, physical weathering are the main natural sources of boron compounds. Furthermore, anthropogenic sources such as mining, biomass burning, fossil fuel, and coal combustion also contribute to the release of boron into the environment [94]. Boron compounds have been widely used in the pharmaceutical and cosmetic industries [95,96], cleaning products [97], flame retardants [97,98], glass and fiberglass [97,99], wood preservatives [100], agriculture field [101], biomedical applications [102], and metal alloys [97,103].

The $\mathrm{H}_{3} \mathrm{BO}_{3}$ and borate $\left(\mathrm{B}(\mathrm{OH})^{-}\right.$) are conjugate acid-base pairs, in which pKa is approximately 9.2 depending on ionic strength and temperature. According to Eq. (1), boron is present as boric acid at $\mathrm{pH}<$ pKa, while borate is the dominant species in $\mathrm{pH}>\mathrm{pKa}$ [94]. Borates can form a strong bond with hydroxyl groups due to an empty $p$-orbital in the boron atom that is very electrophilic and rapidly reacts with various nucleophiles to form stable complexes [104]. It has a remarkable ability to crosslink poly(vinyl alcohol). The crosslinking mechanism of borate with polyhydroxy polymers is divided into two steps, so-called monodiol, and di-diol complexation as shown in Fig. 7 [105-107].

$\mathrm{B}(\mathrm{OH})_{3}+\mathrm{H}_{2} \mathrm{O} \rightarrow \mathrm{B}(\mathrm{OH})^{-}+\mathrm{H}^{+} \mathrm{pK}_{\mathrm{a}}=9.24$

Polysaccharides, such as dextrin [108], cellulose [22], guar gum [20,109], starch [110], konjac glucomannan [21], and scleroglucan [111], are crosslinked via BA. The crosslinking degree is $\mathrm{pH}$ and temperature-responsive. Some researchers performed crosslinking reactions via BA at around $70-80{ }^{\circ} \mathrm{C}[107,108,112,113]$. The equilibrium of borate-ion concentration (pKa) depends on temperature, so a pH adjustment must be applied when high temperatures are used in crosslinking reactions [114]. Furthermore, the dehydration step to form a borate ester bond requires a temperature above room temperature.

BA-crosslinked hybrid hydrogels produced in highly acidic conditions are easily collapsed [111]. To overcome this limitation, an adjustment to high $\mathrm{pH}$ is required. Most crosslinking via boric acid/borate is carried out in $\mathrm{pH}>\mathrm{pKa}$ [114]. The polymerization of the boric acid itself can also occur, which forms dimers, linear trimers, cyclic trimers, and complex structures [96]. Grisel and Muller [115] reported that BAcrosslinked hydrogels could not be observed at $\mathrm{pH}<8$ due to the low borate ion concentration. Wang et al. [20] evaluated the $\mathrm{pH}$ effect on the rheological properties of borate-crosslinked hydroxypropyl guar gum hydrogel. Their findings showed the gel viscosity increases with $\mathrm{pH}$ increase up to 11.5. However, over the range of $\mathrm{pH}$ values from 12 to 14 , the hydrogel network collapsed and the viscosity decreased. This can be justified by electrostatic repulsion among the ionic groups of the polymer chains, and the steric effect of ions. Other approaches as further crosslinking with nucleophiles $\left(\mathrm{SO}_{4}{ }^{2-}, \mathrm{PO}_{4}{ }^{3-}, \mathrm{NO}_{3}{ }^{-}\right)$to substitute the boron ions out of the matrix via the Walden inversion mechanisms have also been evaluated; an improvement of the mechanical stability of scaffolds could be observed [116,117]. 


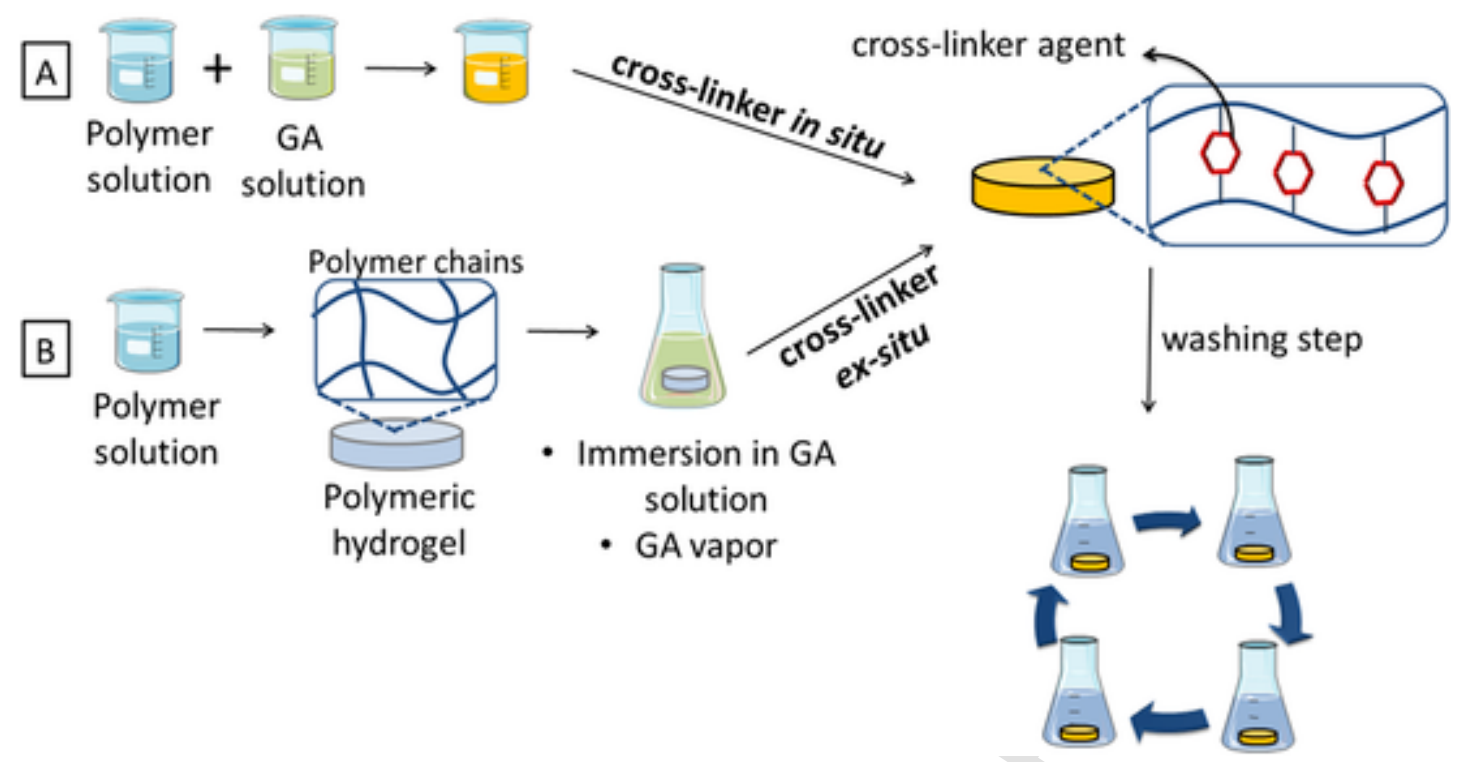

Fig. 5. Chemical crosslinking methods of hydrogels to form $\mathrm{C}=\mathrm{N}$ linkages (Schiff base) with GA. (A) blending polymer and GA solutions, (B) dry hydrogel in contact with solution or vapor of GA.

The BA-crosslinked scaffolds have been applied for drug delivery [118], tissue engineering [108], and environmental remediation [109]. Overall, there is a growing interest in BA-crosslinked hydrogels mainly due to their numerous advantages, such as the facile synthesis in aqueous media, commercial availability, low cost, eco-friendly, and biocompatibility [119,120]. Although boron is linked to harmful effects on human reproduction [121], boron-containing pharmaceuticals have been used in humans [122], and no evidence about genotoxicity and carcinogenicity has been observed [122,123].

\subsection{Sodium trimetaphosphate (STMP)}

Trisodium trimetaphosphate or sodium cyclotriphosphate (STMP, $\mathrm{Na}_{3} \mathrm{P}_{3} \mathrm{O}_{9}$ ) is a salt used as an additive in food and toothpaste $[124,125]$, as dispersing agent [126] and in the water treatment process [127]. The synthesis of STMP occurs via electrolysis of sodium chloride $(\mathrm{NaCl})$ solution forming sodium hydroxide $(\mathrm{NaOH})$, followed by neutralization with orthophosphoric acid $\left(\mathrm{NaH}_{2} \mathrm{PO}_{4}\right)$ and recrystallization [128]. Over the past decades, STMP has been used as crosslinkers for natural polymers [129-132].

Lack and coworkers [107] investigated the species formed during the reaction between STMP and pullulan at $27^{\circ} \mathrm{C}$ and initial pH of 13.5 , by NMR spectroscopy. Several $\mathrm{P}^{31} \mathrm{NMR}$ peaks $\left({ }^{3} J_{\mathrm{PH}}\right)$ were observed: Intermediate species such as sodium polyphosphate $(\delta=0.89 \mathrm{ppm})$ and monophosphate pullulan $(\delta=-20.46 \mathrm{ppm})$; final products based on cross-linked phosphate $\left(\mathrm{PO}_{4}{ }^{3-}\right)$ binding with dual pullulan chains $(\delta=-0.82 \mathrm{ppm})$ and pyrophosphate $\left(\mathrm{P}_{2} \mathrm{O}_{7}{ }^{4-}\right)(\delta=-5.1 \mathrm{ppm})$; and diphosphates $(\delta=-11.5 \mathrm{ppm})$ and monophosphate pullulan (4.43 ppm) moieties as degradation species, respectively. In addition, the reaction period and reactants gradients must be controlled because STMP is totally consumed after $13 \mathrm{~h}$ of reaction. They observed that the initial $\mathrm{pH}$ of 13.5 decreased to 9.5 after $50 \mathrm{~h}$ reaction at $\mathrm{pH} 10$ and the crosslinking reaction was no longer efficient. On the other hand, at $\mathrm{pH}>13.5$ the degradation reactions occur preferentially [133]. Fig. 8 shows schematically the mechanism proposed for the crosslinking of polysaccharide chains and STMP [107]. Under alkaline medium, the intermolecular hydrogen bonding among the polysaccharide chains is considerably reduced due to the formation of alcoholate groups $\mathrm{R}^{-} \mathrm{O}^{-}$ (I). In (II), STMP undergoes nucleophilic attack by the polysaccharidealcoholate chains (R-O-) or $\mathrm{NaOH}$ molecules, generating linear sodium tripolyphosphate (STPP) or mono polysaccharide grafted STPP $\left(\mathrm{STPP}_{\mathrm{g}}\right)$.
Subsequently, STTP $_{g}$ undergoes another nucleophilic attack by R-ONa (III), splitting off into crosslinked chains and pyrophosphate.

The crosslinking reaction of poly (vinyl alcohol) (PVA), which is a biocompatible synthetic polymer, and STMP, performed at $\mathrm{pH} 12$, $120^{\circ} \mathrm{C}$, for $2 \mathrm{~h}$, was investigated by Time of Flight Secondary Ion Mass Spectrometry (ToF-SIMS) [108]. The presence of a fragment assigned to a pyrophosphate group bound to two chains $\left(\mathrm{C}_{4} \mathrm{P}_{2} \mathrm{O}_{7} \mathrm{H}_{6}-\right.$ at $\mathrm{m} / \mathrm{z}=$ 227.96) was identified, but there was no peak relative to fragments of STPP [108], indicating that the crosslinking mechanism presented in Fig. 8 is not necessarily the same as that for the crosslinking of PVA.

The experimental procedure for crosslinking polymer chains with STMP requires initial $\mathrm{pH}>10$, stirring for some hours at mild temperature, followed by casting or freeze-drying [134-137]. The polymer chains stability under an alkaline medium should be considered. Despite this limitation, hydrogels based on STMP crosslinking are excellent 3D matrices. For example, the STMP crosslinked pullulan chains allowed the incorporation of collagen derived from fish skin as secondary polymer into hydrogel matrix, becoming a prominent candidate for skin regeneration with the swelling degree of $390 \%$, enzymatic degradation by collagenase-pullullanase over 7 days was relatively low (37\%) compared with pure pullulan matrix (80.2\%), no cytotoxicity for fibroblasts (NIH3T3) or red blood cells [138]. Biodegradable/edible hemicellulose films produced by crosslinking with STMP at $10 \%$ of polymer presented tensile strength of $30.08 \pm 1.72 \mathrm{MPa}$, which is $118 \%$ higher than that of pure hemicellulose, low oxygen permeability and water vapor permeability, making them adequate for food packing [136].

\subsection{Polycarboxylic acids}

Polycarboxylic acids have been used as crosslinkers for polysaccharides for more than 50 years. In 1967 Rowland and coworkers tested 19 different polycarboxylic acids as crosslinkers for cotton fabrics to replace toxic anti-wrinkle agents based on formaldehyde-based resins [139]. They impregnated the cotton fabrics with a polycarboxylic acid solution at $7.4 \%$, dried at $80{ }^{\circ} \mathrm{C}$ and cured at $160{ }^{\circ} \mathrm{C}$ for $10 \mathrm{~min}$. The unreacted molecules were rinsed with $\mathrm{HCl}$ and distilled water prior to the analyses about the crosslinking efficiency. They observed that (i) polycarboxylic acids with low solubility in water failed to form ester linkages with cotton, (ii) maleic acid was the only dicarboxylic acid that crosslinked cotton cellulose chains efficiently, (iii) polycarboxylic acid 


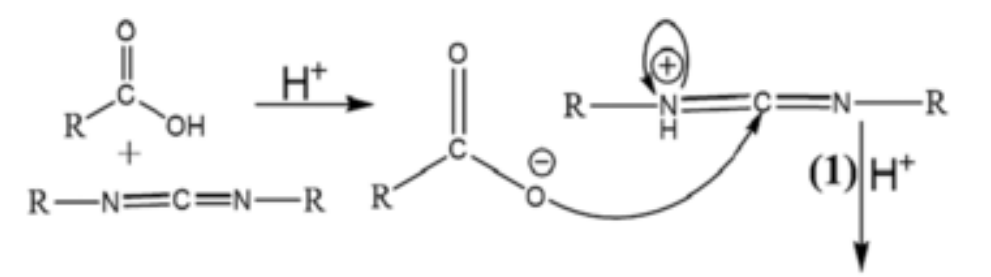<smiles>[R]N=C(CCC([R])(CCC(N)=O)OC(N)=O)NC</smiles><smiles>[R]C(=O)Nc1ccccc1</smiles><smiles>[R]C(=O)Oc1ccccc1</smiles><smiles>[R]NC(=O)N[R]</smiles><smiles>Ic1ccccc1</smiles><smiles>[R]NC(=O)N[R]</smiles>

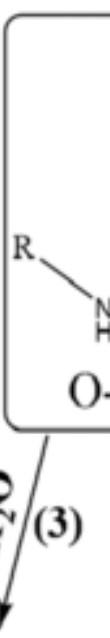<smiles>[R]N=C(C)OC(=O)OCC</smiles>

(6)<smiles>[R]NC(=O)N([R])C([R])=O</smiles><smiles>[R]C(=O)OC([R])=O</smiles><smiles>CC1CCC(=O)N1O</smiles><smiles>[R]C(=O)ON1CCCCCCCCCCCCCC1=O</smiles><smiles>[R]C(=O)O[14C](=O)[18O]C([R])=O</smiles><smiles>O=C1CCC(=O)N1O</smiles><smiles>[R]NC(=O)N[R]</smiles>

Fig. 6. Schematic representation of the crosslinking mechanism via carbodiimide chemistry: (1) activation of the carboxyl groups with $O$-acylisourea formation; (2) reaction between $O$-acylisourea and primary amine or alcohol; (3) hydrolysis of $O$-acylisourea, (4) reaction between $O$-acylisourea and NHS to form a stable intermediate, which reacts with crosslinking with primary amine or alcohol, (5) anhydride formation, and (6) the spontaneous conversion of $O$-acylisourea intermediate to $N$-acylurea.

had three or more carboxylic acid groups per molecule crosslinked more efficiently with cotton.

More than 20 years later, Yang investigated the mechanism of esterification of cotton cellulose with the isomers fumaric acid (trans) and maleic acid (cis), in the presence of sodium hypophosphite using FTIR vibrational spectroscopy [140]. The FTIR spectra evidenced the formation of cyclic anhydrides as intermediates. Sodium hypophosphite accelerated the formation of anhydrides from polycarboxylic acids and reduced the esterification temperature from $200{ }^{\circ} \mathrm{C}$ to $145{ }^{\circ} \mathrm{C}$. The esterification between cotton and fumaric acid was much less favored than between cotton and maleic acid. The difference is due to the easy formation of a five-member ring cyclic anhydride from maleic acid (cisisomer) and the impossible formation of a cyclic anhydride from fu- maric acid (trans-isomer) because the carbonyl groups are on the opposite sides of the $\mathrm{C}=\mathrm{C}$ bond (Fig. 9). This finding evidenced the importance of the anhydride formation on the efficiency of the esterification reaction between cotton cellulose with polycarboxylic acids.

Different catalysts were tested for the esterification of cotton cellulose and polycarboxylic acid. Gillingham and co-workers monitored the anhydride formation of 1,2,3,4-butanetetracarboxylic acid (BTCA) using (sodium carbonate, sodium hypophosphite, or cyanamide as catalysts using FTIR vibrational spectroscopy at different temperatures [141]. The formation of cyclic anhydride was evidenced by the appearance of bands at $1838 \mathrm{~cm}^{-1}, 1781 \mathrm{~cm}^{-1}$ and $1260 \mathrm{~cm}^{-1}$. They observed that the temperature at which the anhydride formation started to take place was $200{ }^{\circ} \mathrm{C}$ in the absence of the catalyst. In the presence of 
Table 2

Some examples of crosslinking reactions via carbodiimide to produce protein or polysaccharide-based hydrogels.

\begin{tabular}{|c|c|c|c|c|}
\hline Biomaterial & $\begin{array}{l}\text { Concentration } \\
\text { of polymers/ } \\
\text { CA }\end{array}$ & $\begin{array}{l}\text { Synthesis } \\
\text { conditions/ } \\
\text { Steps of } \\
\text { reaction }\end{array}$ & Applications & Ref \\
\hline Gelatin & $\begin{array}{l}\text { Gelatin } 10 \% \\
\text { (wt) } \\
\text { EDC } 50 \mathrm{mM}\end{array}$ & $\begin{array}{l}\text { Solvent: water, } \\
\text { ethanol/water } \\
\text { (pH } 4.75 \text { ) } \\
1^{\text {st }} \text { step-Casting } \\
\text { method } \\
2^{\text {nd }} \text { step- } \\
\text { Immersion for } \\
24 \mathrm{~h} \text { at } 25{ }^{\circ} \mathrm{C} \\
3^{\text {rd }} \text { step-dried } \\
\text { in vacuo } \\
\text { for } 24 \mathrm{~h}\end{array}$ & $\begin{array}{l}\text { scaffold for } \\
\text { ophthalmic use: } \\
\text { In vitro- Rat IPE cells; } \\
\text { In vivo- implants in } \\
\text { the eye of rabbits }\end{array}$ & [62] \\
\hline $\begin{array}{l}\text { Hyaluronic acid } \\
\text { (HA) }\end{array}$ & $\begin{array}{l}\text { HA } 0.5 \%(w t) \\
\text { EDC } 100 \mathrm{mM}\end{array}$ & $\begin{array}{l}\text { Solvent: water, } \\
\text { Acetone/water } \\
\text { (pH } 4.75) \\
1^{\text {st }} \text { step-Casting } \\
\text { method } \\
2^{\text {nd }} \text { step- } \\
\text { Immersion } \\
25{ }^{\circ} \mathrm{C} \text { for } \\
2 \text { days. }\end{array}$ & $\begin{array}{l}\text { scaffold for } \\
\text { ophthalmic use: } \\
\text { In vitro- RCECs }\end{array}$ & [64] \\
\hline Gelatin type A/HA & $\begin{array}{l}\text { Gelatin } 4.5 \% \\
\text { (w/v) } \\
\text { HA } 0.09-2.7 \% \\
(w / v) \\
\text { EDC } 50 \mathrm{mM}\end{array}$ & $\begin{array}{l}\text { Solvent: water/ } \\
\text { Ethanol } \\
1^{\text {st }} \text { step- } \\
\text { Electrospinning } \\
2^{\text {nd }} \text { step- } \\
\text { Immersion } \\
\text { method for } 24 \\
\text { h } 4{ }^{\circ} \mathrm{C}\end{array}$ & & [84] \\
\hline $\begin{array}{l}\text { Gelatin fibers (type } \\
\text { A or B) }\end{array}$ & $\begin{array}{l}\text { Gelatin } 2.5- \\
60 \%(\mathrm{w} / \mathrm{v}) \\
\text { EDC } 14 \mathrm{mM} \\
\text { NHS } 5.5 \mathrm{mM}\end{array}$ & $\begin{array}{l}\text { Solvent: formic } \\
\text { acid, water, } \\
\text { ethanol } \\
1^{\text {st }} \text { step- } \\
\text { Electrospinning } \\
2^{\text {nd }} \text { step. } \\
\text { Immersion in } \\
\text { EDC/NHS } \\
\text { solution for } 2 \mathrm{~h}\end{array}$ & & [85] \\
\hline Collagen/HA & $\begin{array}{l}\text { Collagen } 2 \% \\
\text { (w/v) } \\
\text { HA } 1 \%(w / v) \\
\text { EDC } 1.5 \% \\
(w / v) \\
\text { NHS } 0.5 \% \\
(w / v)\end{array}$ & $\begin{array}{l}\text { Solvent: PBS } \\
\text { (pH 7.0) and } \\
\text { HEPES (pH } \\
3.5 \text { ) } \\
1^{\text {st }} \text { step- } \\
\text { Mixture of } \\
\text { polymers } \\
2^{\text {nd }} \text { step-pH } \\
\text { adjusted to } 5.8 \text {; } \\
3^{\text {rd }} \text { step- } \\
\text { Blending: with } \\
\text { EDC/NHS for } \\
24 \mathrm{~h}\end{array}$ & & [86] \\
\hline $\begin{array}{l}\text { Gelatin type B } \\
\text { sponges or } \\
\text { Gelatin/ } \\
\text { Hydroxyapatite } \\
\text { (HP)/chitin } \\
(\mathrm{CW}) / \mathrm{PRGF}\end{array}$ & $\begin{array}{l}\text { Gelatin } \\
30 \mathrm{mg} / \mathrm{mL} \\
\text { HP } 3.33 \mathrm{mg} / \\
\mathrm{mL} \\
\mathrm{CW} 3.33 \mathrm{mg} / \\
\mathrm{mL} \\
\text { PRGF } \\
3.33 \mathrm{mg} / \mathrm{mL} \\
\text { EDC } 50 \mathrm{mM}\end{array}$ & $\begin{array}{l}\text { Solvent: water } \\
1^{\text {st }} \text { step- } \\
\text { Blending } \\
\text { method } \\
2^{\text {nd }} \text { step-stored } \\
\text { overnigh at } \\
4{ }^{\circ} \mathrm{C} \\
3^{\text {rd }} \text { step - } \\
\text { freeze-drying }\end{array}$ & $\begin{array}{l}\text { In vitro-MG-63 } \\
\text { Cells }\end{array}$ & [87] \\
\hline
\end{tabular}

Table 2 (continued)

\begin{tabular}{|c|c|c|c|c|}
\hline Biomaterial & $\begin{array}{l}\text { Concentration } \\
\text { of polymers/ } \\
\text { CA }\end{array}$ & $\begin{array}{l}\text { Synthesis } \\
\text { conditions/ } \\
\text { Steps of } \\
\text { reaction }\end{array}$ & Applications & Ref \\
\hline Alginate & $\begin{array}{l}\text { Chitosan } \\
2 \mathrm{mg} / \mathrm{mL} \\
\text { Alginate } \\
5 \mathrm{mg} / \mathrm{mL} \\
\text { EDC } 50 \mathrm{mg} / \\
\mathrm{mL} \\
\mathrm{NHS} 11 \mathrm{mg} / \\
\mathrm{mL}\end{array}$ & $\begin{array}{l}\text { Solvent: acetic } \\
\text { acid (pH } 4) \text {, } \\
\mathrm{NaCl} \text { in water } \\
1^{\text {st }} \text { step-Layer- } \\
\text { by-layer } \\
2^{\text {nd }} \text { step- } \\
\text { Immersion in } \\
\text { EDC/NHS } \\
\text { solution for } \\
18 \mathrm{~h}, 4^{\circ} \mathrm{C}\end{array}$ & $\begin{array}{l}\text { Wound dressings } \\
\text {-In vitro- NHDF cells }\end{array}$ & [88] \\
\hline Gelatin type A & $\begin{array}{l}\text { Gelatin } 10 \% \\
\text { (wt) } \\
\text { EDC } \\
0.05 \mathrm{mmol} / \\
\mathrm{mg} \\
\mathrm{NHS} \\
0.01 \mathrm{mmol} / \\
\mathrm{mg}\end{array}$ & $\begin{array}{l}\text { Solvent: Acetic } \\
\text { acid } \\
1^{\text {st }} \text { step- } \\
\text { Electrospinning } \\
2^{\text {nd }} \text { step- } \\
\text { Immersion at } \\
25{ }^{\circ} \mathrm{C} \text { for } 48 \mathrm{~h}\end{array}$ & $\begin{array}{l}\text { Scaffold for } \\
\text { ophthalmic use: In } \\
\text { vitro-HCE- } 2 \text { and HLE- } \\
\text { B3 cells; In vivo- } \\
\text { implants in the eye } \\
\text { of rabbits }\end{array}$ & [89] \\
\hline $\begin{array}{l}\text { Gelatin type A or } \\
\text { Albumin/Heparin } \\
\text { gels }\end{array}$ & $\begin{array}{l}\text { Gelatin or } \\
\text { Albumin } 10 \% \\
\text { (wt) } \\
\text { Heparin } 1 \% \\
\text { (wt) } \\
\text { EDC } 0.1- \\
0.15 \mathrm{M}\end{array}$ & $\begin{array}{l}\text { Solvent: PBS } \\
\text { (pH 7.4) or } \\
\text { MES (pH 4.5) } \\
1^{\text {st }} \text { step- } \\
\text { Blending } \\
\text { method at } 37^{\circ} \mathrm{C} \\
\text { for } 1 \mathrm{~h} \text { or } 3 \mathrm{~h}\end{array}$ & $\begin{array}{l}\text { Drug delivery- } \\
\text { release of vascular } \\
\text { endothelial growth } \\
\text { factor }\end{array}$ & [91] \\
\hline Chitosan/Gelatin & $\begin{array}{l}\text { Chitosan } \\
0.5 \%(\mathrm{w} / \mathrm{v}) \\
\text { Gelatin } 5 \% \\
(\mathrm{w} / \mathrm{v}) \\
\text { EDC } 0.25 \% \\
(\mathrm{w} / \mathrm{v})\end{array}$ & $\begin{array}{l}\text { Solvent: PBS } \\
\text { (pH 5.5) } \\
1^{\text {st }} \text { step- } \\
\text { Blending }\end{array}$ & $\begin{array}{l}\text { Prevent } \\
\text { postoperative intra- } \\
\text { abdominal adhesion }\end{array}$ & [92] \\
\hline Alginate & $\begin{array}{l}\text { Alginate 1\% } \\
\text { (w/v) } \\
\text { EDC } 3.8 \% \\
\text { (w/v) } \\
\text { NHS } 1.4 \% \\
\text { (w/v) } \\
\text { Gentamicine } \\
2,1-8.2 \%(w / \\
\text { v) }\end{array}$ & $\begin{array}{l}\text { Solvent: MES } \\
\text { (pH 6) } \\
1^{\text {st }} \text { step- } \\
\text { Blending } \\
\text { method at } \\
24{ }^{\circ} \mathrm{C} \text { for } 24 \mathrm{~h}\end{array}$ & $\begin{array}{l}\text { Gentamicin modified } \\
\text { scaffolds }\end{array}$ & [90] \\
\hline
\end{tabular}

sodium carbonate, sodium hypophosphite and cyanamide, it decreased to $170{ }^{\circ} \mathrm{C}, 160{ }^{\circ} \mathrm{C}$ and $80{ }^{\circ} \mathrm{C}$, respectively. The catalysts that provided the lowest temperatures of anhydride formation, namely, sodium hypophosphite and cyanamide, were considered the best. Fig. 10 shows the mechanism proposed by Brown and co-workers for the formation of cyclic anhydrides from BTCA catalyzed by sodium hypophosphite [142].

Gillingham and co-workers proposed that the reaction would occur with the phosphonic acid (Fig. 11) instead of its salt, forming linear anhydrides. However, the FTIR spectra showed characteristic bands of both linear and cyclic anhydrides and a band at $1147 \mathrm{~cm}^{-1}$, which was assigned to the stretching of $\mathrm{P}=\mathrm{O}$ bond [141]. In the case of citric acid or BTCA (Fig. 10), the formation of cyclic or linear anhydrides in the same acid molecule occurs stepwise. The same acid molecule can react with different polysaccharide chains, increasing the crosslinking efficiency.

The model considering the linear anhydrides (Fig. 12a) yields one ester linkage more than the one considering the cyclic anhydrides (Fig. 12b). Nevertheless, both models clearly show that carboxylic acids with three or more carboxylic acid groups tend to be more efficient than the dicarboxylic acids. Ji and co-workers compared the catalytic effects of sodium hypophosphite (SHP) monohydrate, sodium phosphite dibasic (SP) pentahydrate, monosodium phosphate (MSP) anhydrous, pyrophosphoric acid (PPA) and dichloroacetic acid (DCAA) on the esterification of cellulose with BTCA [143]. They observed that the $\mathrm{pH}$ range of 2.5-3.0, below the BTCA pK $\mathrm{a}_{\mathrm{a}}$ of 3.43, resulted in the best catalytic 


$$
\mathrm{B}(\mathrm{OH})_{3}+\mathrm{H}_{2} \mathrm{O} \rightarrow \mathrm{B}(\mathrm{OH})^{-}+\mathrm{H}^{+} \quad \mathrm{pK}_{\mathrm{a}}=9.24
$$
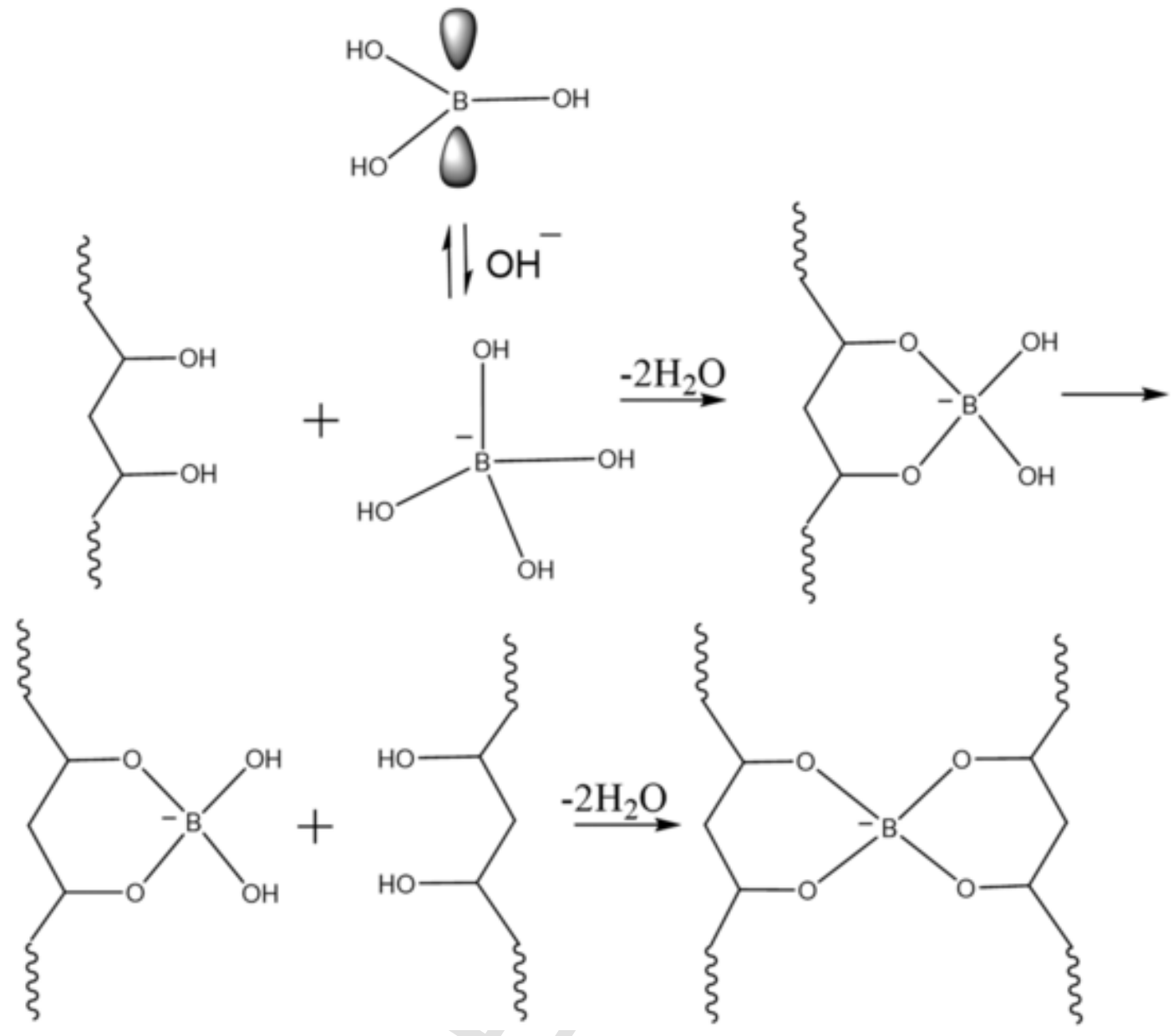

Fig. 7. Crosslinking mechanism of polyhydroxylated polymers via BA.

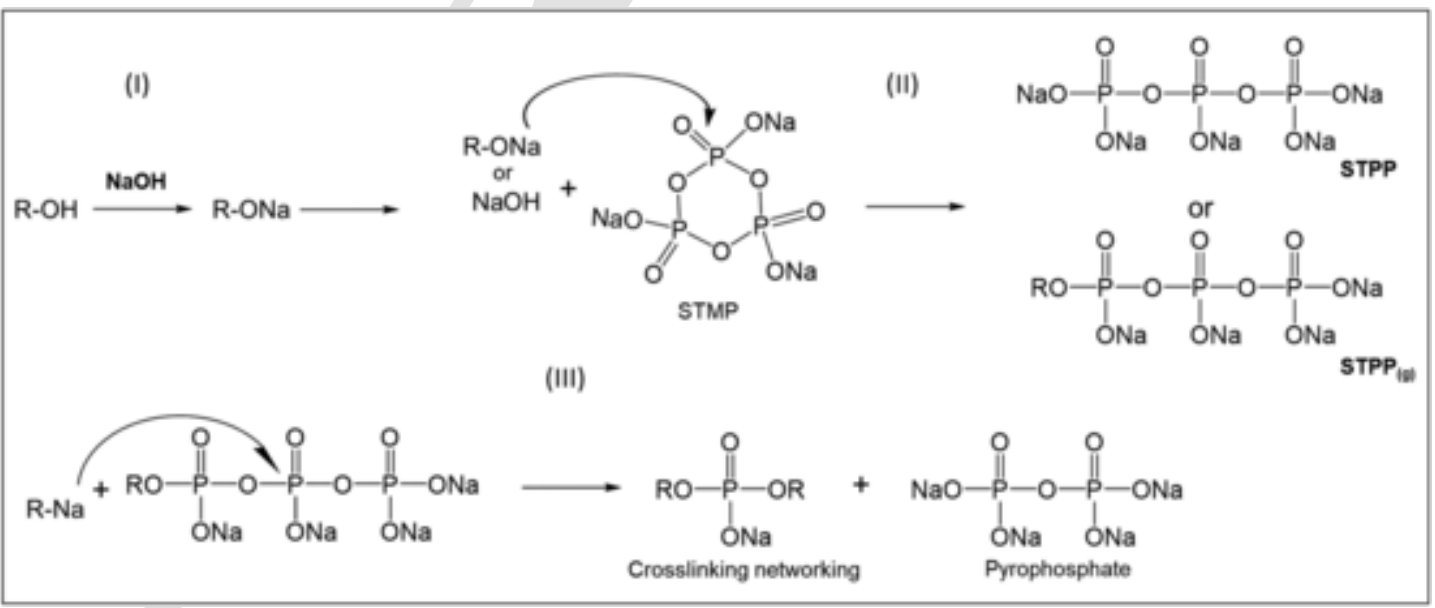

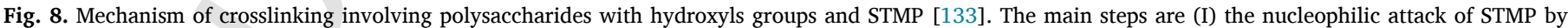

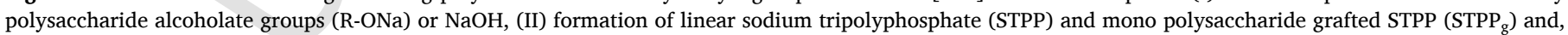
(III) further nucleophilic attack of $\mathrm{STPP}_{\mathrm{g}}$ by (R-ONa), promoting the crosslinking of polysaccharide chains and formation of pyrophosphate.

performance for all catalysts, indicating that the anhydride formation is favored under acid conditions, and that the corresponding acid anions favored the removal of the intermediate, as depicted in Fig. 13. Noteworthy, 3,3',4,4'-benzophenonetetracarboxylic acid (BPTCA) is a rela- 


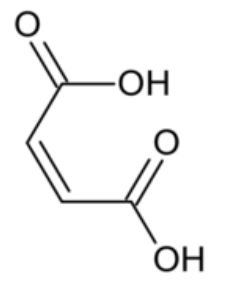

Maleic acid

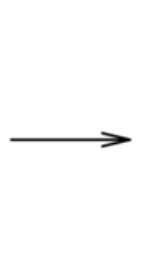

Maleic anhydride

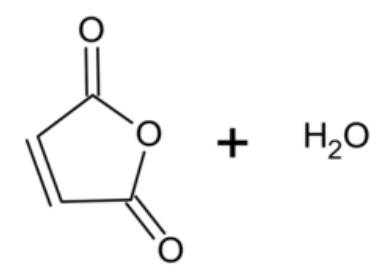

(a)

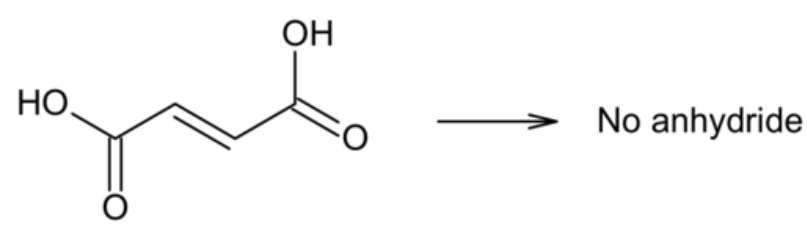

Fumaric acid

Fig. 9. Schematic representation of (a) the formation of a five-member ring cyclic anhydride from maleic acid (cis-isomer) and (b) the impossible formation of a cyclic anhydride from fumaric acid (trans-isomer).

tively strong acid with $\mathrm{pK}_{\mathrm{a} 1}$ at 2.23 , which undergoes a typical Fischer's esterification reaction with cellulose, without the formation of anhydrides, as shown in Fig. 14 [144].

The catalytic properties of cyanamide on the esterification was explained with basis on the carbodiimide chemistry. Carbodiimide, a tautomer of cyanamide, reacts with the carboxylic acid, forming a cationic adduct (Fig. 15a). In a second step, a cyclic anhydride and urea are formed (Fig. 15b) [141]. In fact, in this case, the carbodiimide acts as a reactant and not exactly as a catalyst because urea is not reverted to carbodiimide.

Carboxylic acids react with alcohols to form esters, releasing water molecules as sub-product. All polysaccharides carry many hydroxyl groups along the chains, which might react with carboxylic acid groups to form stable ester linkages. Some polysaccharide chains have both hydroxyl and carboxylic acid groups; in this case, intra and interchain esterification might occur. For instance, the esterification between xanthan acid groups (pyruvyl or acetyl) and $\mathrm{OH}$ groups present in the same chain or in a neighbor chain can occur upon heating the xanthan sample in the dried state (film or cryogel) at $165^{\circ} \mathrm{C}$ for $7 \mathrm{~min}$, as repre- sented in Fig. 16a. One should notice that the esterification reaction takes place in the dried state at $165{ }^{\circ} \mathrm{C}$ to remove the water molecules by evaporation and to drive the equilibrium reaction to the esterification direction. Noteworthy, this reaction would not take place in an aqueous solution. The esterification reaction of xanthan chains was evidenced by FTIR spectra, which revealed a relative increase of the intensity of the carbonyl band of ester bond at $1728 \mathrm{~cm}^{-1}$ and gel content of $20 \%$ [145]. However, in the presence of citric acid (Fig. 16b), a polycarboxylic acid, the same reaction led to a gel content of $75 \%$ because the esterification among the xanthan chains was more pronounced. In the case of polysaccharides that do not carry carboxylic acid groups in their structure, for instance, starch [146] or hydroxypropyl methylcellulose (HPMC) [147].

Table 3 displays some examples of polysaccharides crosslinked with polycarboxylic acids. Sodium L-glutamate proved to be an alternative catalyst to sodium hypophosphite in the anhydride formation of 1,2,3,4-butanetetracarboxylic acid (BTCA) and crosslinking with cellulose [148]. The radical copolymerization of maleic acid and itaconic acid, both unsaturated dicarboxylic acids, resulted in effective polymeric crosslinkers for cotton cellulose [149]. Carboxymethyl cellulose (CMC) chains crosslinked with fumaric acid presented higher thermal stability than those crosslinked with citric acid, when the concentration of CMC was $2.5 \mathrm{wt} \%$. Still, in both cases, the glass and crystalline phase transitions of CMC shifted to higher temperatures after crosslinking [150]. Dispersion of cassava starch containing citric acid or 1,2,3,4-butanetetracarboxylic acid (BTCA) were successfully used as adhesive for wood panels; BTCA led to stiffer panels, but citric acid acted as crosslinker and plasticizer of starch [151]. The crosslinking among carboxymethyl cellulose (CMC) and poly(ethylene glycol) (PEG) was mediated by citric acid; in this case not only the CMC hydroxyl groups but also PEG terminal $\mathrm{OH}$ groups might react with citric acid, forming ester linkages, as evidenced by solid state ${ }^{13} \mathrm{C}$ NMR analyses [152]. Cassava starch and xanthan gum were successfully crosslinked with citric acid by extrusion and thermopressing [153]. In systems containing HPMC and amino acids, citric acid molecules act simultaneously as crosslinker for the HPMC chains and as mediators for the grafting of amino acid molecules along the HPMC chains [154]. The crosslinking of HPMC [155], or xanthan gum, locust bean gum and chitosan [156], and functionalization with $\beta$-cyclodextrin was successfully achieved with the aid of citric acid.<smiles>O=C(O)CC(C(=O)O)C(CC(=O)O)C(=O)O</smiles><smiles>N#[R]O[Na]</smiles><smiles>O=C(O)CC1C(CO)CC1C(=O)O</smiles>

Fig. 10. Mechanism proposed by Brown and co-workers [142] for the formation of cyclic anhydrides from BTCA catalyzed by sodium hypophosphite.<smiles>O=C(O)CC(C(=O)O)C(C(=O)O)C(=O)OP(=O)(O[Na])OC(=O)CC(C(=O)O)C(CC(=O)O)C(CC(=O)O)C(=O)O</smiles>

Fig. 11. Mechanism proposed by Gillingham and co-workers [141] for the formation of linear anhydrides from BTCA catalyzed by phosphonic acid. 


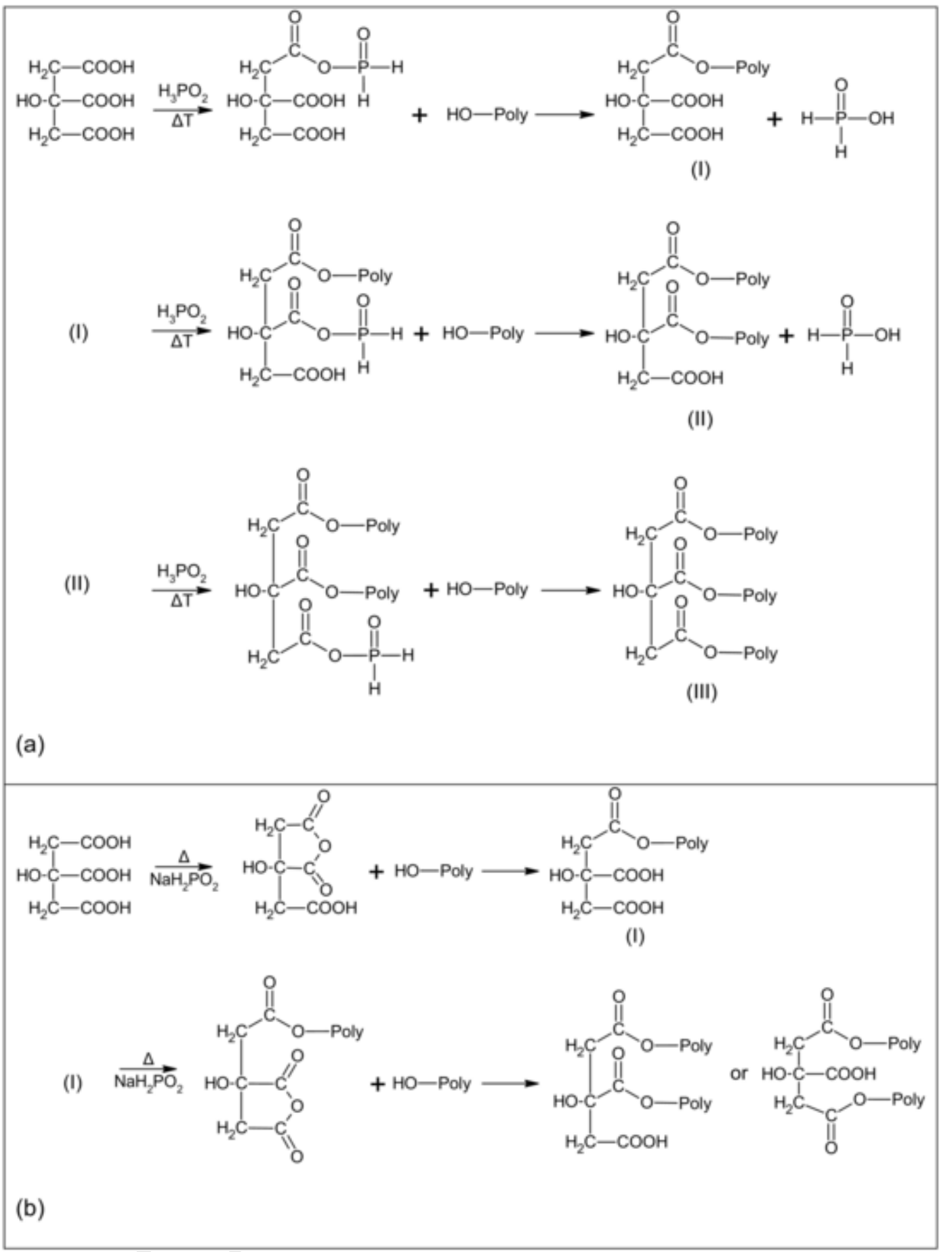

Fig. 12. Stepwise formation of cyclic or linear anhydrides in the same polyacid molecule. (a) The model considers the (a) linear anhydrides that yields one ester linkage more than the one considering the (b) cyclic anhydrides. [141]

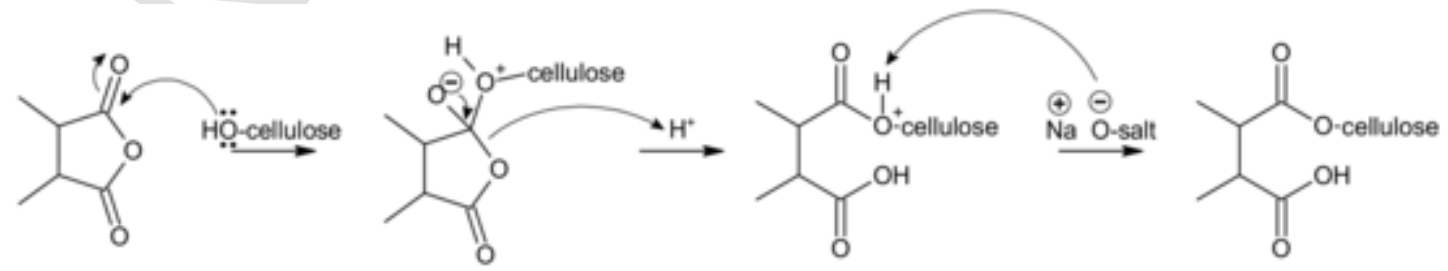

Fig. 13. Schematic representation of the mechanism proposed by $\mathrm{Ji}$ and coworkers for the reaction between anhydride and cellulose [143] 


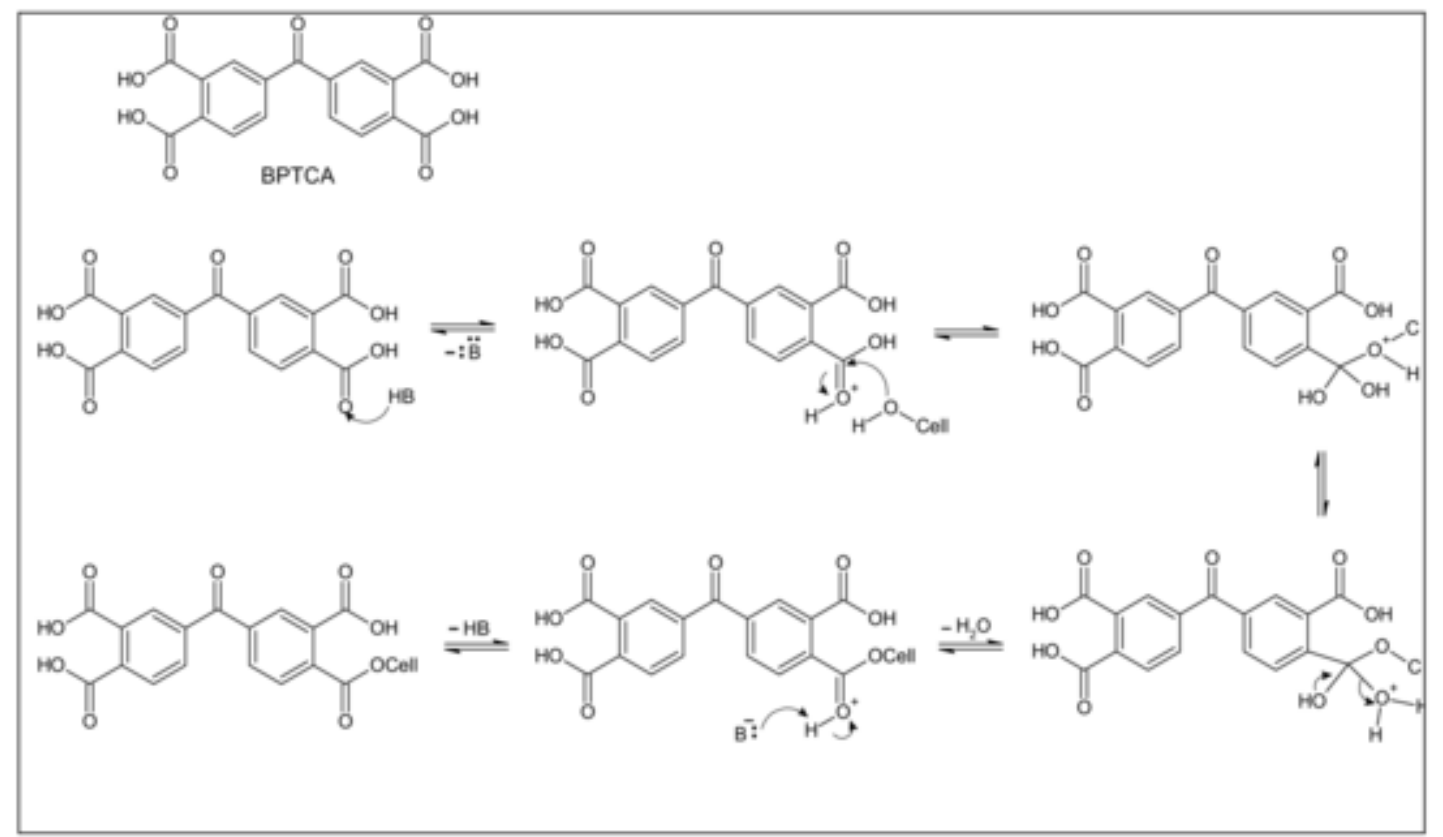

Fig. 14. Schematic representation of BPTCA molecule and Fischer esterification mechanism, where B- stands for hypophosphite ion.

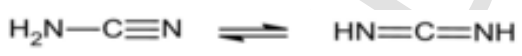

cyanamide carbodiimide

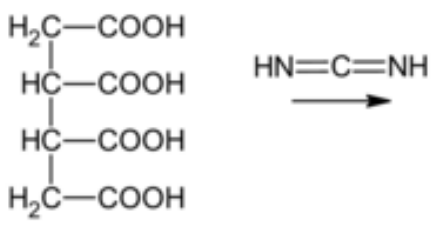<smiles>N=C(N)OC(=O)CC(C(=O)O)C(=O)O</smiles><smiles>CCCCC(CC(=O)O)C(CC(=O)O)C(=O)O</smiles><smiles>N[C](N)OC(=O)CC(C(=O)O)C(=O)O</smiles><smiles>O=C(O)CC(C(=O)O)C1CC(=O)OC1=O</smiles><smiles>NC(N)=O</smiles>

Fig. 15. Mechanism for the carbodiimide mediate anhydride. (a) Carbodiimide tautomer of cyanamide, reacts with the carboxylic acid, forming a cationic adduct. (b) In a second step, a cyclic anhydride and urea are formed [141]

\section{6. $N, N^{\prime}$-methylene bisacrylamide}

The $N, N$-methylene bisacrylamide (MBA) is a bifunctional molecule well-known for producing hydrogels based on acrylic acid (AAc) and acrylamide (ACL) [157]. However, in the last years, a lot of researches have been focused on the synthesis of hybrid materials based on polysaccharides, proteins, and monomers crosslinked via MBA, such as soy protein/AAc [158], gum acacia/alginate/AAc [159], alginate/chitosan/ACL [160], and Gel/Dextrin/ACL [161]. These materials are commonly prepared by free-radical polymerization (FRP), in which free radicals are triggered by a stimulus such as light, voltage, mechanical force, or chemical initiation $[162,163]$.
In addition to the MBA and polymer, a thermosensitive initiator and catalyst are required to induce the FRP upon heating. Some initiators include ammonium persulfate (APS), potassium persulfate (KPS), and azobisisobutyronitrile (AIBN), while tetramethylethylenediamine (TEMED) acts as a catalyst [163,164]. In the free-radical photopolymerization, a photoinitiator is exposed to UV light or electron beam to generate free radicals, and then the propagation step takes place [165]. The free radical polymerization induced by irradiation has sufficient energy to promote crosslinking at once. This methodology is environmentally friendly because toxic initiators are not required [166]. Irradiationmediated crosslinking is discussed in Section 6. 


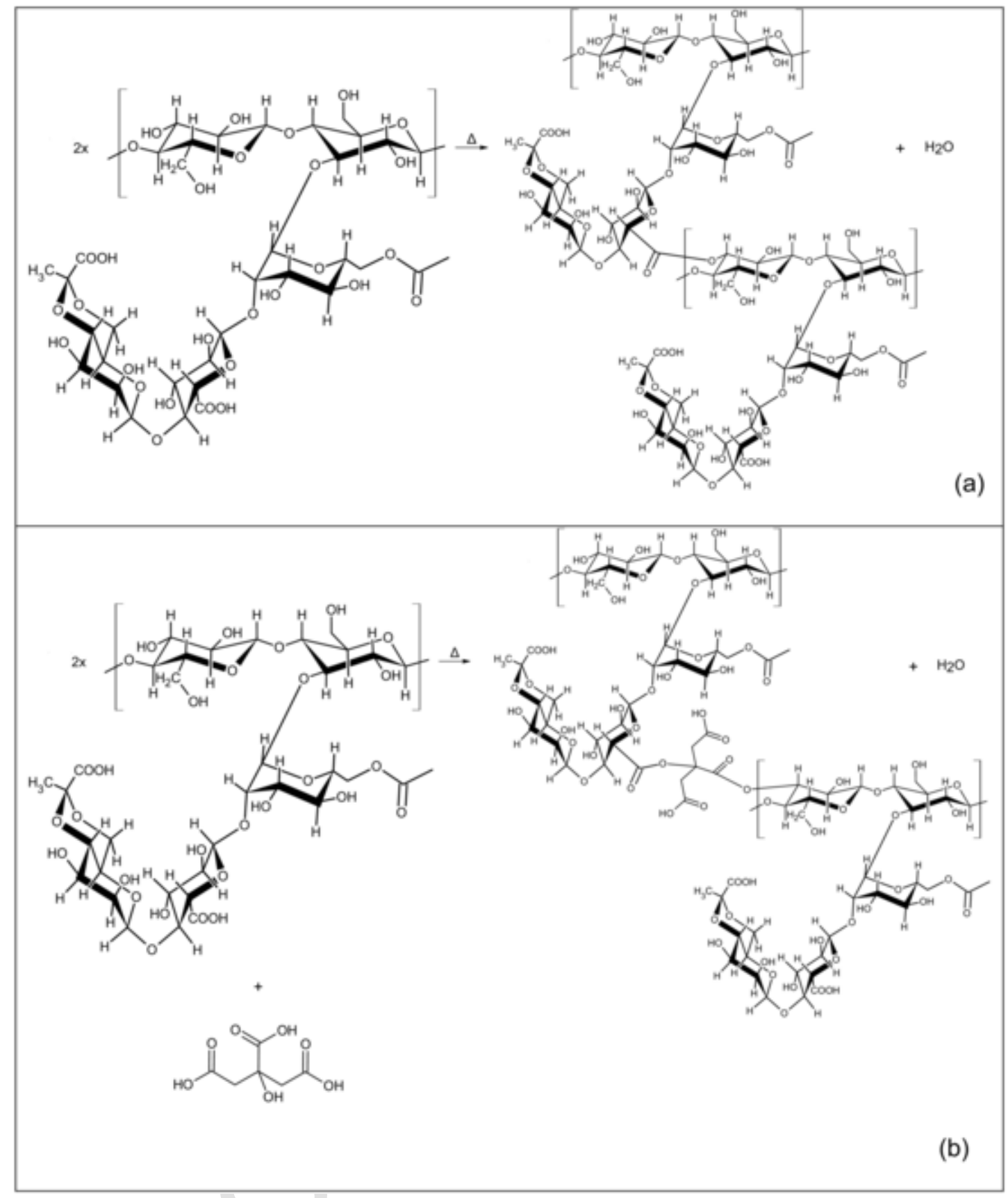

Fig. 16. Schematic representation of xanthan crosslinking reaction by dehydration (a) in the absence of citric acid and (b) in the presence of citric acid [145].

Fig. 17 shows a possible mechanism for forming polysaccharide grafted to poly(acrylic acid) hydrogel. The initiator free radicals (I-) are generated in the polysaccharide aqueous solution, under mechanical stirring, by heating the system at $65-80{ }^{\circ} \mathrm{C}[161,167,168]$. The free radical species (I-) react with the polysaccharide hydroxyl groups, promoting the transfer of reactive center to the polysaccharide chains. In a second step, AAc and MBA monomers, and TEMED are added to the system. The polysaccharide radicals attack AAc and MBA vinyl groups, transfering the active centers to these monomers, which can successively react to the neighbor monomers leading to crosslinking and chain propagation [167]. Unlike thermal free-radical polymerization, photopolymerization via MBA can be performed under mild conditions, at room temperature or up to $40{ }^{\circ} \mathrm{C}$ [165,170-172].

Polymerization rate, swelling degree (SD), and gel porosity can be controlled by synthesis parameters, such as temperature, $\mathrm{pH}$, amount of initiator, MBA, and monomer. Qavi and coworkers [173] suggested that the reaction rate increases with temperature in a free-radical polymerization between ACL and MBA. However, the increasing MBA/ACL ratio can cause a phase separation process, decreasing the reaction rate. According to Priya and coworkers [161], for the synthesis of Gel/Dextrin/ACL hydrogel the optimum time and temperature were $150 \mathrm{~min}$ and $65{ }^{\circ} \mathrm{C}$, respectively. The SD values determined for the resulting hydrogels achieved $345 \%$ with the increase of temperature reaction. However, the SD values decreased abruptly, when the reaction occurred above the optimum temperature; it was attributed to the high amount of free radicals. The increase of persulfate initiator [174] led to an increase of SD; on the other hand, the increase of MBA reduced the SD values [175]. Sharma et al [160] determined the optimum values of reaction temperature, time reaction, solvent amount, monomer, MBA, and KPS to synthesize chitosan/alginate hybrid hydrogel. Maximum SD values were achieved at $70{ }^{\circ} \mathrm{C}, 210 \mathrm{~min}$ of reaction time, and $\mathrm{pH}$ 7.0; at this $\mathrm{pH}$ alginate carboxylic groups are deprotonated. 
Table 3

Some examples of polysaccharides crosslinked with polycarboxylic acids, along with the corresponding highlights.

\begin{tabular}{|c|c|c|c|c|}
\hline Crosslinker & Catalyst & Polysaccharide & Highlight & Ref. \\
\hline $\begin{array}{l}\text { 1,2,3,4- } \\
\text { Butanetetracarboxylic } \\
\text { acid (BTCA, } 6.4 \text { wt } \% \text { ) }\end{array}$ & $\begin{array}{l}\text { Sodium L- } \\
\text { glutamate }\end{array}$ & Cellulose & $\begin{array}{l}\text { Optimum molar } \\
\text { ratio of sodium } \mathrm{L}- \\
\text { glutamate to BTCA } \\
\text { amounted to } 0.4: 1\end{array}$ & [148] \\
\hline $\begin{array}{l}\text { Copolymers of itaconic } \\
\text { and maleic acids }\end{array}$ & KHP & Cellulose & $\begin{array}{l}\text { Polymeric } \\
\text { crosslinker }\end{array}$ & [149] \\
\hline $\begin{array}{l}\text { Fumaric acid } \\
\quad(0.35 \mathrm{wt} \%) \text { or citric } \\
\text { acid }(2.0 \mathrm{wt} \%)\end{array}$ & None & CMC & $\begin{array}{l}\text { Increase of } \mathrm{T}_{\mathrm{g}} \text { and } \\
\mathrm{T}_{\mathrm{m}} \text { after } \\
\text { crosslinking }\end{array}$ & [150] \\
\hline $\begin{array}{l}\text { Citric acid (10 wt } \% \text { to } \\
80 \mathrm{wt} \% \text { ) or } 1,2,3,4- \\
\text { butanetetracarboxylic } \\
\text { acid (BTCA, } 10 \mathrm{wt} \% \\
\text { to } 80 \mathrm{wt} \%)\end{array}$ & None & $\begin{array}{l}\text { Starch and } \\
\text { wood by- } \\
\text { products }\end{array}$ & $\begin{array}{l}\text { BTCA was a better } \\
\text { crosslinker agent } \\
\text { than CA, but CA } \\
\text { acted as crosslinker } \\
\text { and plasticizer }\end{array}$ & [151] \\
\hline $\begin{array}{l}\text { Citric acid ( } 20 \mathrm{wt} \% \text { of } \\
\text { the polysaccharide) }\end{array}$ & None & $\begin{array}{l}\text { CMC ( } 2 \text { wt } \%) \\
\text { and poly } \\
\text { (ethylene } \\
\text { glycol) (PEG, } \\
0.6 \mathrm{wt} \%)\end{array}$ & $\begin{array}{l}\text { Solid state }{ }^{13} \mathrm{C} \text { NMR } \\
\text { analysis confirmed } \\
\text { the crosslinking } \\
\text { among CMC and } \\
\text { PEG chains } \\
\text { mediated by CA } \\
\text { molecules }\end{array}$ & [152] \\
\hline $\begin{array}{l}\text { Citric acid }(0.75 \mathrm{wt} \% \text { to } \\
2.25 \mathrm{wt} \%)\end{array}$ & SHP & $\begin{array}{l}\text { Cassava starch } \\
(90 \mathrm{wt} \%) \text { and } \\
\text { xanthan gum } \\
(10 \mathrm{wt} \%)\end{array}$ & $\begin{array}{l}\text { crosslinking took } \\
\text { place in a single- } \\
\text { screw extruder } \\
\text { followed by } \\
\text { thermopressing }\end{array}$ & [153] \\
\hline $\begin{array}{l}\text { Citric acid }(0.1 \mathrm{wt} \% \text { or } \\
0.2 \mathrm{wt} \%)\end{array}$ & $\begin{array}{l}\text { SHP } 0.05 \\
\text { wt } \% \text { or } \\
0.1 \text { wt } \%\end{array}$ & $\begin{array}{l}\text { HPMC }(2 \mathrm{wt} \%) \\
\text { and amino acid } \\
\text { up } 2 \mathrm{~g} / \mathrm{L}\end{array}$ & $\begin{array}{l}\text { Crosslinking and } \\
\text { amino acid grafting } \\
\text { simultaneous } \\
\text { reactions }\end{array}$ & [154] \\
\hline Citric acid (0.4 wt\%) & $\begin{array}{l}\text { SHP } 0.16 \\
\mathrm{wt} \%\end{array}$ & $\begin{array}{l}\text { HPMC }(2 \mathrm{wt} \%) \\
\text { and } \beta- \\
\text { cyclodextrin } \\
(0.2 \mathrm{wt} \%)\end{array}$ & $\begin{array}{l}\text { Crosslinking and } \\
\text { functionalization } \\
\text { with } \beta \text {-cyclodextrin }\end{array}$ & [155] \\
\hline Citric acid (1.30 g) & & $\begin{array}{l}\text { Xanthan gum, } \\
\text { locust bean } \\
\text { gum or } \\
\text { chitosan } \\
(1.435 \mathrm{~g}) \text { and } \\
\beta \text {-cyclodextrin } \\
(1.435 \mathrm{~g})\end{array}$ & $\begin{array}{l}\text { Crosslinking and } \\
\text { functionalization } \\
\text { with } \beta \text {-cyclodextrin }\end{array}$ & [156] \\
\hline
\end{tabular}

The morphology and mechanical properties of resulting hydrogels can be affected by biopolymer:monomer ratio, as reported by He and collaborators [158]. They produced a soy protein isolate/poly-AAc composite hydrogel with different soy protein:poly-AAc ratios via MBA crosslinking. The results showed that at lower AAc concentration, no network was formed. As AAc concentration increased, more joint points were built and the hydrogel became harder. Similarly, the increase of MBA amount led to gel porosity decrease, enhancing the mechanical stability [175].

Despite acrylamide compounds being known as neurotoxicant [176], hybrid hydrogels produced via MBA have shown good biocompatibility and no toxic effects for some types of cells [177-179]. Besides, MBA based hydrogels proved to be suitable for biomedical applications, mainly for tissue engineering and release of co-enzyme A [180], verapamil [181], amoxicillin [177], quercetin [167], and cephalexin [168].

\section{Natural crosslinkers}

\subsection{Enzymes}

In the natural process, several classes of enzymes catalyze the covalent linkage or crosslinking of proteins [182]. The advances in the extraction and production of enzymes from multiple sources reduce the costs, making enzymes attractive crosslinkers for the synthesis of hy- drogels. Particularly, injectable hydrogels based on natural proteins are designed to produce soft matrices (scaffolds) capable of mimicking human brain and ocular tissues or even filling possible chronic injuries in bone, cartilage, or skin [183-185]. The scaffold elasticity might tune the cell fate [186]. The elastic (Young's) modulus (E) of enzymatically crosslinked hydrogels tends to be low in comparison to hydrogels prepared with other crosslinkers, as depicted in Fig. 18. Enzymatically crosslinked gelatin hydrogels are soft $(\mathrm{E}<27 \mathrm{kPa})$, making them adequate for applications as injectable or printable materials, whereas gelatin hydrogels crosslinked with genipin or GA are stiff (E > 4.8 $\mathrm{MPa}$ ) and inadequate for bioprinting. Achieving the desired properties is a challenging task, considering that hydrogels might be temperature or $\mathrm{pH}$ sensitive.

This section focuses on the reaction mechanisms involving five enzymes frequently used, namely, transglutaminase (TGase), tyrosinase, horseradish peroxidase (HRP), laccase and sortase A (SrtA). Table 4 comprises the enzyme, its source, the type of protein or polysaccharide to be crosslinked, the reaction mechanism, the optimal $\mathrm{pH}$ and temperature for the enzymatic catalysis along with the corresponding references. Noteworthy, in all cases, the reaction temperature is kept under a mild range to avoid protein denaturation.

\subsection{Transglutaminase (TGase)}

TGase, is an enzyme found in microorganisms, plants, and mammals. The large isoenzyme activity of TGase in mammals' is not fully known. Their interactions with specific substrates established a family group known as TGases. For instance, when transglutaminase type I (TG1) is linked to the plasma membrane of keratinocyte cells, it catalyzes lipids and proteins anchored to form the cornified envelope, an active component to the epidermal barrier, whereas type II (TG2) is used as cell signaling and cell adhesion [207]. The properties of TGase are well explored in food processing and packing technology for emulsification, gelation, foaming, and solubilizing [208]. TGases have good stability in $\mathrm{pH}$ ranging from 4.5 to 8 ; the highest catalytic activity of mTGase (bacteria source) was observed at pH 5.5 [209].

TGase catalyzes the formation of a peptide bond between $\gamma$ carboxamide of glutamine residues and $\varepsilon$-amino groups of lysine residues. Fig. 19 shows that a $\gamma$-carboxamide group from protein first reacts with nucleophilic cysteine (thiolate group) from TGase. Then, the intermediary thiolester group reacts with the amine group (from lysine) from another protein molecule, forming the peptide bond among the protein chains and restoring the TGase [207,210]. The amino acids triad composed by cysteine, aspartate, and histidine forms the active site of TGase; its localization might vary according to source of TGase.

The protein crosslinking mediated by TGase takes a few hours of reaction, at $\mathrm{pH}$ 5.5. The temperature is a critical parameter not only during the reaction, but also after crosslinking, due to the denaturation of proteins. For example, the triple helix structure of collagen extracted from bovine skin is compromised when the synthesis temperature exceeds $35{ }^{\circ} \mathrm{C}, \alpha 1$ and $\alpha 2$ chains bands $(\sim 100 \mathrm{kDa})$ expressed via SDSPAGE electrophoresis disappear after crosslinking mediated by TGase [125]. Notably, pure or crosslinked collagen hydrogels formed at $4{ }^{\circ} \mathrm{C}$ and $25{ }^{\circ} \mathrm{C}$ maintained the native collagen structure and both hydrogels presented similar tensile strength or elasticity values. However, the TGase catalyzed crosslinking at $35{ }^{\circ} \mathrm{C}$ led to gelatin (denatured collagen) hydrogels with superior mechanical properties [191].

The physicochemical properties of functionalized self-assembling peptide (SAP) hydrogels were improved upon crosslinking catalyzed by TGase [145]. The peptide sequences were modified in C-terminal by glutamines and lysines, which interacted with mTGase (bacteria source). After mTGase mediated SAP crosslinking (i) the peptides kept their secondary $\beta$-sheet structures, (ii) an increase in the fibrous density of SAP scaffolds was revealed by transmission electron microscopy, (iii) the elastic $\left(G^{\prime}\right)$ and viscous $\left(G^{\prime \prime}\right)$ moduli of hydrogels increased five- 


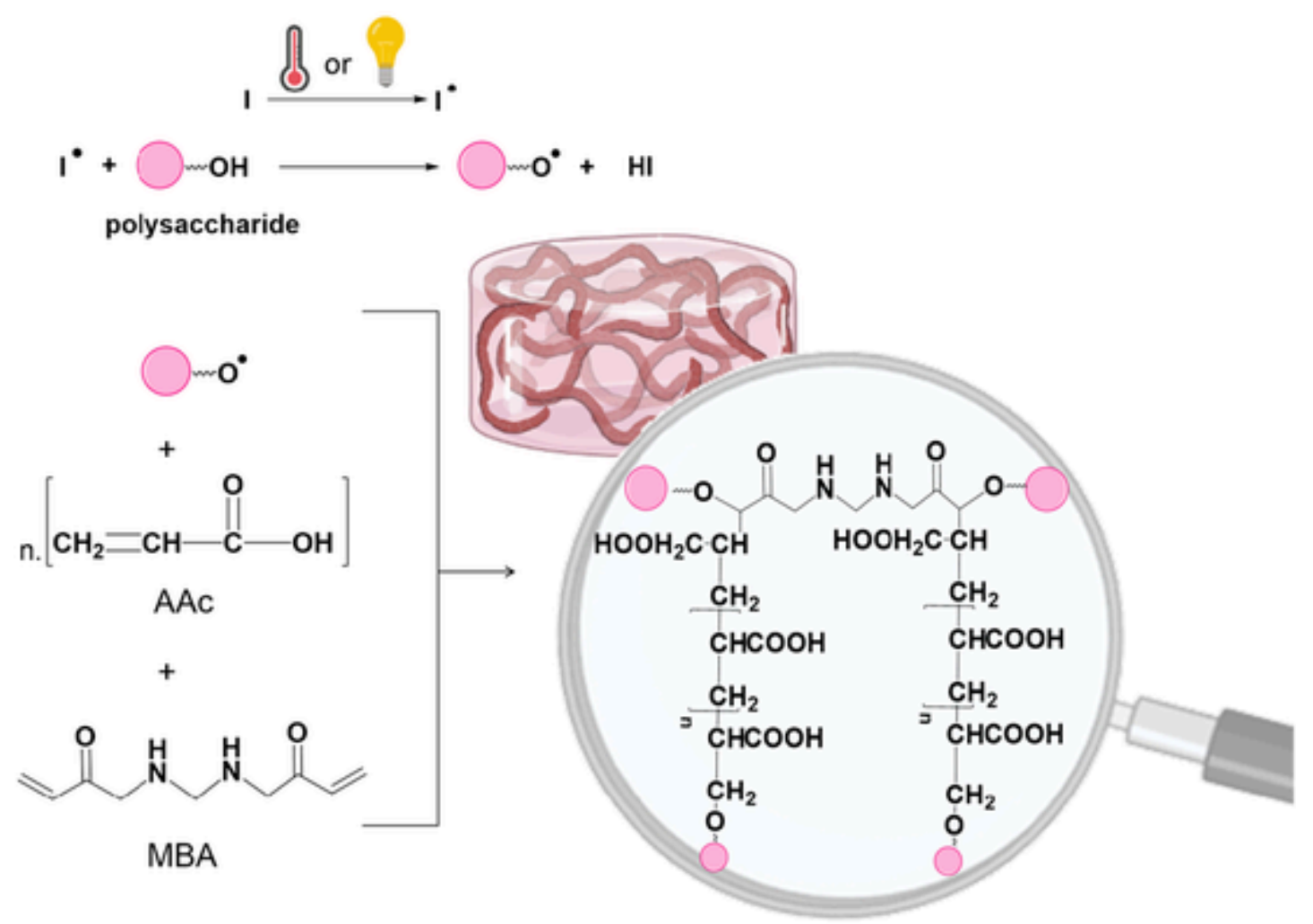

Fig. 17. Schematic representation of possible mechanism for forming polysaccharide grafted to poly(acrylic acid) hydrogel. Adapted from Ref. [167].

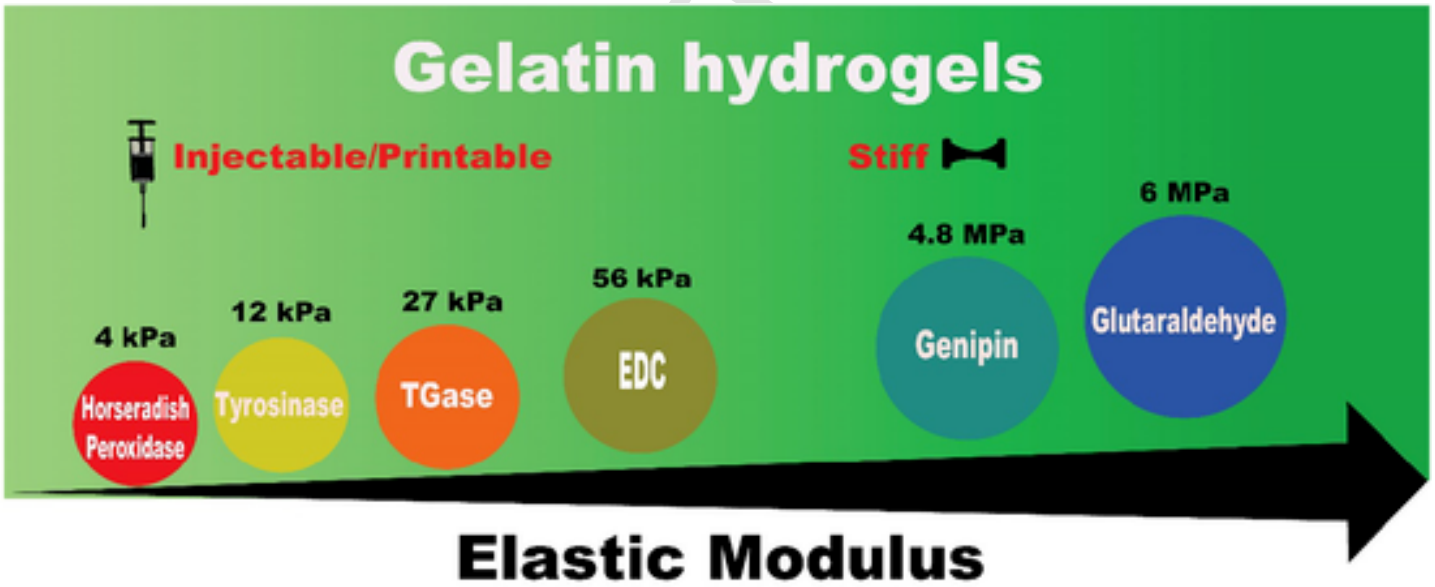

Fig. 18. Elastic (Young's) moduli of gelatin hydrogels. Gelatin crosslinked with the aid of TGase [187], tyrosinase [188], and horseradish peroxidase [189] yield soft injectable or even printable hydrogels, whereas Genipin and GA [190] yield stiff hydrogels.

fold, allowing the extrusion by conventional syringe and (iv) the hydrogels stimulated the angiogenesis [211].

\subsection{Sortase A (SA)}

Transpeptidation is a crosslinking reaction between relatively small substrates (peptides), catalyzed by transpeptidases (TPs). Grampositive bacteria have a special TP known as sortase A (SA); SA catalyzes the reaction between LPXTG pentapeptide, where $X$ represents any amino acid except proline, and oligoglycine groups [212]. Fig. 20 schematically represents the reaction mechanism. SA thiol group cleavages the threonine(T)-glycine(G) bond of LPXTG motif (C-terminus) grafted to the protein backbone, forming an enzymatic adduct (acylenzyme intermediary) (I) (Fig. 20a). The nucleophilic attack of (Nterminus) oligoglycine groups to the carbonyl group from acyl-enzyme is assisted by a SA histidine (His) group (II), resulting in peptides bridging and release of SA (III). Fig. 20b depicts the formation of a stiff hydrogel catalyzed by SA. On the other hand, the addition of SA and glycine precursor (e.g. glycinamide) turns the process reversible, producing a soft matrix [205,212].

The remarkable feature of SA catalyzed crosslinking is the possibility of reversing it, by controlling the addition of SA and glycine precursor solutions. The amounts of SA and glycinamide added to the system tuned the softening of PEG-GGGG and PEG-LPRTG conjugates hydrogels, and the gelation took only 10 min with $300 \mu \mathrm{M} \mathrm{SA}$, but reducing the SA concentration to $50 \mu \mathrm{M}$ the gelation time increased to $90 \mathrm{~min}$ [205]. Thus, catalyzing peptides crosslinking with SA represents an elegant strategy for tuning the softness/stiffness of hydrogels. 
Table 4

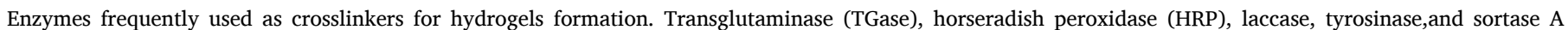

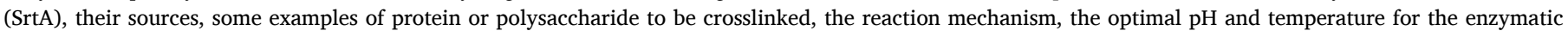
catalysis along with the corresponding references.

\begin{tabular}{|c|c|c|c|c|c|}
\hline Enzymes & Source & Polymers & Mechanism & $\begin{array}{l}\mathrm{pH} \\
\text { temperature }\end{array}$ & Ref \\
\hline $\begin{array}{l}\text { Transglutaminase } \\
\text { (TGase) }\end{array}$ & $\begin{array}{l}\text { Bacteria, mammals } \\
\text { and plants }\end{array}$ & $\begin{array}{l}\text { Gelatin, collagen, whey and soy } \\
\text { protein, chitosan, carboxymethyl } \\
\text { cellulose }\end{array}$ & $\begin{array}{l}\text { Presence of Glutamic acid and lysine groups; } \\
\text { Acyl ligands/amine ligand from Glu and Lys AA }\end{array}$ & $5.5,40 \mathrm{C}$ & $\begin{array}{l}{[191-} \\
193]\end{array}$ \\
\hline $\begin{array}{l}\text { Horseradish } \\
\text { peroxidase } \\
\text { (HRP) }\end{array}$ & $\begin{array}{l}\text { Root (Amoracia } \\
\text { rusticana) }\end{array}$ & $\begin{array}{l}\text { Hyaluronic-Tyramine (®Corgel), } \\
\text { alginate-tyramine, } \\
\text { gelatin norbornene/4-arm PEG } \\
\text { dihydrogentetrazine, silk-friboin }\end{array}$ & $\begin{array}{l}\text { Oxidation of phenolic and catechol groups } \\
\text { (requires hydrogen peroxide addition) } \\
\text { Peroxidation, isomerization, dimerization, enolization process }\end{array}$ & $7.0,45 \mathrm{C}$ & $\begin{array}{l}{[194-} \\
197]\end{array}$ \\
\hline Laccase & Fungi & $\begin{array}{l}\text { Gelatin, arabinoxylans (AX), chitosan, } \\
\text { carboxymethyl chitosan, }\end{array}$ & $\begin{array}{l}\text { Presence of phenolic/catechol groups. } \\
\text { Oxidation }\left(\mathrm{O}_{2} \text { species), semi-quinone formation through Schiff base }\right. \\
\text { mechanism, isomerization, dimerization, enolization process }\end{array}$ & $\begin{array}{l}4.0-5.5 \text { and } \\
30 \mathrm{C} \mathrm{a} \\
40 \mathrm{C}\end{array}$ & $\begin{array}{l}{[132-} \\
135] \\
{[202]}\end{array}$ \\
\hline Tyrosinase & $\begin{array}{l}\text { Microorganisms, } \\
\text { plants, and } \\
\text { animals }\end{array}$ & $\begin{array}{l}\text { Alginate, hyaluronic acid/gelatin, } \\
\text { glycol chitosan }\end{array}$ & $\begin{array}{l}\text { Presence of phenolic/catechol groups. } \\
\text { Oxidation }\left(\mathrm{O}_{2} \text { species), semi-quinone formation through Micheal }\right. \\
\text { addition mechanism, isomerization, dimerization, enolization process }\end{array}$ & $6.5,50 \mathrm{C}$ & $\begin{array}{l}{[188} \\
203 \\
204]\end{array}$ \\
\hline Sortase A (SrtA) & E. coli BL21(DE3) & PEG grafted peptides & $\begin{array}{l}\text { Hydolysis of peptides residues } \\
\text { Transpeptidation between LPXTG and GGG substrates }\end{array}$ & $8.0,35 \mathrm{C}$ & $\begin{array}{l}{[205,} \\
206]\end{array}$ \\
\hline
\end{tabular}

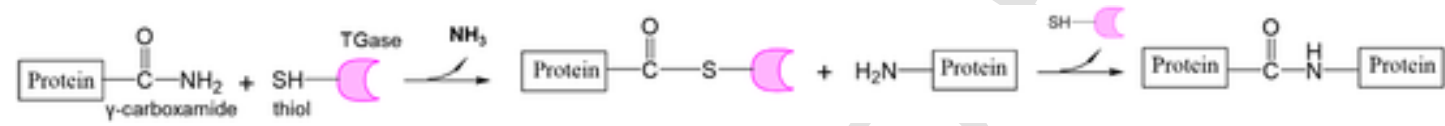

Fig. 19. Schematic representation of the mechanism involved in the protein crosslinking catalyzed by TGase. [210].

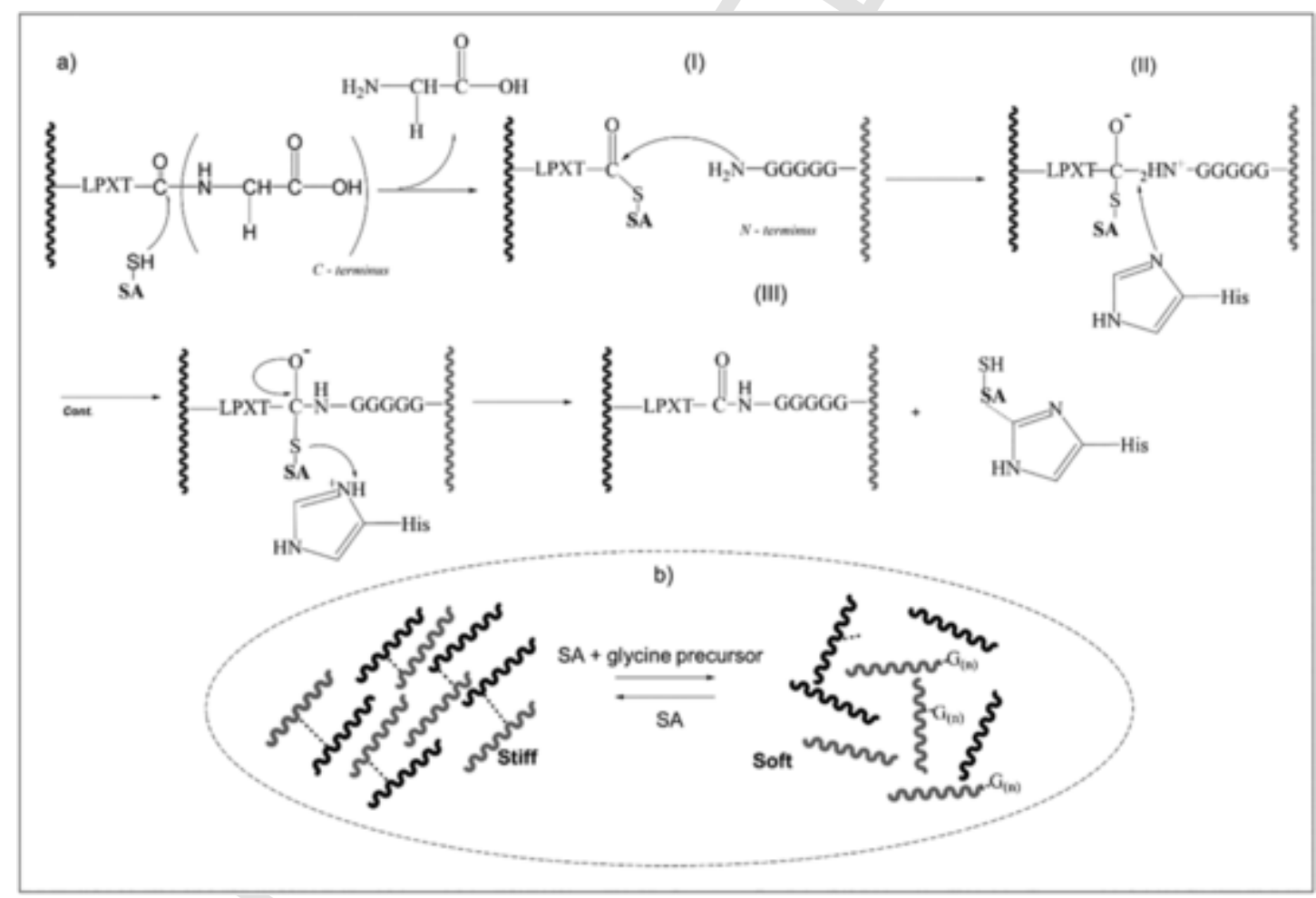

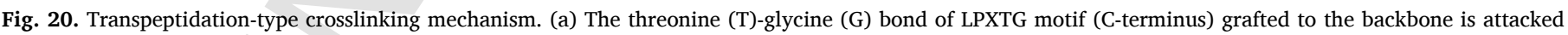

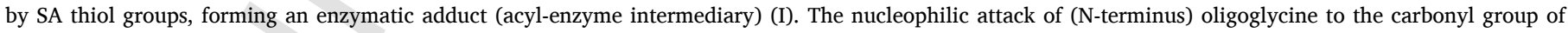

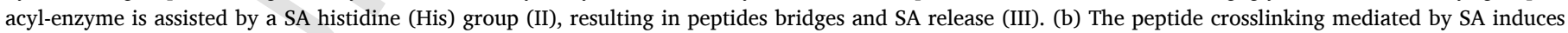

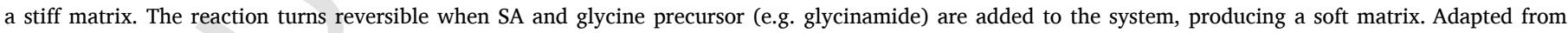
Refs. [205,212].

\subsection{Horseradish peroxidase (HRP)}

HRP is a well-known enzyme extracted from roots and plants containing 308 amino acids residues, with two terminal $\mathrm{N}$ acetylglucosamines, a heme group and mannose residues [207]. The extensive use of HRP in organic synthesis is due to the free radical forma- tion in the presence of hydrogen peroxide, allowing radical polymerization to take place at room temperature [207]. HRP has been employed in the last decades as a treatment for wastewater or soils because the free radicals can decompose the contaminants efficiently [213-215]. The oxidation states of HRP in the presence of $\mathrm{H}_{2} \mathrm{O}_{2}$, which can oxidize many organic compounds at room temperature [216]. The $\mathrm{pH}$ and tem- 
perature ranges to achieve the highest enzymatic activity are 4.0-5.5 and $30{ }^{\circ} \mathrm{C}$ a $40{ }^{\circ} \mathrm{C}$, respectively [202].

Hydrogels of tyramine-modified polysaccharide [193,194] can be prepared with the aid of $\mathrm{HRP} / \mathrm{H}_{2} \mathrm{O}_{2}$, as depicted in Fig. 21. $\mathrm{HRP} / \mathrm{H}_{2} \mathrm{O}_{2}$ promotes the abstraction of the phenolic hydroxyl $\mathrm{H}$ belonging to tyramine conjugated to hyaluronic acid (HA) chains, leaving a reactive free radical. The free radical can undergo isomerization to one of the two equivalent ortho-position carbons; two isomers can dimerize forming a covalent bond between the HA chains, which after enolizing, generates dityramine. Other polysaccharides such as alginate [219], carboxymethyl chitin [220], dextran [221], gellan gum [222] have been conjugated to tyramine by carbodiimide chemistry and crosslinked in a similar way as HA.

Hydrogels designed to be applied in wound healing might carry molecules that can regulate a possible excess of reactive oxygen species (ROS) in the matrix. For instance, the rapid (23 s) HRP assisted gelation between modified gelatin-gallic acid and gelatin-3-(4-hydroxy-phenyl) propionic acid led to an injectable gel-like, which reduced the oxidative damage by ROS [223].

\subsection{Laccase and tyrosinase}

Similar to HRP, laccase and tyrosinase catalyze crosslinking reactions via the oxidative process. However, instead of $\mathrm{H}_{2} \mathrm{O}_{2}$, laccases and tyrosinases use oxygen $\left(\mathrm{O}_{2}\right)$ molecules as an oxidizing agent. Laccases derived from fungi, plants, and invertebrates belong to the multicopper protein family, with multiple activities in biological organism such as crosslinking protein-protein, depolymerization, and quinones species formation [224]. Laccases carry four copper atoms, they present redox potential ranging from $0.4 \mathrm{~V}$ to $0.8 \mathrm{~V}$, depending on the source [225]. The typical laccase catalyzed reaction is the oxidation of phenolic groups with simultaneous reduction of $\mathrm{O}_{2}$ to water [226]. The intermediary substrates such as semiquinones or aryloxy radicals undergo coupling by dimerization, polymerization, and oligomerization process [227,228].

Tyrosinases can be found in plants and animals; they use $\mathrm{O}_{2}$ to catalyze the oxidation of phenolic groups, such as tyrosine and dopamine. They carry within their active site two copper atoms, each one coordinated by three histidine residues [229]. Tyrosinases are involved in the production of melanin. First, they catalyze the oxidation of secondary catechol groups forming two $\mathrm{Cu}^{+}$(deoxy-tyrosinase state) ions; then, both copper ions bind to an $\mathrm{O}_{2}$ molecule (oxy-tyrosinase state), and $\mathrm{O}$ quinones are formed by monooxygenase (phenol groups) or oxidase (catechol) process [229]. The optimum $\mathrm{pH}$ and temperature for achieving the maximum activity might depend on the tyrosinase source. The activity of tyrosinases derived from yam species immobilized in polyacrylamide gels showed the best optimum $\mathrm{pH}$ at 6.5 , and at $\mathrm{pH}<5$ or $\mathrm{pH}>8$, the activity decreased to $50 \%$ [230].

Laccase was used to modify chitosan with phenolic groups substrates (e.g. eugenol, trans-ferulic acid, dopamine, and catechol) and promote their gelation [200]. The efficiency of laccase and tyrosinase for the crosslinking of chitosan chains might be assessed by FTIR spectroscopy through the intensity decrease of the band at $1420 \mathrm{~cm}^{-1}$ assigned to $\mathrm{NH}_{3}{ }^{+}$groups (from chitosan glucosamine rings) and the appearance of a new band at $\sim 1465 \mathrm{~cm}^{-1}$ attributed to phenyl group (trans-ferulic acid and ethyl ferulate, phenolic substrates) [231], and a shoulder $\sim 1750 \mathrm{~cm}^{-1}$ assigned to carbonyl stretching (from chlorogenic acid, phenolic substrate) [232]. Fig. 22a shows schematically the oxidation of catechol to o-semiquinone or o-quinone catalyzed by laccase or tyrosinase, respectively; the oxidized species react with chitosan amino group yielding imide linkages (Schiff base) or secondary amines (Michael addition), or their tautomers [232-234]. Fig 22b shows the isomerization and dimerization steps catalyzed by laccase and tyrosinase to form the hydrogels; these steps are similar to those observed in HRP catalyzed crosslinking reactions (Fig. 21).

Silk fibroin (SF) is composed of a heavy chain $(\sim 390 \mathrm{kDa})$ and a light chain $(\sim 26 \mathrm{kDa})$; the heavy chain contains $5.3 \%$ of tyrosine (tyr) [235], making SF a suitable candidate to form hydrogels mediated by laccase. Such SF hydrogels present low elastic modulus, but the simultaneous conjugation of SF with hyaluronic acid-tyramine resulted in increased toughness and flexibility [236]. The increase in elasticity can be due to extra hydrogen bonds and van der Waals forces, and decrease of $\beta$-sheet conformation in the SF chains [237]. Tyrosinase was used to increase the crosslinking in pre-formed PEG-8-Norbonene hydrogels, by interconnecting dopamine dimers; low concentration of tyrosinase $(0.01 \mathrm{kU} / \mathrm{mL})$ had no significant effect on the storage modulus $\left(\mathrm{G}^{\prime}\right)$ of hydrogels; however, at $0.1 \mathrm{kU} / \mathrm{mL}$ or $1.0 \mathrm{kU} / \mathrm{mL}$ the $\mathrm{G}^{\prime}$ values were $2 \mathrm{kPa}$ and $4 \mathrm{kPa}$, after $48 \mathrm{~h}$ reaction, evidencing the stiffening effect upon tyrosinase addition [238].

\subsection{Genipin}

Genipin is a water-soluble and colorless iridoid, which belongs to the large group of monoterpenoids composed of a cyclopentan-[C]pyran skeleton [239]. It is manufactured today from geniposide, a glucoside firstly isolated from Genipa americana L. fruits [240]. According to a modern microbiological process [241], the extract from Gardenia jasmioides Ellis fruits can also be applied as a source of geniposide, which is enzymatically hydrolyzed to genipin in the presence of $\beta$ glucosidase enzyme as schematically represented in Fig. 23a.

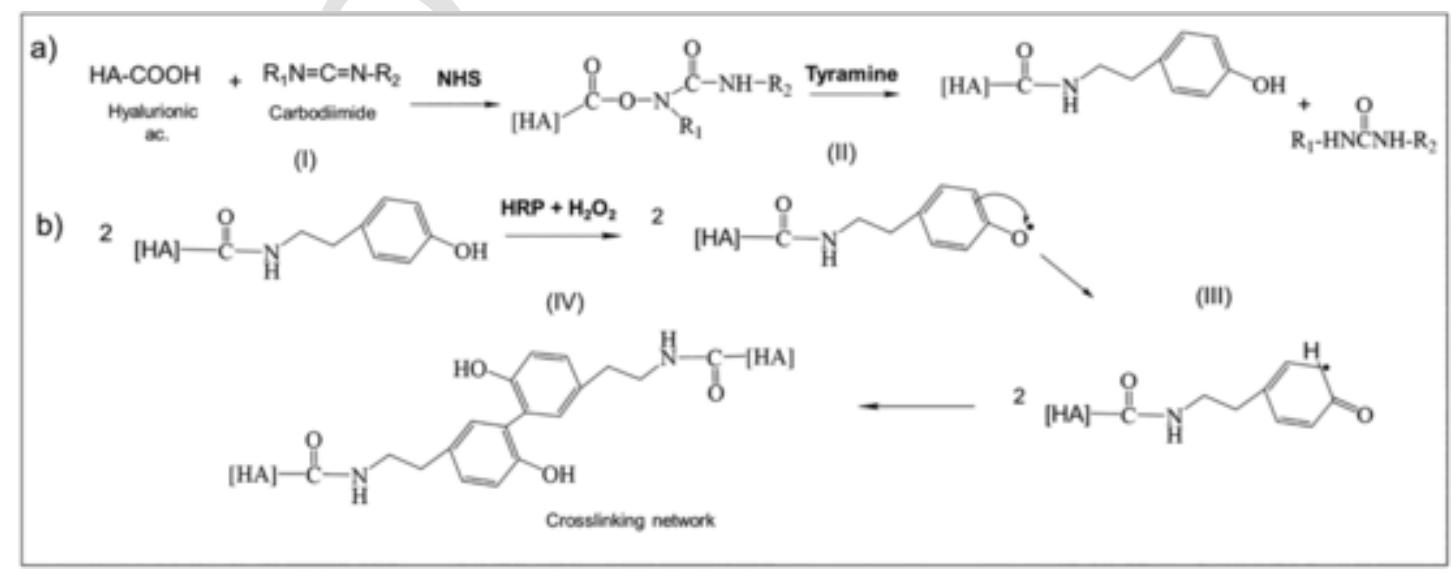

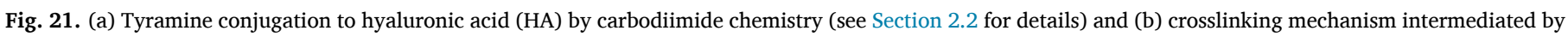

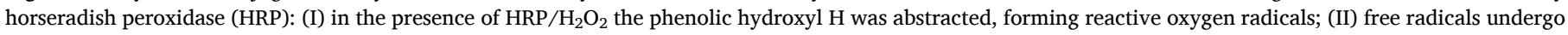

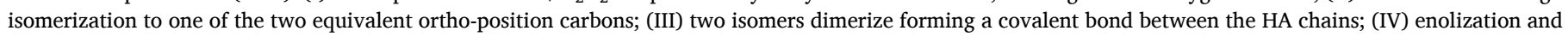
dityramine generation [218]. 


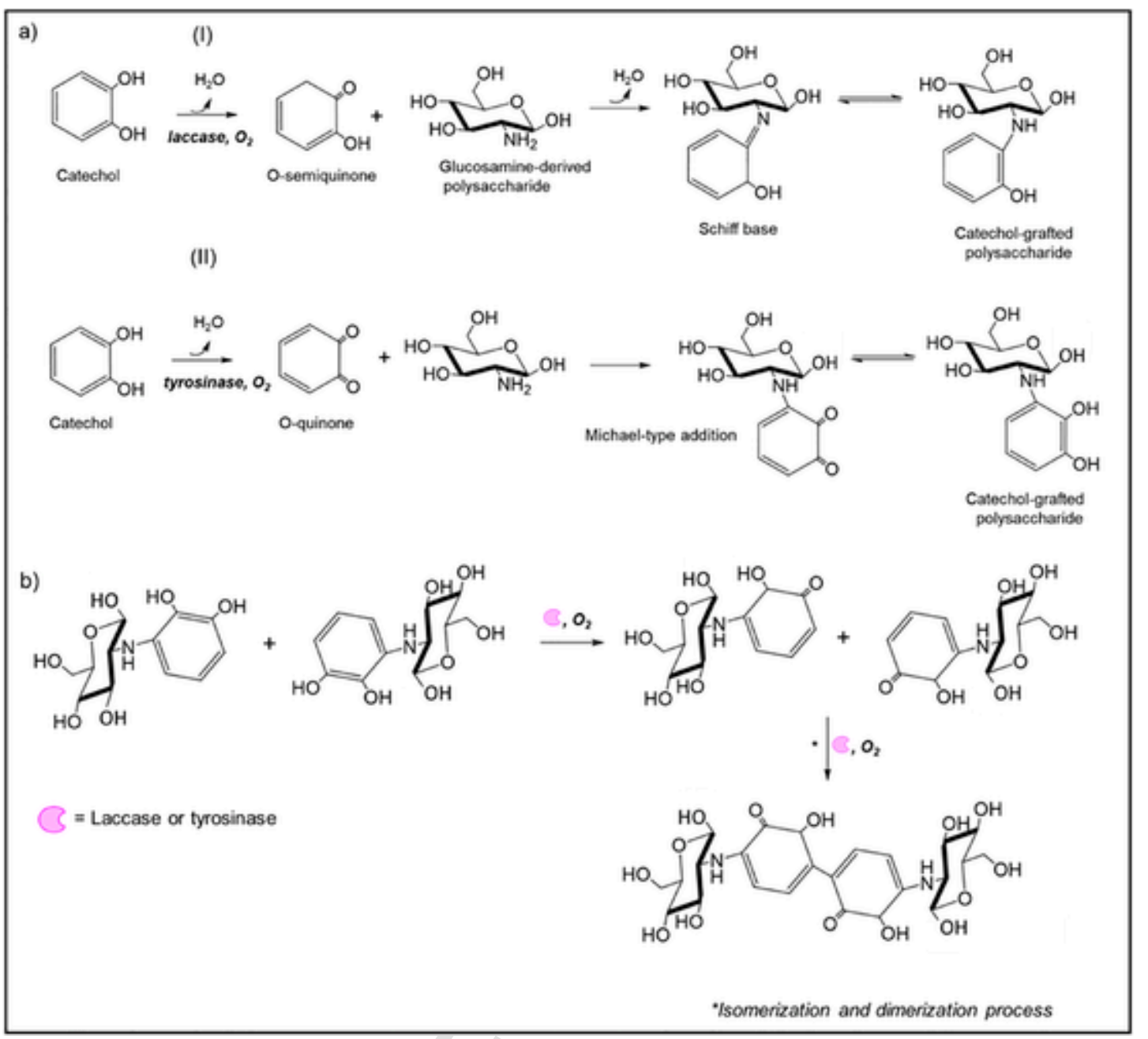

Fig. 22. Schematic representation of laccase or tyrosinase catalyzed reactions to form catechol modified chitosan hydrogels. (a) oxidation of catechol to orthosemiquinone or ortho-quinone catalyzed by laccase (I) or tyrosinase (II), respectively, which react with chitosan amino group yielding imide linkages (Schiff base) or secondary amines (Michael addition), or their tautomers. (b) The tautomerization is interrupted by laccase or tyrosinase activity occurring isomerization and dimerization steps between two intermediaries of the soft hydrogels.

Due to its low cytotoxicity, when compared to the most common synthetic crosslinkers, and its anti-inflammatory properties, genipin has been applied for the production of biomaterials [240,242,243]. Genipin reacts promptly with free primary amino groups, abundantly found in proteins and chitosan, yielding blue-colored fluorescent hydrogels [242,244]. The crosslinking reaction of chitosan with genipin is strongly pH-dependent [240]. Under mild acidic and neutral conditions, a nucleophilic attack by the chitosan amino groups to the genipin olefinic carbon atom at C3 occurs, followed by the dihydropyran ring opening and nucleophilic attack of the secondary amine to the newly formed aldehyde group (steps 1 to 6 of Fig. 23b). Subsequently, a nucleophilic attack of an amino group of chitosan to the carboxyl group of genipin with amide formation leads to the formation of the crosslinked structure (steps 7 to 10), as depicted in Fig. 23b. Gelatin is a natural polymer derived from the hydrolysis of collagen. Due to the presence of free primary amine groups in its structure, gelatin has also been extensively crosslinked by genipin [242,245,246], yielding the so-called gelapin hydrogels [247].

The gel content of chitosan gels crosslinked with genipin at $\mathrm{pH}$ 5.0, $\mathrm{pH} 7.4, \mathrm{pH} 9$ and $\mathrm{pH} 13.6$ amounted to $39.9 \pm 3.8 \%, 96.0 \pm 1.9 \%$, $45.4 \pm 1.8 \%$ and $1.4 \pm 1.0 \%$, respectively [244,248]. Under an alkaline medium, genipin molecules undergo a ring-opening polymerization prior to crosslinking with chitosan, reducing the amount of genipin available for the crosslinking reaction [244,248]. Regarding the kinet- ics, the reaction of genipin with amino sources in an acidic medium has been reported to be accelerated upon increasing the reaction temperature to about $60-85{ }^{\circ} \mathrm{C}$ [249].

Oxygen radical-induced polymerization of genipin molecules already linked to amino groups of chitosan is possible [242]. This process leads to the formation of genipin copolymers with high conjugation of $\mathrm{C}=\mathrm{C}$, resulting in the characteristic dark-blue color of genipin crosslinked hydrogels [242,243].

\subsection{Vanillin}

Vanillin is the primary component of vanilla bean extract and is widely used as a flavoring agent in foods, beverages, cosmetics, and pharmaceuticals [250]. Due to the presence of an aldehyde group in its structure, vanillin reacts with primary amines forming a Schiff base (imine), as depicted in Fig. 24 [250-252]. The presence of the hydroxyl group, in a para orientation in relation to the previously formed Schiff bond, is responsible for the formation of a hydrogen bond with hydroxyl or amino groups present in the backbone of the neighbor chain (Fig. 24) [250-252]. This provides the basis for the construction of a reversible hybrid network and yields self-healing hydrogels [250]. Due to the formation of reversible hydrogen bonds, vanillin crosslinked hydrogels are sensitive to $\mathrm{pH}$ and temperature. Despite the instability of Schiff-base bonds in acetic acid, the vanillin crosslinked hydrogels are 


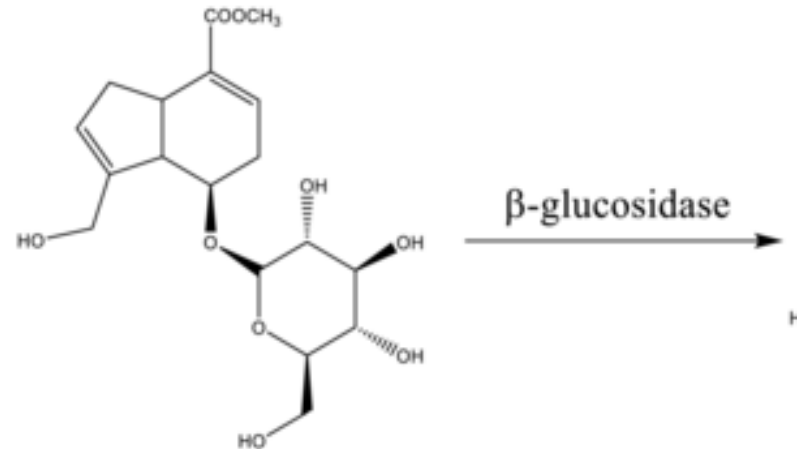

Geniposide<smiles>CC(=O)C1=CO[C@H](O)C2C(CO)=CCC12</smiles>

Genipin<smiles>OC[C@H]1O[C@H](O)[C@@H](O)[C@H](O)[C@@H]1O</smiles>

HO

(a)

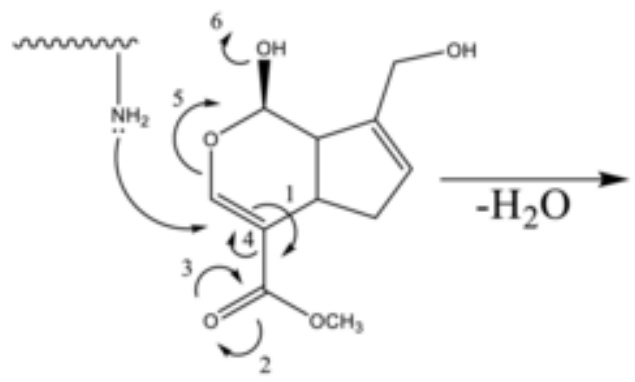<smiles>COC(=O)/C(=C/NS(C)(F)F)[C@@H]1CC=C(CO)[C@H]1C=O</smiles><smiles>CCN1C=C(C(=O)OC)[C@H]2CC=C(CO)C2C1O</smiles>

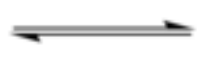<smiles>CCCCCCC</smiles>

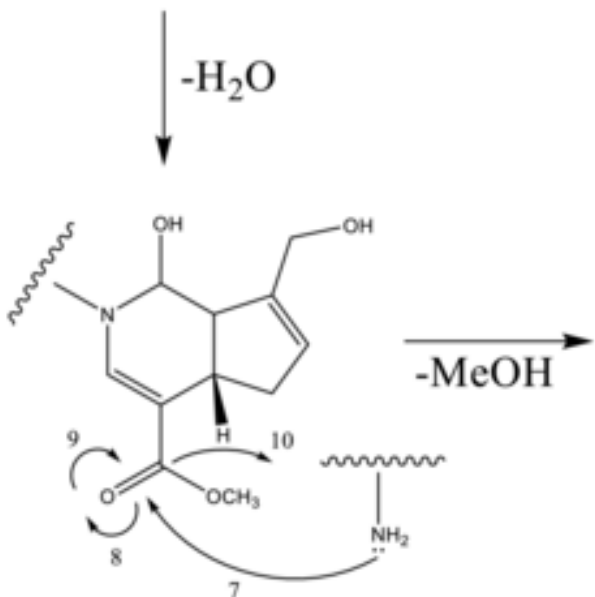<smiles>COC(=O)C1=C[N+](S)([Hg])C([O-])C2C(CO)=CC[C@@H]12</smiles><smiles>CCNC(=O)C1=CN(CC)C(O)C2C(CO)=CC[C@]12C</smiles>

(b)

Fig. 23. (a) Hydrolysis of geniposide by $\beta$-glucosidade yielding genipin and glucose. (b) Schematic representation of reaction mechanism for the crosslinking of chitosan or proteins mediated by genipin under acidic or neutral conditions. The mechanism steps are numbered in the genipin structure from 1 to 10. 

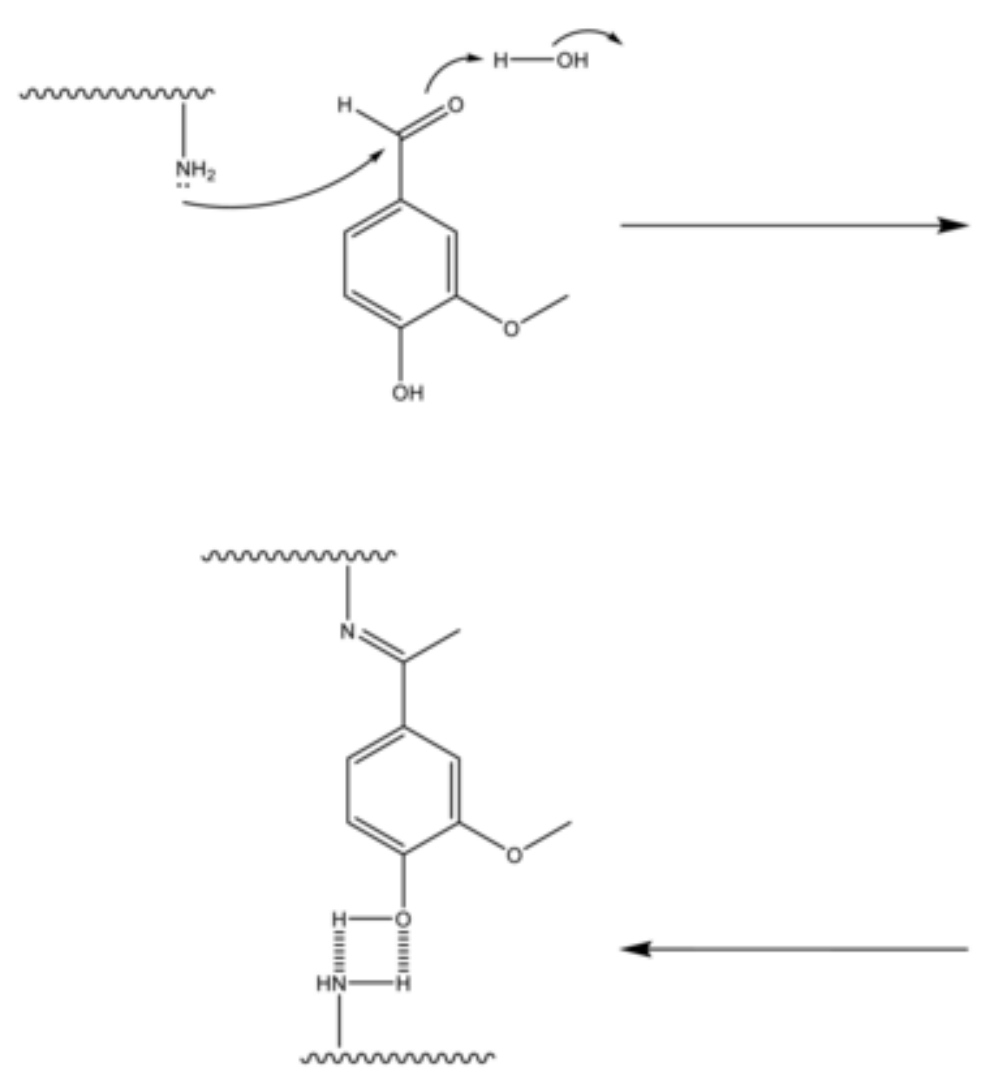
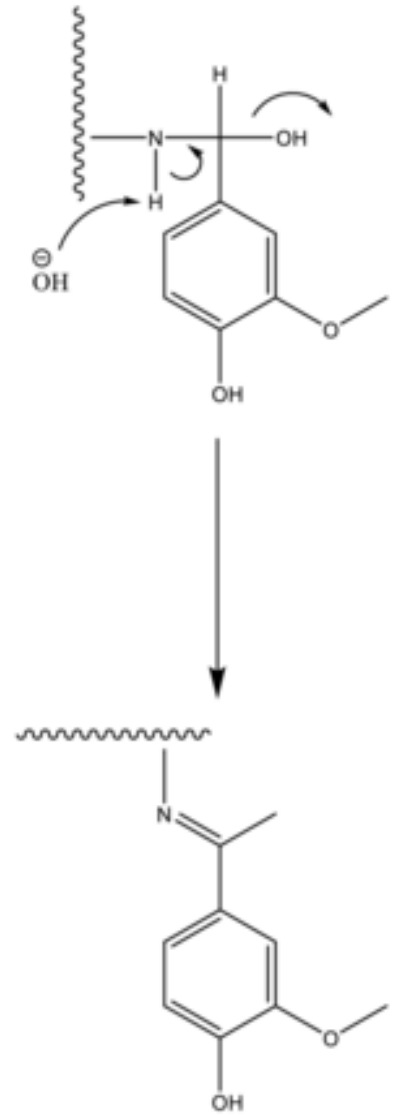

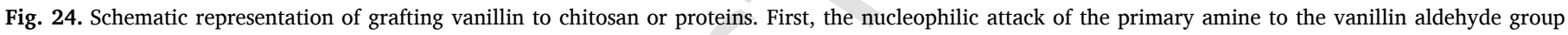

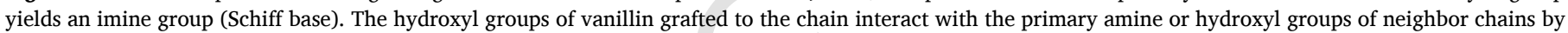
$\mathrm{H}$ bond, yielding hydrogels.

stable at low temperatures. On the other hand, upon increasing the temperature, the hydrogels present no stability due to the $\mathrm{H}$ bond breaking [250].

Vanillin crosslinked chitosan hydrogels are commonly produced in an acidic medium because chitosan is soluble only at $\mathrm{pH}$ lower than 4.5. Firstly, the crosslinker is dissolved in a polar organic solvent like ethanol [250,253] or acetone [252], followed by its dropwise addition to chitosan solutions in $2 \%$ acetic acid under vigorous mixing. After that, the solvent is allowed to evaporate yielding yellowish vanillin crosslinked chitosan hydrogels. The formation of imine bonds can be evidenced by FTIR spectroscopy, because the typical imine band appears at $1637 \mathrm{~cm}^{-1}[26,250,253]$.

\subsection{Tannic acid}

Tannic acid (TA) is a natural polyphenolic compound found in practically all aerial plant tissues [254]. It is composed of a glucose ring esterified with five digallic acid. Therefore, it contains one glucose core and ten gallic ester moieties, as presented in Fig. 25a. Although TA molecule carries no carboxylic acid group, it is called "acid" due to the presence of numerous phenol groups, which are responsible for its acidic character [255]; $\mathrm{pH}$-metric titrations indicate $\mathrm{pK}_{\mathrm{a} 1}$ at $6.14 \pm 0.01, \mathrm{pK}_{\mathrm{a} 2}$ at $7.19 \pm 0.01$, and $\mathrm{pK}_{\mathrm{a} 3}$ at $8.39 \pm 0.01$ [256]. Due to the presence of multiple phenolic groups, TA presents a direct antioxidant effect by binding free radicals [255]. Furthermore, TA is also known to present antimicrobial, anticancer, antiviral, and anti-inflammatory properties [257], making it a strong candidate for developing new therapeutic materials.

Crosslinking modifications occur mainly through physical interactions or chemical bonding [258]. Phenolic hydroxyl groups of TA can easily interact with lysine, tyrosine, and cysteine [259]. For this reason, TA has been used widespread as a natural protein crosslinker, especially for gelatin and collagen [258,260-262].

The covalent bonding between phenolic compounds and proteins or amino functionalized polysaccharides involves the initial oxidation of phenolic structures, under alkaline condition, yielding quinone intermediates, which can readily react with nucleophiles from reactive amino acid groups and generate chemically crosslinked networks upon the formation of new C-N bonds either by Michael addition or Schiffbase reactions with more than one chain, as depicted in Fig. 25b [196-199]. The reaction conditions for the crosslinking of TA with different polymers are not straightforward. Some studies report the mixture of TA to macromolecule solution under acidic medium $[257,266,267]$, whereas others report the crosslinking reaction under alkaline conditions [258,263,268].

\subsection{Phytic acid}

Phytic acid (PA), also known as myo-inositol hexaphosphate (IP6), is a natural antioxidant and anticancer compound commonly found in plant seeds and organic soil [269]. Due to its large availability and low price, $\mathrm{PA}$ is a promising natural crosslinker candidate to replace the expensive genipin [25]. PA has six strong acid protons $\left(\mathrm{pK}_{\mathrm{a} 1} \sim 1.5\right)$, three weak acid protons ( $\mathrm{pK}_{\mathrm{a} 2}$ between 5.7 and 7.6) and three very weak acid protons $\left(\mathrm{pK}_{\mathrm{a} 3}>10\right)$, as depicted in Fig. 26. [270]

Crosslinking between PA and natural polymers happens mainly via electrostatic interactions between phosphate groups and cations belonging to the macromolecules [25]. For this reason, PA has been used as a crosslinking agent for proteins, such as collagen [269] and gelatin [25] and cationic polysaccharides like chitosan [271-276]. Ionic 


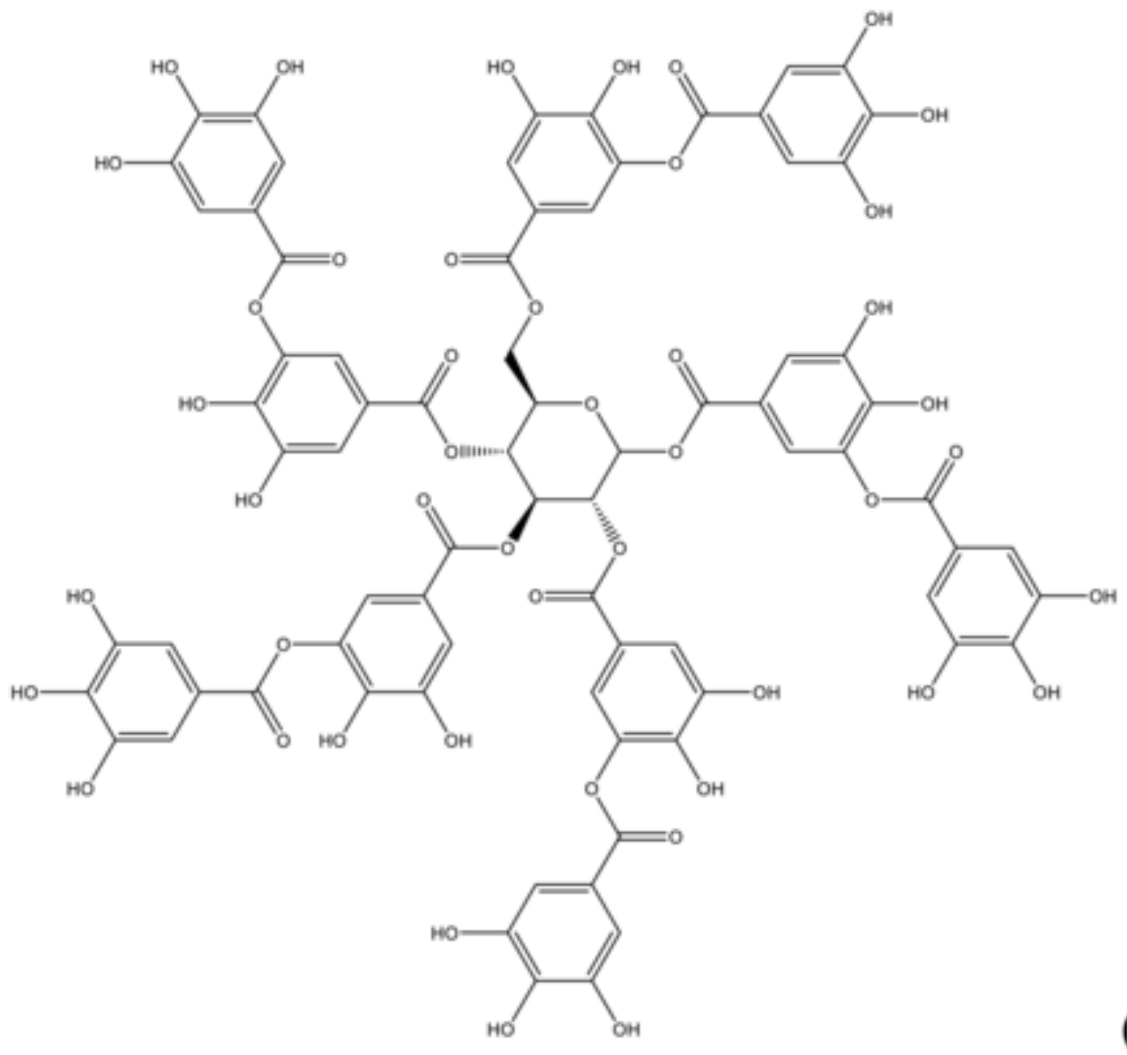

(a)

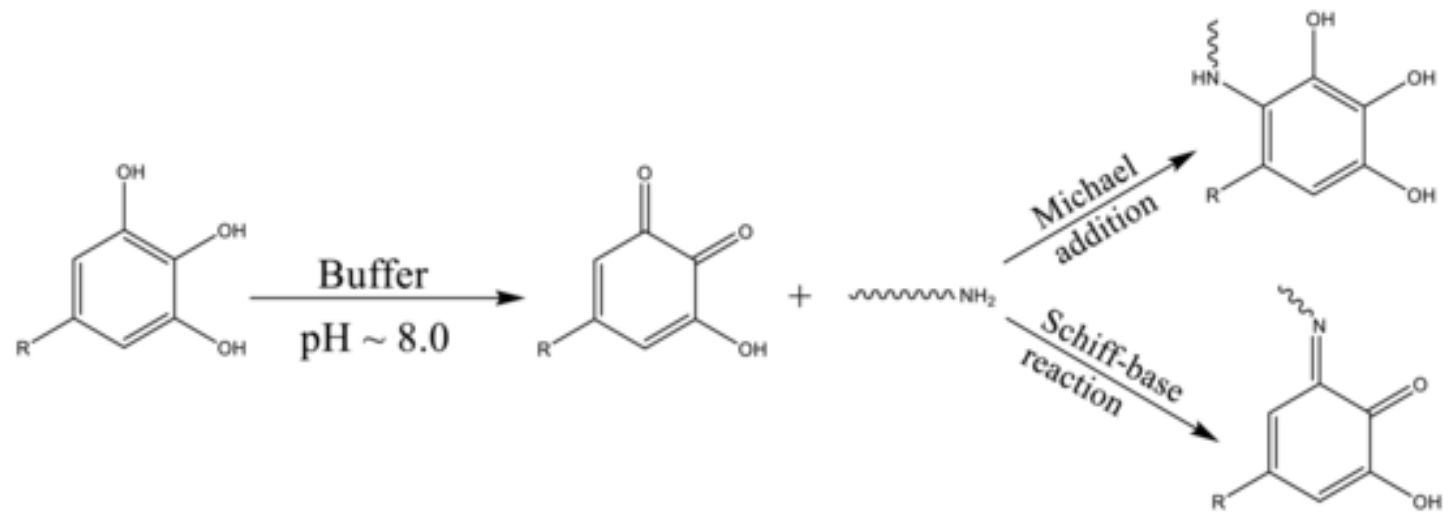

(b)

Fig. 25. (a) Representation of the chemical structure of tannic acid (TA). (b) Covalent bonding between phenolic compounds and proteins or amino functionalized polysaccharides under alkaline conditions at room temperature. The oxidation of phenol yield quinone intermediates, which can react with primary amine (protein or polysaccharide) either by Michael addition or Schiff-base reactions [199].

crosslinking methods are simple and do not require organic solvents or heat [277], which makes them beneficial for biomaterial applications. At $\mathrm{pH}>10$, PA presents twelve negatively charged groups, which is a relatively larger ionic strength than other ionic crosslinkers at the same concentration [278]. In this context, for in vitro insulin delivery studies, chitosan matrices crosslinked with PA exhibited better stability than those crosslinked with tripolyphosphate (TPP) [279].

The ion gelation method mediated by PA allows the formation of chitosan microspheres [276,280], microcapsules [272,274,279], selfassembled polyelectrolyte complexes (PECs) [271] and nanoparticles [273]. In most cases, an aqueous solution of PA (usually at $50 \mathrm{wt} \%$ ) is added dropwise to an acidic solution of chitosan (usually $\mathrm{HCl}$ ) under continuous stirring, which promptly precipitates upon crosslinking. Table 5 comprises some examples of the aforementioned natural crosslinkers for different macromolecules, the reaction conditions and the corresponding crosslinking mechanism.

\section{Click chemistry in the production of hydrogels}

The term "click chemistry" was first introduced by Sharpless et al. [284] in 2001 and describes a class of reactions that are rapid, spontaneous, versatile, extremely selective, and result in high yields of products when two molecular substances or components are mixed or reacted at mild reaction conditions [285,286]. The "click chemistry" approach allows for a variety of synthetic strategies to accomplish the cross-linking and chemical functionalization of hydrogels with tailored physical, chemical, and biological properties [287]. 

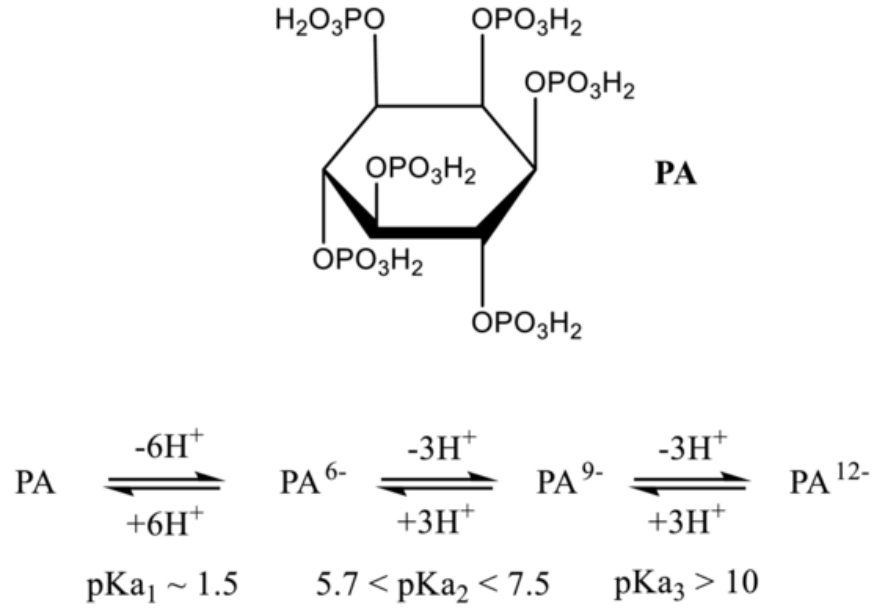

Fig. 26. Representation of chemical structure of phytic acid with six protonated phosphate groups (PA) and its respective deprotonation equilibrium to $\mathrm{PA}^{12-}$.

Table 5

Examples of natural crosslinkers with the corresponding sources, applied for chitosan (CS), proteins and polycations, along with the reaction conditions and crosslinking mechanism.

\begin{tabular}{|c|c|c|c|c|c|}
\hline Crosslinker & Source & Macromolecule & $\begin{array}{l}\text { Crosslinking } \\
\text { mechanism }\end{array}$ & $\begin{array}{l}\text { reaction } \\
\text { conditions }\end{array}$ & Ref \\
\hline Genipin & $\begin{array}{l}\text { Gardenia } \\
\text { jasminoides } \\
\text { Ellis/ } \\
\text { Genipa } \\
\text { americana } \\
\text { L. }\end{array}$ & $\begin{array}{l}\text { Chitosan/ } \\
\text { gelatin }\end{array}$ & $\begin{array}{l}\text { Nucleophilic attack } \\
\text { by the chitosan } \\
\text { amino groups to the } \\
\text { genipin C3, } \\
\text { dihydropyran ring } \\
\text { opening and } \\
\text { nucleophilic attack } \\
\text { of the secondary } \\
\text { amine to the newly } \\
\text { formed aldehyde } \\
\text { group }\end{array}$ & $\begin{array}{l}\mathrm{pH} \text { from } \\
4.5 \text { to } 6.0 \\
\text { Temp. } \\
\text { from } \\
60{ }^{\circ} \mathrm{C} \text { to } \\
85{ }^{\circ} \mathrm{C}\end{array}$ & [248] \\
\hline Vanillin & $\begin{array}{l}\text { Vanilla } \\
\text { bean } \\
\text { extract }\end{array}$ & Chitosan & $\begin{array}{l}\text { Schiff base reactions } \\
\text { with primary } \\
\text { amines/H bond }\end{array}$ & $\begin{array}{l}\text { Acetic } \\
\text { acid } \\
\text { solution } \\
1-2 \%\end{array}$ & $\begin{array}{l}{[26,} \\
250, \\
253]\end{array}$ \\
\hline $\begin{array}{c}\text { Tannic } \\
\text { acid }\end{array}$ & $\begin{array}{l}\text { Aerial } \\
\text { plant } \\
\text { tissues }\end{array}$ & $\begin{array}{l}\text { Gelatin, } \\
\text { chitosan, } \\
\text { collagen }\end{array}$ & $\begin{array}{l}\text { Michael addition/ } \\
\text { Schiff Base reactions } \\
\text { with primary } \\
\text { amines/H bond }\end{array}$ & $\begin{array}{l}\text { Addition } \\
\text { of TA to } \\
\text { acidic or } \\
\text { basic } \\
\text { polymer }\end{array}$ & $\begin{array}{l}{[257,} \\
258, \\
263, \\
281- \\
283]\end{array}$ \\
\hline $\begin{array}{r}\text { Phytic } \\
\text { acid }\end{array}$ & $\begin{array}{l}\text { Plant } \\
\text { seeds/ } \\
\text { organic } \\
\text { soil }\end{array}$ & $\begin{array}{l}\text { Cationic } \\
\text { polymers/ } \\
\text { proteins }\end{array}$ & $\begin{array}{l}\text { Electrostatic } \\
\text { interactions }\end{array}$ & $\begin{array}{l}\text { Dripping } \\
\text { of PA } \\
\text { aqueous } \\
\text { solution } \\
\text { into acidic } \\
\text { polymer } \\
\text { solution }\end{array}$ & $\begin{array}{l}{[271,} \\
275, \\
279]\end{array}$ \\
\hline
\end{tabular}

Several well-known reactions for the synthesis of hydrogels comply with the "click chemistry" approach. Fig. 27 summarizes various click reactions that have been applied for the crosslinking of macromolecules. They can be separated into three groups, which include coppercatalyzed azide-alkyne cycloaddition (Cu-AAC); copper-free click reactions, such as strain-promoted azide-alkyne cycloaddition (SPAAC), Diels-Alder (DA), radical mediated thiol-ene and oxime-forming reactions; and pseudo click reactions, which include thiol-Michael addition and aldehyde-hydrazide reactions (Schiff base reactions) [288].

From this point on, the discussion will focus on the review of click chemistry reactions regarding the formation of protein (e.g., collagen and gelatin) and polysaccharide-based hydrogels (e.g., hyaluronic acid (HA), alginate, and chitosan (CS)), with emphasis on the improvement of the hydrogel's mechanical properties. Hopefully future readers might take some advantages in terms of the selection of appropriate polymer backbones in the research of new biomaterials.

\subsection{Protein-based hydrogels}

\subsubsection{Collagen}

SPAAC, oxime-forming and Schiff base reactions are the most common methods for crosslinking collagen chains in aqueous medium [287]. SPAAC can be facilitated by crosslinking collagen functionalized with either azide or DBCO groups using $N$-hydroxysuccinimide (NHS) coupling chemistry [289]. Mechanical properties of the resulting gels were controlled by changing functional group ratios and conjugated collagen concentrations. Higher concentrations of conjugated collagen yielded enhanced mechanical properties; the storage modulus increased from $42.39 \pm 8.95 \mathrm{~Pa}$ to $112.03 \pm 3.94 \mathrm{~Pa}$ after SPAAC crosslinking.

Feng et al. [290] prepared a hybrid hydrogel comprising aminated collagen (AC), oxidized sodium alginate (OSA) and antimicrobial peptides (polymyxin B sulfate and bacitracin). The Schiff base reaction took place, under mild conditions, between the free amino groups of AC and the aldehyde groups of OSA yielding an effective hybrid hydrogel against $E$. coli and $S$. aureus. The storage modulus of hydrogels increased gradually from $250 \mathrm{~Pa}$ to $3000 \mathrm{~Pa}$ upon increasing AC concentration, indicating that $\mathrm{AC}$ favored the formation of a tighter network gel due to the Schiff base reaction.

Hydrogels prepared by aldehyde-aminooxy oxime click reactions are especially interesting because the reaction product (an oxime) is more stable than Schiff bases in the biological milieu [291]. In a fundamental work, Hentzen et al. [292] proved the formation of crosslinked collagen triple helices by oxime bonds between proline residues in adjacent collagen strands. The covalently connected strands folded into hyperstable collagen triple helices with remarkable thermal stability (Tm $\approx 80^{\circ} \mathrm{C}$ ).

\subsubsection{Gelatin}

The physical crosslinking of gelatin is spontaneously induced by intra- and intermolecular hydrogen bonds [293], leading to low stiffness hydrogels. In this context, click crosslinking methods for the enhancement of gelatin-based hydrogels' mechanical properties have been applied, which includes CuAAC, DA, and radical mediated thiol-ene reactions [287]. CuAAC reaction of alkyne functionalized gelatin with diazides led to the production of hydrogel networks with tailorable mechanical properties by the ratio of diazide to gelatin and the diazide rigidity. For example, 4,4'-diazido-2,2'-stilbene-disulfonic acid, a rigid crosslinker, yielded hydrogels with Young's moduli of $50-390 \mathrm{kPa}$, whereas 1,8-diazidooctane, a more flexible crosslinker, resulted in hydrogels with Young's moduli of 125-280 kPa [294].

Garcia-Astrain et al. [295] designed biopolymeric hydrogels of furfuryl-gelatin-polyetheramine through Diels-Alder (DA) reaction in a simple one step procedure free of catalysts, additives or coupling agents. For that, gelatin was firstly modified by the reaction of the free $\varepsilon$-amino groups (mainly lysine and hydroxylysine residues) of the main chain with furfuryl glycidyl ether (FGE). Afterwards, a Jeffamine ${ }^{\circledR}$ based bismaleimide (BMI) was employed as crosslinker. Different furan-to-maleimide ratios were used in order to study the influence of employing an excess of crosslinker on the final hydrogel properties. GelFGE to BMI weight ratios for hydrogel formation were 1:1.0 (HGEL11.0), 1:1.5 (HGEL1-1.5) and 1:2.0 (HGEL1-2.0). Upon increasing the gel-FGE to BMI weight ratio from 1:1.0 to $1: 1.5$ the $\mathrm{G}^{\prime}$ value increased from $1709.0 \pm 278.9$ to $2040.2 \pm 59.6 \mathrm{~Pa}$, indicating higher amounts of bismaleimide would lead to a more crosslinked network. However, for HGEL1-2.0 the $G^{\prime}$ value amounted to $1705.0 \pm 132.3$, suggesting that the excess of crosslinker did not improve the elastic properties of the hydrogels and could, instead, act as a plasticizer lowering the $\mathrm{G}^{\prime}$ value. According to the authors, the elastic properties of these materials 


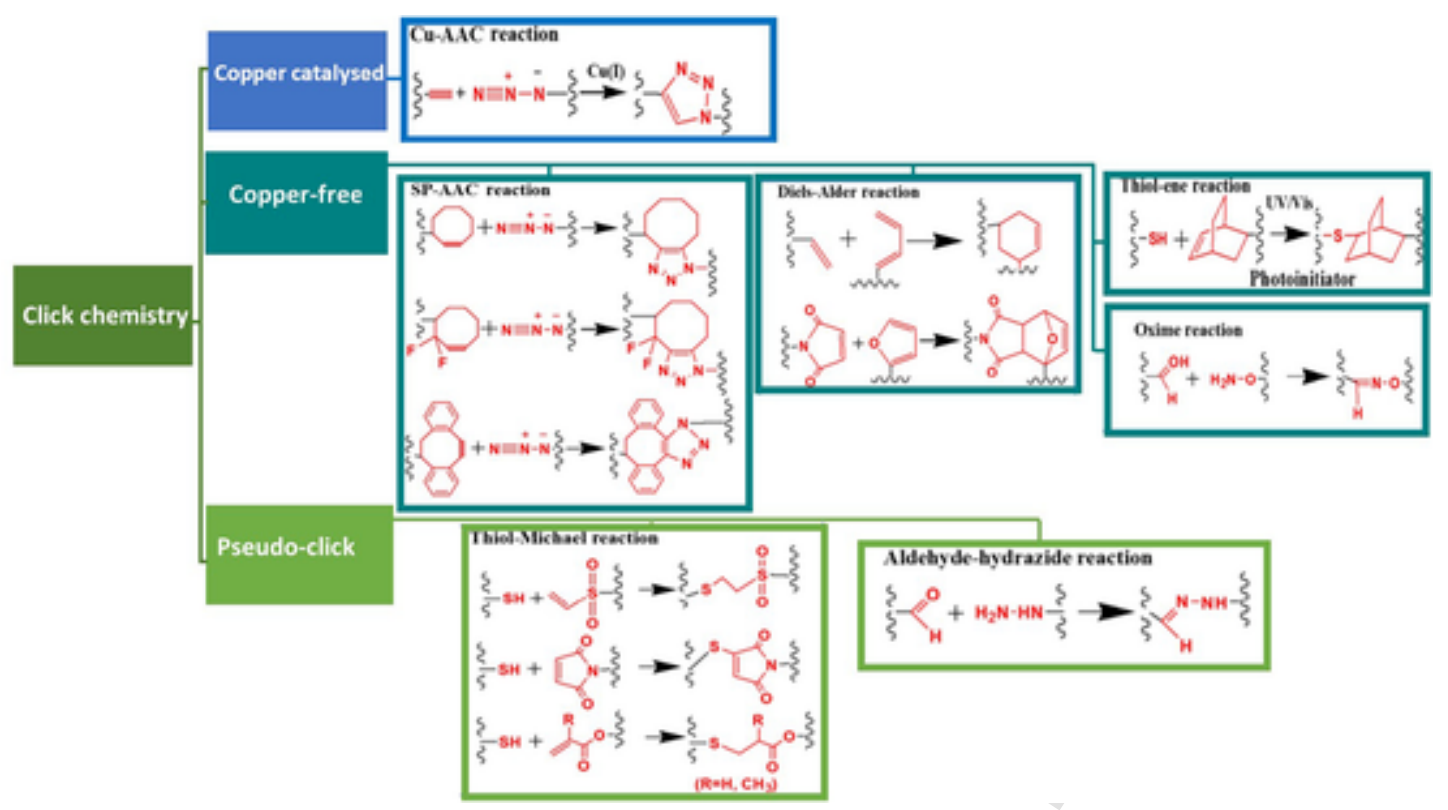

Fig. 27. Schematic representation of three groups of click reactions that have been often applied for polysaccharides and proteins crosslinkings: Copper-catalyzed azide-alkyne cycloaddition (Cu-AAC); copper-free click reactions, such as strain-promoted azide-alkyne cycloaddition (SPAAC), Diels-Alder (DA), radical mediated thiol-ene and oxime-forming reactions; and pseudo click reactions, which include thiol-Michael addition and aldehyde-hydrazide reactions. Adapted from Ref. [288].

are crucial in terms of tissue engineering applications since the mean values of the storage modulus obtained for all the hydrogel compositions are in the range of those of liver, fat, relaxed muscle and breast gland tissue, namely from $10^{3}$ to $10^{4} \mathrm{~Pa}$.

Regarding the formation of gelatin hydrogels via radical mediated thiol-ene reactions, Tytgat et al. [296] developed a photo-click crosslinkable gelatin hydrogel for adipose tissue engineering purposes. For that, norbornene-functionalized gelatin type B (Gel-NB) was combined with thiolated gelatin (Gel-SH) (in the presence of the photoinitiator Li-TPO-L) and the photo-click scaffolds were compared to the conventional methacrylamide-modified gelatin (GelMa) hydrogels. The biomaterial inks were evaluated via extrusion-based 3D printing; the hydrogel precursors were inserted into a disposable plastic syringe and pneumatically dispensed into a 3D scaffold by stacking 2D layers. Mechanical tests showed a significant difference between the Young's modulus of the Gel-NB/Gel-SH scaffolds $(1.0 \pm 0.1 \mathrm{kPa})$ versus the GelMa scaffolds ( $1.6 \pm 0.2 \mathrm{kPa}$ ). Furthermore, in vitro biocompatibility assays showed similar cell viability for the Gel-NB/Gel-SH scaffolds in comparison to the GelMa scaffolds. However, the adipogenic differentiation potential of the developed Gel-NB/Gel-SH scaffolds proved to be better in comparison to the GelMa gold standard (see more details about GelMa in Section 6).

\subsection{Polysaccharide based hydrogels}

\subsubsection{Hyaluronic acid}

Several click chemistry methods have been employed to prepare hyaluronic based hydrogels. In order to mimic the natural cartilage extracellular matrix, a hydrogel based on hyaluronic acid (HA), chondroitin sulfate (CS) and gelatin was synthesized via click chemistry [297]. HA and CS were modified with 11-azido-3,6,9-tri-oxaundecan-1amine (AA) and gelatin was modified with propiolic acid (PA). HA-AA and $\mathrm{CS}-\mathrm{AA}-\mathrm{N}_{3}$ groups reacted with the acetylene groups of Gelatine-PA in the presence of $\mathrm{Cu}(\mathrm{I})$, leading to the formation of a triazole ring crosslinked hydrogel. The resulting hydrogels presented Young's modulus of $\sim 7 \times 10^{3} \mathrm{~Pa}$, which is higher than that of the slightly crosslinked hyaluronan hydrogel (several hundred $\mathrm{Pa}$ ) and similar to that of the highly cross-linked hyaluronan hydrogel [298].
Hozumi et al. [299] developed a novel injectable hydrogel composed of carbohydrazide-modified gelatin (Gel-CDH) and monoaldehyde-modified hyaluronic acid (HA-mCHO). Upon mixing the two precursor polymers, Gel-CDH/HA-mCHO hydrogels were produced through Schiff's base formation; the new hydrogels are more stable in PBS because the imine structure formed by $\mathrm{CDH}$ generates resonance structure. Besides the superior stability, the Gel-CDH/HAmCHO hydrogels are suitable for soft-tissue regeneration with shear storage modulus $\left(\mathrm{G}^{\prime}\right)$ in the range of 0.1 to $1 \mathrm{kPa}$ depending on the polymer concentration; these values of G' are in the same range as those of lung, liver, pancreas, and skin.

A series of alkene functionalized polyamidoamine (PAMAM) dendrimers was applied to form hydrogels with thiolated hyaluronic acid (HS-HA) via thiol-ene crosslinking click reaction. The different systems presented tailored gelation times and mechanical properties according to the electron density of the alkenyl end groups on the dendrimer. The storage modulus of the hydrogels decreased in the same order as for gelation time with functional groups on PAMAM from maleimide, to vinyl sulfone, acrylic, methacrylic, and alkene, respectively, ranging from 36 to $183 \mathrm{~Pa}$ under the experimental condition [300].

$\mathrm{Yu}$ et al. [301] integrated simultaneously enzymatic crosslinking and DA click chemistry in the formation of an injectable hyaluronic acid/PEG hydrogel for cartilage tissue engineering. For that, hyaluronic acid (HA) was firstly modified by furylamine (furan) and tyramine (TA) functional groups followed by the HA/PEG hydrogel formation via enzymatic (in the presence of $\mathrm{HRP}$ and $\mathrm{H}_{2} \mathrm{O}_{2}$ solutions) and sequential DA click chemistry crosslinking. Hydrogels with different degrees of substitution (DS) of tyramine were labeled DS1 (DS 9.5\%), DS2 (DS 11.2\%) and DS3 (DS 5.8\%). The storage modulus and breakage strength of hydrogels were close to $27 \mathrm{kPa}$ and $109.4 \mathrm{kPa}$, respectively, with the DS3 hydrogel presenting better mechanical properties than the other hydrogels with different degrees of substitution.

Biodegradable crosslinked hydrogels based on the oxime click chemistry were produced upon mixing linear PEGs terminated at both ends with aminooxy moieties and HA derivatives displaying aldehydes in different proportions. The compressive moduli of the hydrogels varied between 2 and $12 \mathrm{kPa}$ which, according to the authors, is in the range of soft tissues of the nervous system [291]. 
Li et al. [302] fabricated a new hydrogel through a thiol-ene Michael addition reaction by crosslinking thiol-functionalized hyaluronic acid and hyperbranched poly (ethylene glycol) multiacrylate macromer as a cell carrier system for cartilage-derived progenitor cells (CPCs). By fixing the thiol-functionalized hyaluronic acid in $1 \%(\mathrm{w} / \mathrm{v})$ and varying the hyperbranched poly (ethylene glycol) proportion the authors managed to modulate the hydrogel's storage modulus $\left(\mathrm{G}^{\prime}\right)$. Hydrogels fabricated with $1 \%(\mathrm{w} / \mathrm{v}) \mathrm{HA}-\mathrm{SH}$ and $2.5 \%$ HB-PEG recorded a stiffness of $1 \mathrm{kPa}$ on average, which is ideal for chondrogenic differentiation according to the authors.

\subsubsection{Alginate}

Injectable self-healing hydrogels based on oxidized alginate-hybridhydroxyapatite nanoparticles and carboxymethyl chitosan (CMChi) were synthesized via Schiff base reaction [303]. First, the hybrid hydroxyapatite/alginate (HAH) was fabricated. Afterwards, the alginate of HAH was directly oxidized to form oxidized hydroxyapatite/alginate hybrid (OHAH). The injectable hydrogels were prepared by mixing $\mathrm{OHAH}$ and $\mathrm{CMChi}$, which undergo Schiff base reaction. The oxidation time and OHAH concentration were modulated in order to obtain hydrogels with different properties. The $\mathrm{G}^{\prime}$ of the hydrogels increased with the concentration of OHAH and the oxidation time, which was related to the formation of more imine linkages via Schiff base reaction with the more aldehyde groups in hydrogels. Hydrogels prepared with the highest oxidation time (48 h) and highest OHAH (12 wt\%) presented $\mathrm{G}^{\prime} \sim 1220 \mathrm{~Pa}$.

Sánchez-Morán et al. [304] successfully modified the backbone of sodium alginate $(\mathrm{NaAlg})$ to introduce alkoxyamine functional groups for the first time. The resulting polymer was combined with aldehyde containing oxidized alginate (NaAlg-Ald) with different degrees of oxidation (DOx) in order to produce oxime crosslinked alginate hydrogels. Highly tunable stress relaxation and mechanical properties could be achieved by systematically varying the system composition (concentration, polymer mixing ratios and degree of oxidation of NaAlg-Ald) or environmental factors $(\mathrm{pH}$, temperature, and use of catalyst). Just to mention, the chain flexibility of one of the hydrogel components, NaAlg-Ald-X, could be very different depending on the varying DOx. By mixing a $5 \%(\mathrm{w} / \mathrm{v})$ NaAlg-AA and $5 \%(\mathrm{w} / \mathrm{v})$ NaAlg-Ald-X precursor solutions in a $1: 1(\mathrm{v} / \mathrm{v})$ mixing ratio, the authors prepared five different gels with NaAlg-Ald containing aldehyde groups that were 25, 50, 70, 90 , and $100 \%$ oxidized from the alginate diols. The G' values were relatively stable for a wide range of DOx (varying from $4.4 \mathrm{kPa}$ to $5.9 \mathrm{kPa}$ in the range of 25 to $90 \%$ DOx, respectively) but decreased significantly to $1.5 \mathrm{kPa}$ in the DOx of $100 \%$, which was attributed to the complete breakdown of saccharide rings into a purely linear chain in NaAlg-Ald100 with enhanced chain flexibility.

Degradable hydrogels were prepared by crosslinking norbornenemodified alginate and two different thiol-coupled peptides using UVinitiated thiol-ene chemistry [305]. The crosslinking was achieved as the amino acid sequences contained cysteines on both ends, which enabled the formation of thiol-ene bonds between the norbornene and thiol groups in the presence of photo-initiator, when exposed to UV light. The hydrogel degradation was attained as the particular amino acid sequences are susceptible to recognition and cleavage by matrix metalloproteinases. Low and high molecular weight alginate samples were tested in the production of the hydrogels. The range of stiffness attained was 2-14 kPa for the low molecular weight alginate gels and 1-11 kPa for the high molecular weight alginate gels; the range of stiffnesses is similar to that of many tissues such as lung, fat, breast, brain, kidney, and heart.

Crosslinked hydrogels were also prepared by combining different click reactions. Wang et al. [306], for example, designed alginate-based hydrogels formed by integrating Diels-Alder and the thiol-ene click reactions. First, a furyl modified sodium alginate (NaAlg) was obtained by amidation between the carboxyl groups of NaAlg and the amine groups of furan, yielding products with different degrees of substitution (DS). Afterwards, a bimaleimide PEG was mixed to the modified NaAlg to form NaAlg/PEG hydrogels. The cysteine-terminated peptide HHC10-CYS (HHC10) was grafted into the hydrogel by the thiol-ene reaction between the oxy-norbornene group and the thiol group, yielding NaAlg/PEG-HHC10 antimicrobial hydrogels. The hydrogel mechanical properties were optimum for the NaAlg/PEG-DS2 hydrogel, with a DS of $35.52 \%$, which presented the highest value of stress-atfailure (33.01 $\mathrm{kPa})$ and compress modulus $(52.53 \mathrm{kPa})$.

\subsubsection{Chitosan}

Several click chemistry reactions, such as the DA and Schiff base reactions, have been employed to prepare chitosan-based hydrogels. Guaresti et al. [307] synthesized a chitosan-based hydrogel crosslinked via Diels-Alder (DA) reaction. Furan-modified chitosan (Chi-Fu) was synthesized by the reaction of furfural with the free amino groups of chitosan, whereas maleimide-functionalized chitosan (Chi-AMI) was prepared by the reaction of a maleimide-modified amino acid with the amino groups of chitosan through amide coupling. Afterwards, the two complementary chitosan derivatives were crosslinked to yield the final hydrogel network. The storage modulus $\left(\mathrm{G}^{\prime}\right)$ presented a maximum value of $210 \mathrm{~Pa}$, which according to the authors is in the range of those of brain and nerve tissues $\left(10^{2}-10^{3} \mathrm{~Pa}\right)$ and makes the hydrogel a highly recommended candidate for tissue engineering applications.

Jia et al. [308] developed an injectable chitosan-based hydrogel to repair full-thickness cartilage defects in femoral patellar grooves in rabbits. For that, rabbit synovial fluid mesenchymal stem cells (rbSFMSCs) were encapsulated into the structure of the previously crosslinked hydrogel. The hydrogel was formed by glycol chitosan and benzaldehyde capped poly(ethylene oxide) derivatives (OHC-PEO$\mathrm{CHO}$ ) via Schiff's base linkage at room temperature. The storage and loss moduli of the hydrogel were modulated by varying the glycol chitosan and OHC-PEO-CHO concentrations. Higher polymer concentrations yielded a hydrogel with higher storage modulus. The hydrogel containing $2 \mathrm{wt} \%$ glycol chitosan and $2 \mathrm{wt} \%$ OHC-PEO-CHO reached the highest storage modulus of about $1300 \mathrm{~Pa}$ and promoted MSCs differentiation into chondrogenic lineage.

Table 6 summarizes the types of click chemistry for collagen, gelatin, hyaluronic acid, alginate and chitosan crosslinking.

\section{Table 6}

Types of click chemistry reactions to crosslink biopolymers (proteins and polysaccharides) for regenerative purposes.

\begin{tabular}{lll}
\hline Biopolymer & Schematic diagram & $\begin{array}{l}\text { Types of click chemistry } \\
\text { reactions }\end{array}$ \\
\hline Collagen & $\begin{array}{l}\text { SPAAC, oxime-forming and } \\
\text { Schiff base reactions } \\
\text { CuAAC, DA, and radical } \\
\text { mediated thiol-ene reactions } \\
\text { Cu-AAC, Schiff base reaction, } \\
\text { radical mediated thiol-ene, DA, } \\
\text { oxime- forming and thiol- } \\
\text { Michael reaction } \\
\text { Schiff base reaction, oxime- } \\
\text { forming reaction, radical } \\
\text { mediated thiol- ene and DA } \\
\text { reaction }\end{array}$ \\
$\begin{array}{ll}\text { DA, Schiff base reaction. } \\
\text { Chitosan }\end{array}$
\end{tabular}

Adapted from Ref. [287]. 


\section{Macromolecular crosslinkers}

Macromolecular crosslinkers are in general oligomers or low molecular weight polymers carrying functional groups at the chain ends. If both ends carry the same functional group, they are named as homofunctional (an example in Fig. 28a). If the reactive groups at either end are different, they are heterofunctional (see an example in Fig. 28b). PEG and dextran based macromolecular crosslinkers are interesting due to their biocompatibility and target-reactivity. The functional groups attached to the chain ends should present reactivity towards intrinsic functional groups of polysaccharides (hydroxyl, amines, and carboxylic acid groups) or proteins (amines, acid carboxylic and sulfhydryl groups). There is a plethora of commercially available macromolecular crosslinkers [309,310], most of them are PEG modified chains, where the chain size might vary from $\sim 200 \mathrm{~g} / \mathrm{mol}$ to $2500 \mathrm{~g} / \mathrm{mol}$. For protein crosslinking, $\mathrm{N}$-hydroxysuccinimide esters (NHS esters) (Fig. 6) and imidoesters are the functional groups most commonly used due to their high reactivity towards primary amino groups.

Despite the large offer of commercial macromolecular crosslinkers, there are literature reports, where macromolecular crosslinkers are synthesized to perform a dual function. For instance, PEG $\left(M_{n}=1000 \mathrm{~g} /\right.$ mol) was modified in order to create an acid-degradable crosslinker, as represented in Fig. 29 [311]. PEG was first transformed into bis(succinic acid ester)polyethylene glycol, which reacted with EDC to yield $O, O^{\prime}$-bis[2-( $N$-succinimidyl-succinate)]polyethylene glycol (1). (1) reacted with 2,2-bis(aminoethoxy)propane (2) yielding the acid-sensitive crosslinker 2,2-Bis(\{O-[(N-Succinimidyl)succinyl]- $\mathrm{O}^{\prime}$-[succinylamino] polyethylene glycolethoxy)propane (3). (3) was used for the crosslinking of carboxymethyl chitosan chains by the reaction between chitosan amino groups and (3) $\mathrm{N}$-hydroxysuccinimide ester groups, creating hydrogels stable at $\mathrm{pH} 7.5$, but readily degradable at $\mathrm{pH}<6.0$, due to the presence of ketal moieties in the macromolecular structure [311].

Proteinosomes are crosslinked conjugates that offer suitable conditions for encapsulating guest biomolecules (enzymes, proteins) and ge- netic expression [312]. The homofunctional macromolecular crosslinker poly(ethylene glycol)-bis( $N$-succinimidyl succinate) (PEGdiNHS) was successfully applied for the crosslinking of bovine serum albumin and poly( $N$-isopropylacrylamide) (BSA/PNIPAM), forming semipermeable and elastic membranes [313].

Bulk hydrogel based on dextran was prepared via the Schiff base formation between aldehyde-functionalized dextran (Dex-CHO, MW $\sim 70,000 \mathrm{~g} / \mathrm{mol}$ ) and cationized bovine serum albumin (BSA- $\mathrm{NH}_{2}$ ) and L-arginine grafted chitosan oligosaccharides (COS-Arg) [314]. These proteinosome-based hydrogels served for the adsorption of $E$. coli ( $\sim 93$ cells per proteinosome) from deionized water at $37^{\circ} \mathrm{C}$; the local acidification due to the metabolism of $E$. coli led to the death of some $E$. coli cells. The dead cells could be desorbed from the hydrogels by cooling the system to $25^{\circ} \mathrm{C}$ and adding $50 \mathrm{mM}$ phosphate buffered saline (PBS) pH 7.4, enabling the reusability of the hydrogels [314]. Dextran dialdehyde (MW $\sim 40,000 \mathrm{~g} / \mathrm{mol}$ ) prepared from the oxidation of dextran by sodium periodate [315] reacted with zein and sodium caseinate by imine bond formation (Shiff base reaction), increasing the system stability [316].

\section{Photocrosslinking}

The energy (E) of one photon radiation is given by

$E=h \nu$

where $\mathrm{h}\left(6.62607015 \times 10^{-34} \mathrm{~J} \times s\right)$ is the Planck's constant and $\nu$ is the frequency radiation $(\mathrm{Hz})$.

Ultraviolet (UV), X-rays and gamma radiation are electromagnetic radiations of high energy because of their high frequencies and might be used to promote crosslinking among the macromolecules. Radiation crosslinking has the advantage of crosslinking and sterilizing in one step, but the disadvantage of causing possible chain fragmentation and degradation. The irradiation technologies applied for the preparation of<smiles>CC(C)OCCNC(=O)CCC(=O)NOC(=O)CCC(=O)ON1C(=O)CCC1=O</smiles>

(a)<smiles>CC(CCOCCN)C(=O)O</smiles>

(b)

Fig. 28. Representation of (a) $O, O^{\prime}$-bis[2-( $N$-Succinimidyl-succinylamino)ethyl]polyethylene glycol, a homofunctional macromolecular crosslinker, and (b) amino$\mathrm{dPEG}_{36}$-acid, a heterofunctional macromolecular crosslinker.
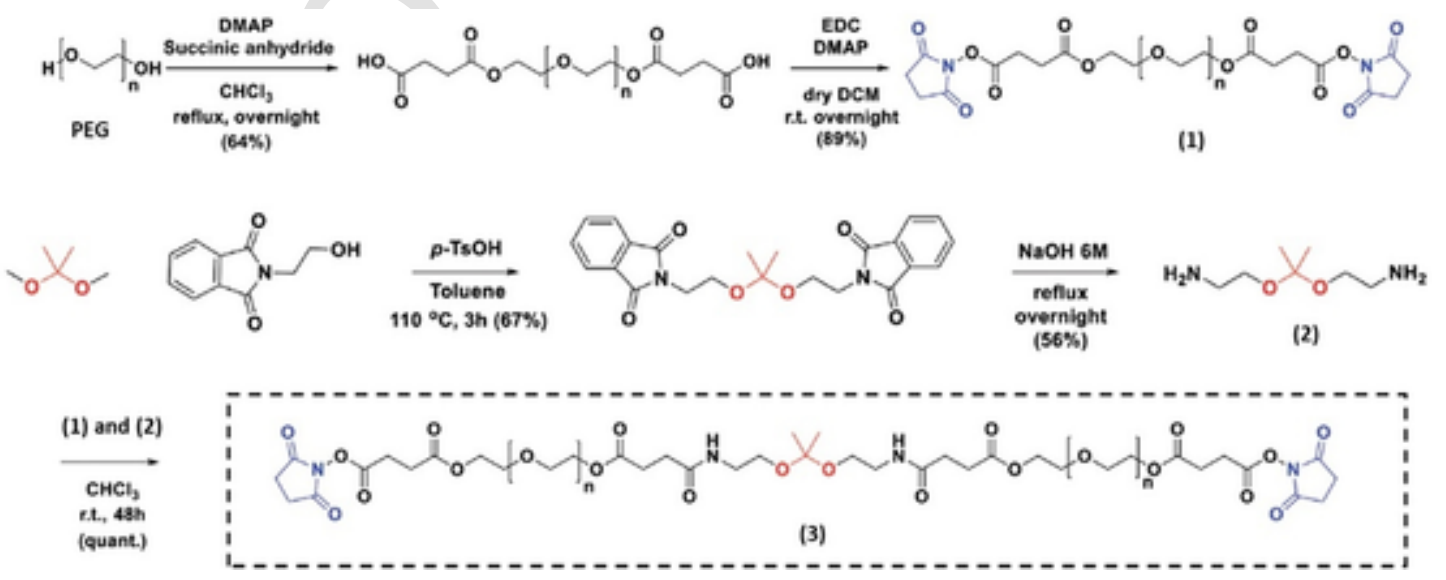

Fig. 29. Simplified representation of the reaction steps to produce a homofunctional acid-sensitive macromolecular crosslinker. PEG reacted with succinic anhydride to form bis(succinic acid ester)polyethylene glycol, which reacted with EDC to yield $O, O^{\prime}$-bis[2-( $N$-succinimidyl-succinate)]polyethylene glycol (1). The reaction between 2,2-bis(aminoethoxy)propane (2), prepared from 2,2-bis(phthalimidoethoxy)propane, and (1) led to (3). The acetal moieties and the reactive $N$ hydroxysuccinimide ester groups are highlighted in red and blue, respectively. Adapted from Ref. [311]. 
hydrogels were recently reviewed [317]. Gamma rays have typically wavelength on the order of $10^{-12} \mathrm{~m}$ and energy of $120 \mathrm{MeV}$ [318]. Gamma irradiation generated by commercial ${ }^{60} \mathrm{Co}$ source provides beams of $8-10 \mathrm{MeV}$, which are often used to sterilize medical instruments, pharmaceuticals and food [319]. The production of hydrogels by irradiation of macromolecules in water is schematically represented in Fig. 30. The radiolysis of water generates several chemical species $\left(\mathrm{e}_{\mathrm{aq}}{ }^{-}, \mathrm{OH}, \cdot \mathrm{H}, \mathrm{HO}_{2}, \mathrm{H}_{3} \mathrm{O}^{+}, \mathrm{OH}^{-}, \mathrm{H}_{2} \mathrm{O}_{2}, \mathrm{H}_{2}\right.$ ) [320]. The radicals abstract $\mathrm{H}$ atoms from the macromolecules, creating macroradicals. The reaction between two macroradicals yields crosslinkings.

The irradiation of proteins might cause chains scission, abstraction of $\mathrm{H}$ and crosslinking. For instance, after gamma irradiation dried collagen became more soluble and was better reabsorbed by the in vivo bone$$
\mathrm{H}_{2} \mathrm{O} \underset{\text { radiolysis of water }}{\stackrel{\text { Gamma rays }}{\longrightarrow}} \cdot \mathrm{OH}, \cdot \mathrm{H}
$$$$
\mathrm{RH}+\cdot \mathrm{OH}(\cdot \mathrm{H}) \stackrel{\text { abstraction of } \mathrm{H}}{\longrightarrow} \cdot \mathrm{R}+\mathrm{H}_{2} \mathrm{O}\left(\mathrm{H}_{2}\right)
$$$$
\cdot R+\cdot R \stackrel{\text { crosslinking }}{\longrightarrow} R-R
$$

Fig. 30. Schematic representation of the reactions mechanism involved in the radiation-induced crosslinking of polysaccharides or proteins, represented by $\mathrm{RH}$, in the presence of water. matrix; on the other hand, in aqueous medium collagen underwent crosslinking favored by the hydroxyl radicals (Fig. 30) [319]. Gamma radiation proved to be very efficient for the crosslinking of polysaccharides, such as carboxymethyl cellulose (CMC) [321], CMC combined with starch [322], acrylic acid and starch [323], CMC and sodium alginate [324], hyaluronic acid and chondroitin sulfate [325] carboxymethylchitosan [326]. The chemical structure and size of the polysaccharide chains, the polysaccharide concentration, radiation dose and atmosphere can affect the crosslinking process. For instance, the concentration of aqueous solution of CMC with a DS of 1.32 [327] at 20 wt $\%$ [328] was favorable for irradiation driven crosslinking because these conditions provided adequate chains mobility and adequate distance among the macroradicals.

UV irradiation is effective for crosslinking vinyl groups in the presence of a radical photoinitiator; however, vinyl groups are not present in polysaccharides and proteins. For this reason, vinyl groups should be introduced to the chains in order to enable the UV driven crosslinking. One of the most successful modifications is the reaction of proteins or polysaccharides with methacrylic anhydride; there are a plethora of commercial bioinks or hydrogels based on such methacrylate derivatives. Gelatin methacrylamide (GelMa) (Fig. 31a) can be prepared by the reaction between methacrylic anhydride and gelatin; the different amounts of gelatin and methacrylic anhydride yield GelMa with different degrees of substitution (DS) [329,330]. The subsequent crosslinking requires the presence of a photoinitiator. Irgacure ${ }^{\circledR} 2959$ is a low odor and water-soluble (1 g/100 g) photoinitiator, which under UV exposi-

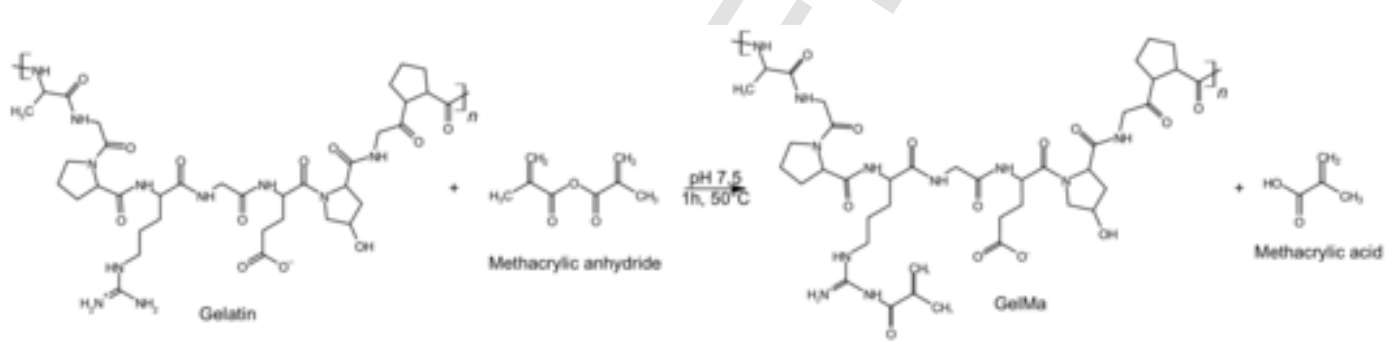

(a)<smiles>CC(C)(O)C(=O)c1ccc(OCCO)cc1</smiles>

HOR.

(b)
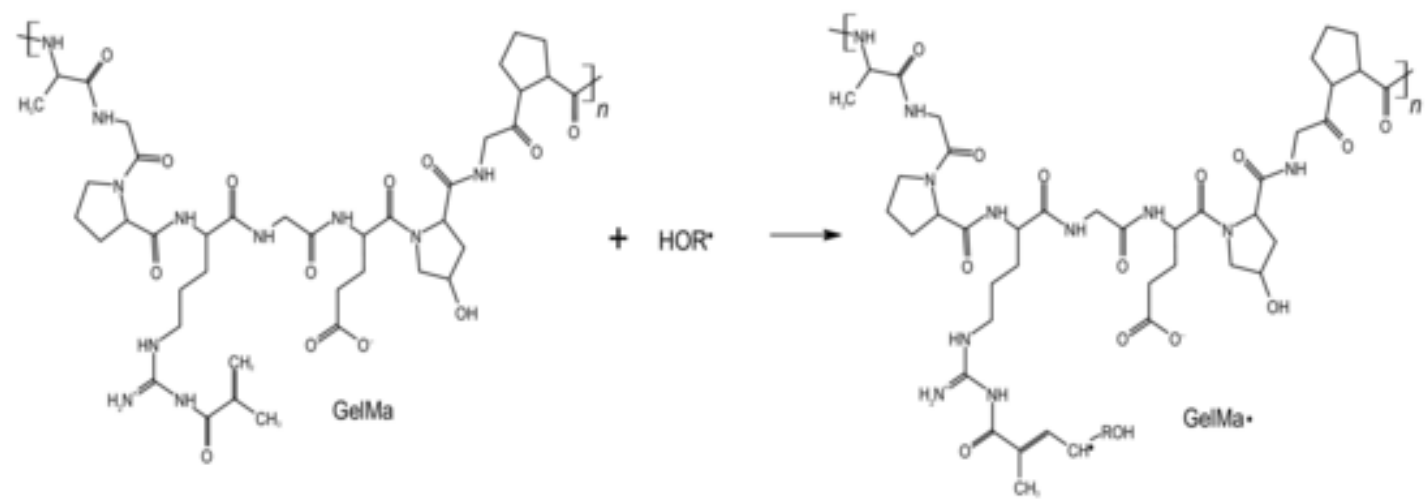

(c)

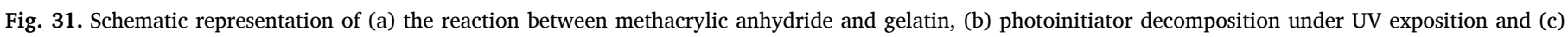
the reaction between the free radical ( $\mathrm{HOR}^{\bullet}$ ) and the methacrylate double incorporated into the gelatin chain, resulting in the GelMa radicals. 
tion undergoes cleavage from the excited triple state and generates free radicals (Fig. 31b) [331]. The primary free radical (HOR ${ }^{\bullet}$ ) reacts with the methacrylate double incorporated to the gelatin chain, forming the macroradical GelMa $\bullet$ (Fig. 31c); the reaction between two GelMa $\bullet$ radicals results in the crosslinked GelMa (not represented).

The rheological behavior of the resulting crosslinked hydrogels depends on the GelMa DS, the amount of photoinitiator and the exposition time [329]. Particularly for 3D printing and bioinks cured by UV exposition, this kind of modification is very useful [332]. Not only gelatin, but also polysaccharides were modified to become photo-crosslinkable. The addition of small quantities of modified hyaluronic acid methacrylate (HA-MA) to GelMa hydrogels favored the chondrogenesis and improved the mechanical properties of the hydrogels [333]. Chitosan modified with methacrylamide (ChMA) and GelMa were photocrosslinked at different ratios; the hydrogels achieved the highest porosity, swelling degree and cell viability at ChMa:GelMa 2:1 [334]. Alginate was modified with carbodiimide and 2-aminoethyl methacrylate in order to become photo-crosslinkable [335]. Dextranmethacrylate (DexMa) with DS of 0.60 took only $90 \mathrm{~s}$ for gelation, whereas the gelation took up to 5 min when DS was 0.09 , additionally gels prepared with DexMa of DS 0.09 showed the highest swelling degree [336].

\section{Techniques and methods for determining the crosslinking efficiency}

Regardless of the crosslinker type, no reaction ever proceeds with $100 \%$ yield. There are different methods to evaluate the crosslinking efficiency. Gravimetry is a simple method that allows estimating the crosslinking efficiency or the gel content (gel\%):

$g e l \%=\left(\frac{m_{\text {final }}}{\mathrm{m}_{\text {initial }}}\right) \times 100$

where $m_{\text {initial }}$ is the mass of gel phase after reaction and drying, and $m_{\text {final }}$ is the mass of gel after rinsing to remove the unreacted molecules and drying.
Low gel content means few junction points among the chains or low crosslinking density (Fig. 32a), whereas high gel content indicates many junction points among the chains or high crosslinking density (Fig. 32b). Particularly for hydrogels, the consequences are that networks with low gel content tend (i) to swell more than those with high gel content because the internal network volume is reduced [145,337], and (ii) to be softer than those with high gel content due to chains movement restriction [338]. The swelling degree (SD) is the amount of water ( $m_{\text {water }}$ in grams) that a given amount of dried polymer network ( $m_{\text {poly }}$, in grams) can uptake under equilibrium conditions:

$S D=\frac{m_{\text {water }}}{m_{\text {poly }}}$

Crosslinking reactions might be monitored along the reaction time by means of rheological measurements, because the gelation is accompanied by changes in the viscoelastic behavior. Oscillatory shear rheology provides the storage $G^{\prime}(\omega)$ and loss $G^{\prime \prime}(\omega)$ moduli as a function of frequency $\omega$; when $G^{\prime}>G^{\prime \prime}$ the sample shows a solid-like structure, and when $\mathrm{G}^{\prime \prime}>\mathrm{G}^{\prime}$ the sample has a liquid-like structure [339]. Noteworthy, the measurements should be performed under strain or stress that does not disrupt the sample structure, or in the linear viscoelastic region. Fig. 33a and 33b show schematically $\mathrm{G}^{\prime}$ and $\mathrm{G}^{\prime \prime}$ measured as a function of time for chitosan under gelation in the presence of genipin at $0.10 \mathrm{wt} \%$ and $0.15 \mathrm{wt} \%$, respectively [340]. The time at which $\mathrm{G}^{\prime}$ intersects $\mathrm{G}^{\prime \prime}$ is the so-called cross-over and corresponds to the gelation time. The increase of genipin content from $0.10 \mathrm{wt} \%$ to $0.15 \mathrm{wt} \%$ decreased the gelation time of chitosan hydrogels from $4 \mathrm{~min}$ to $2 \mathrm{~min}$ [340]. In addition, the gelation of four-arm poly(ethylene glycol) sulfhydryl, PEG-SH, chains was carried out in the presence of $\mathrm{HRP}, \mathrm{H}_{2} \mathrm{O}_{2}$ and tyramine; the crossover (Fig. 33c) tended to decrease with the increase of $\mathrm{H}_{2} \mathrm{O}_{2}$ content and with the decrease of PEG-SH concentration, as shown in Fig. 33d [341].

The concentration range of TGase necessary for the crosslinking of Bambara groundnut proteins was evaluated by measuring $\mathrm{G}^{\prime}$ and $\mathrm{G}^{\prime \prime}$; in the TGase concentration range from $5 \mathrm{U} / \mathrm{mL}$ to $20 \mathrm{U} / \mathrm{mL}$, the $\mathrm{G}^{\prime}$ and $\mathrm{G}^{\prime \prime}$ values were on the order of $10^{3} \mathrm{~Pa}$ and $10^{2} \mathrm{~Pa}$, respectively, but at

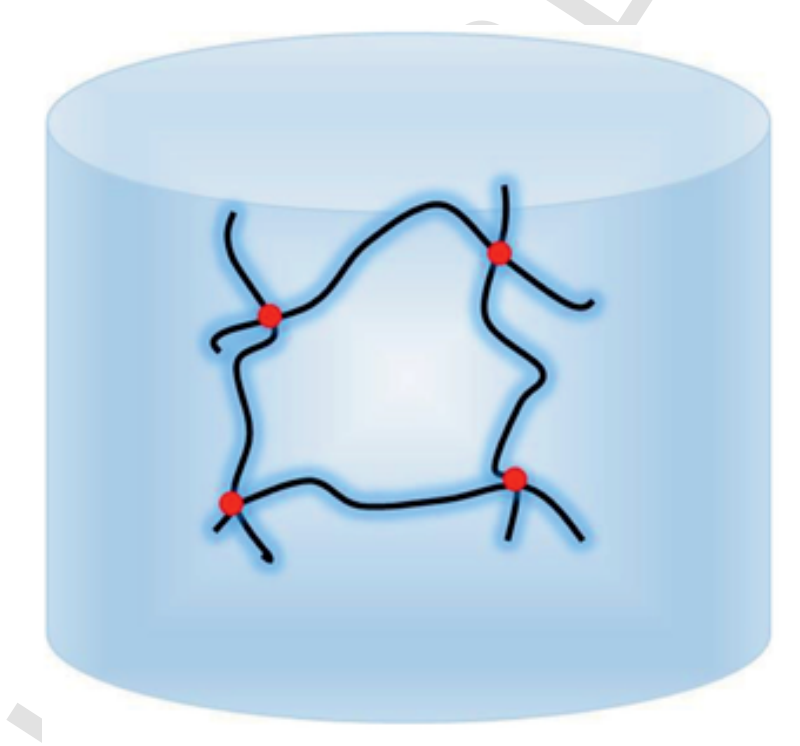

(a) Low gel content, high swelling

\section{degree}

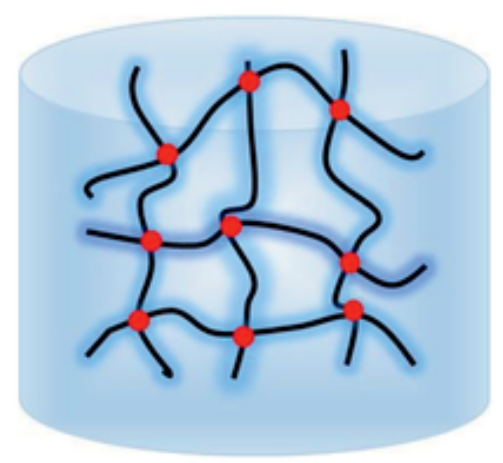

(b) High gel content, low swelling degree

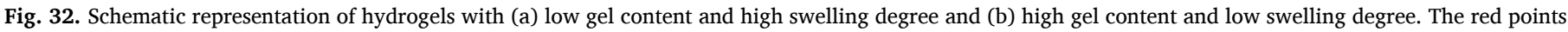

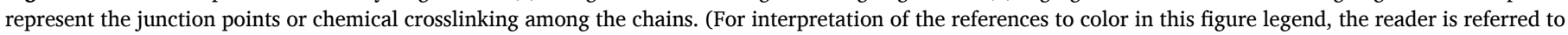
the web version of this article.) 


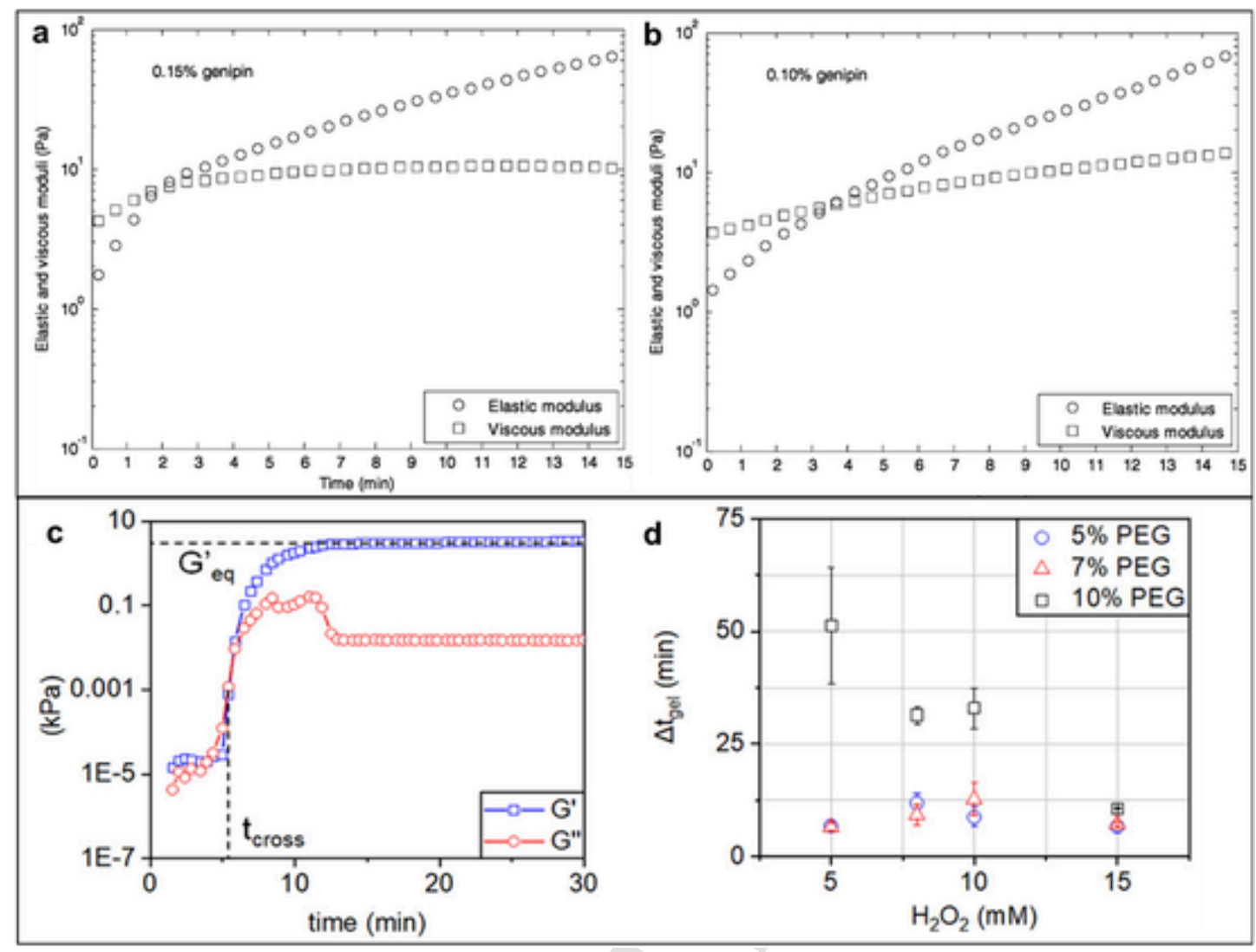

Fig. 33. Elastic $\left(\mathrm{G}^{\prime}\right)$ and viscous $\left(\mathrm{G}^{\prime \prime}\right)$ moduli near the gel point $1 \mathrm{~Hz}$ determine for chitosan hydrogels crosslinked in the presence of genipin at (a) $0.10 \mathrm{wt} \%$ and (b) $0.15 \mathrm{wt} \%$. The arrows indicate the gelation time (cross-over) (Reproduced with permission from Ref [340]. Copyright 2007 American Chemical Society). (c) $\mathrm{G}^{\prime}$ and $\mathrm{G}^{\prime \prime}$ as function of time for the system containing four-arm poly(ethylene glycol) sulfhydryl, PEG-SH, chains, $\mathrm{HRP}, \mathrm{H}_{2} \mathrm{O}_{2}$ and tyramine, the crossover (gelation time) is indicated. (d) crossover time determined for different PEG-SH and $\mathrm{H}_{2} \mathrm{O}_{2}$ concentrations. Reproduced with permission from Ref [341]. Copyright 2019 American Chemical Society).

higher concentrations the crosslinking was less efficient because the $\mathrm{G}^{\prime}$ values decreased [342].

Polymer solutions at high concentrations often present shearthinning or pseudoplastic behavior. For many practical applications, such as bioprinting, polymer solutions and gels should flow under stress and rapidly recover the entangled structure to keep the printed geometry upon crosslinking. For 3D printing, crosslinking should take place after printing to avoid needle clogging. The rheological behavior of thermosensitive gels based on chitosan, sodium hydrogen carbonate (SHC) and beta-glycerophosphate (BGP) was carefully investigated to optimize the printing conditions [343]. The rapid crosslinking reaction (10 min) between chitosan and BPG/SHC due to electrostatic interactions, hydrophobic interactions and hydrogen bonds was evidenced the viscosity decrease in the shear rate range from $0.01 \mathrm{~s}^{-1}$ to $100 \mathrm{~s}^{-1}$. The solution viscosity increased upon applying a constant shear rate in the first $10 \mathrm{~min}$. After that, the solution was at rest for $1 \mathrm{~min}$; the viscosity decreased dramatically below that at the initial time and then the same shear rate was re-applied recovering partially the viscosity value determined in the first $10 \mathrm{~min}$ [343]. Such studies help predict if the candidate bioink retains the rheological behavior during the filament layer formation because it may take a long time to conclude the object printing.

Fourier transform infrared vibrational spectroscopy (FTIR) is an important tool for identifying functional groups in organic and inorganic materials. Changes in the characteristic absorption bands indicate changes in the material composition. For instance, the chemical crosslinking generally creates new linkages that can be detected by the appearance of new bands and by the possible disappearance of typical bands of non-crosslinked polysaccharides or proteins. For example, as discussed in Section 2.5, the esterification reaction between citric acid and polysaccharides hydroxyl groups is evidenced by an absorption band at $\sim 1730 \mathrm{~cm}^{-1}$. If the spectrum shows a broadband in the $1800-1500 \mathrm{~cm}^{-1}$ region due to overlapping, deconvolution might help. For instance, the deconvolution of FTIR spectra obtained for a hydrogel based on $\beta$-cyclodextrin $(\beta C D)$ and locust bean gum crosslinked with citric acid yielded individual bands assigned to ester and carbonyl groups (1750 and $1710 \mathrm{~cm}^{-1}$ ) from the citric acid, water hydroxyl groups $\left(1650 \mathrm{~cm}^{-1}\right)$ and a weak band of protein residues $\left(1580 \mathrm{~cm}^{-1}\right)$ [344]. Fig. 34a shows FTIR spectra obtained for pure hydroxypropyl methylcellulose (HPMC), pure $\beta C D$ and HPMC crosslinked with $\beta C D$ mediated by the esterification with citric acid [155]. The characteristic bands observed in the spectra of pure HPMC and pure $\beta C D$ were also found in the crosslinked HPMC- $\beta C D$ with the exception of a band at $1731 \mathrm{~cm}^{-1}$, which was observed only in the crosslinked films and was assigned to $\mathrm{C}=\mathrm{O}$ stretching stemming from esterification reaction. The band at $\sim 1643 \mathrm{~cm}^{-1}$ was assigned to water bending mode [345].

The hydrogels mediated via Schiff base formation can be identified by FTIR spectroscopy as well. As previously discussed in Section 2.1, this type of crosslinking reaction results in imine group formation $\left(\mathrm{R}_{2} \mathrm{C}=\mathrm{NR}\right)$; the imine group has typical band absorption in the $1690-1640 \mathrm{~cm}^{-1}$ range [346]. Balitaan et al. synthesized a hydrogel based on the reaction between $\beta$-acrylamide-modified $\beta$-chitin (Am- $\beta$ $\mathrm{Chn}$ ) and alginate dialdehyde (ADA), yielding imine linkages at $1650 \mathrm{~cm}^{-1}$ [347]. The crosslinking of $O$-carboxymethylchitosan (CMChi) with imino-PEGylated dynamers by the formation of imine bonds was monitored for $48 \mathrm{~h}$ by the decrease of the aldehyde absorption vibrational band at $1700 \mathrm{~cm}^{-1}$ and increase of the imine band at $1645 \mathrm{~cm}^{-1}$, as shown in Fig. 34b [348] 

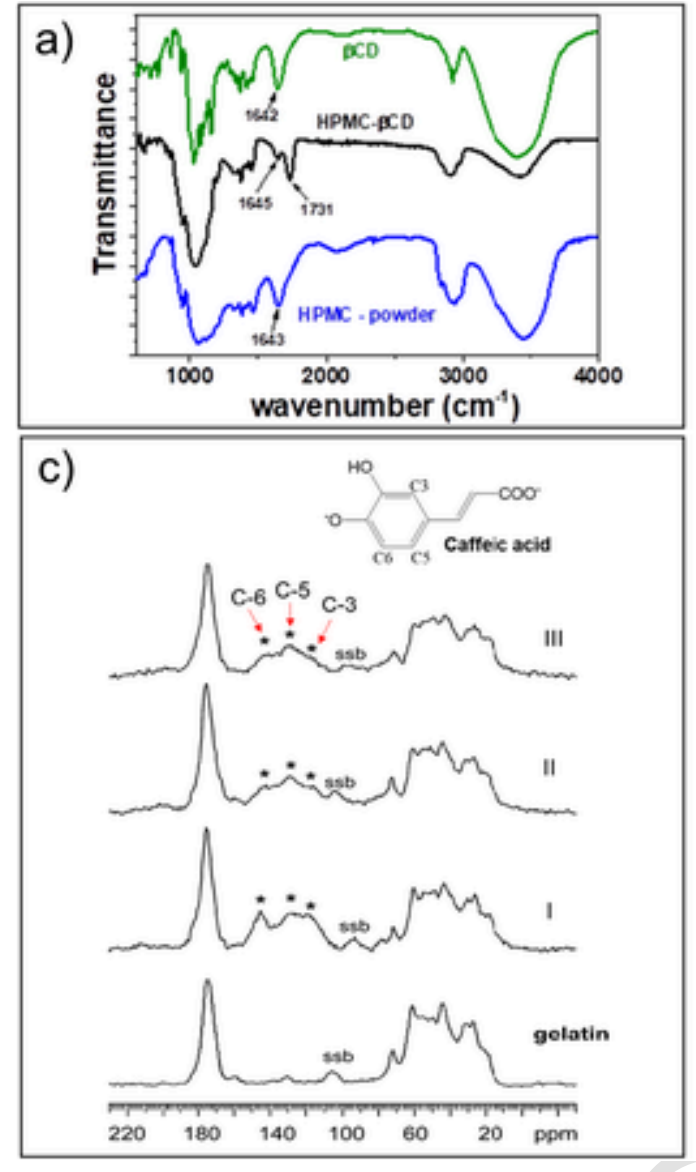

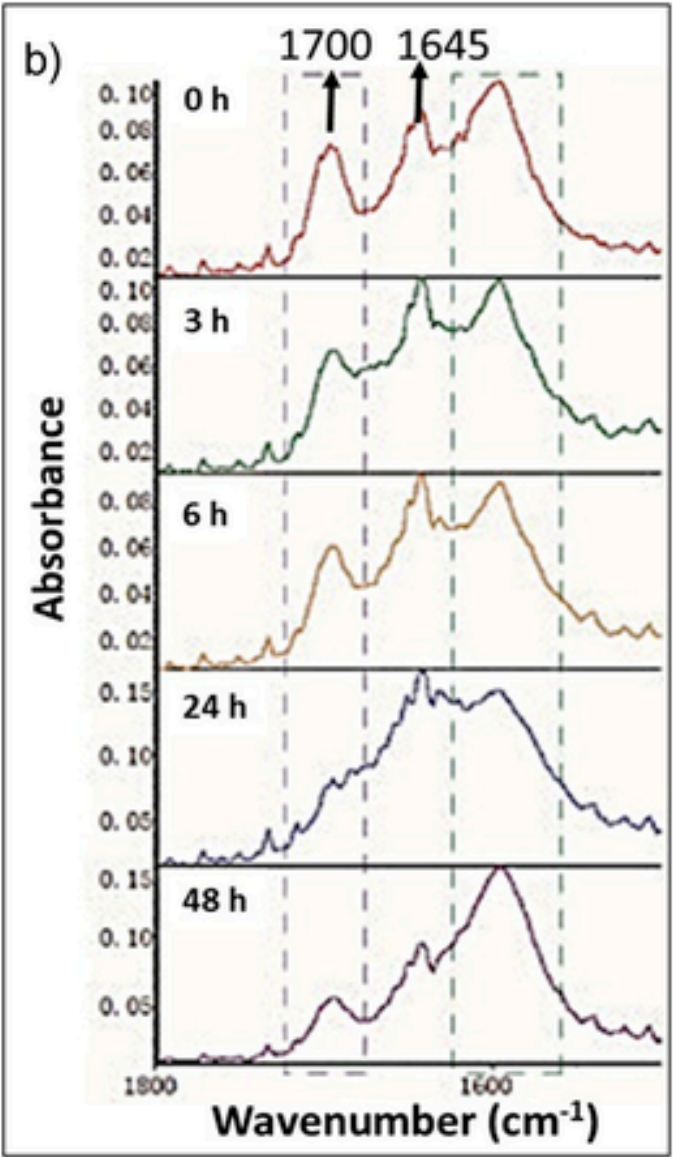

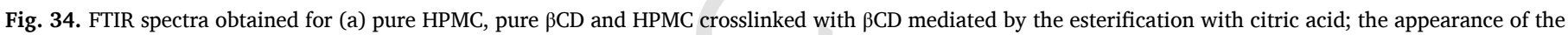

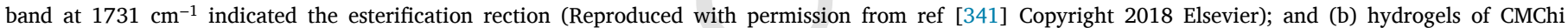

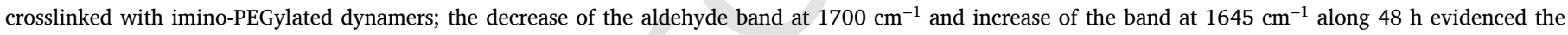

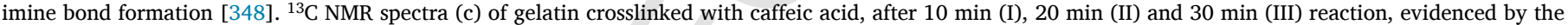

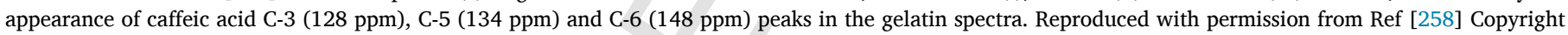
2010 American Chemical Society.

FTIR spectra of hydrogels formed through tannic acid (decagalloyl glucose) crosslinking reaction (Section 3.4) present characteristic bands of tannic acid, namely, $\mathrm{C}=\mathrm{H}\left(1180 \mathrm{~cm}^{-1}, 1020 \mathrm{~cm}^{-1}\right.$ and $\left.750 \mathrm{~cm}^{-1}\right)$ and $\mathrm{C}=\mathrm{C}\left(1600-1400 \mathrm{~cm}^{-1}\right.$ band regions) groups from aromatic rings, $-\mathrm{OH}$ (3500-3000 $\left.\mathrm{cm}^{-1}\right)$ from phenolic groups and $\mathrm{C}=\mathrm{O}$ (1700-1650 $\mathrm{cm}^{-1}$ ) from ester groups, as for instance in hydrogels based on chitosan-methacrylated silk fibroin [349], cellulose [350], and gelatin [351].

Solid-state nuclear magnetic resonance (NMR) is a powerful tool to understanding the products of chemical reactions. As previously discussed in Section 2.4, the crosslinking mechanism of pullulan with STMP was dynamically monitored by ${ }^{1} \mathrm{H},{ }^{13} \mathrm{C}$, and ${ }^{31} \mathrm{P}$ NMR spectroscopies; the changes of chemical shifts as a function of reaction time allowed proposing not only a mechanism for the crosslinking but also for the degradation process [133].

In case of citric acid, ${ }^{13} \mathrm{C}$ NMR spectroscopy shows three indubitable signals peaks in 170-180 ppm region, related to three carbons of ester groups $\left(\mathrm{OCOCH}_{3}\right)$ [352]. After esterification reaction, only one peak still remains present in the solid-state spectrum, reinforcing that the two ester groups are used as crosslinking sites in hydrogels, moreover, the position of the chemical shifts changes and they become weaker. Many authors inferred this event as a consequence of esterification reactions with several natural polymers [353-356]. The presence of ester linkages and free carboxylic acid groups might broaden the peak at $174.3 \mathrm{ppm}$ [357]. The ${ }^{13} \mathrm{C}$ NMR solid-state spectrum of hydrogels based on caffeic acid crosslinker have three reactive sites ranging from 110 ppm to $150 \mathrm{ppm}$ (attributed to C-3, C-5 and C-6 bonds from phenolic ring), which can form covalent bonds with $-\mathrm{NH}_{2}$ from gelatin or oligomers through dimerization process [258] (Fig. 34c).

The very low reactivity of genipin to crosslink chitosan chains under strongly basic conditions was confirmed by the absence of the shift of C1 resonance in the solid state 13C-NMR spectrum; it is probably due to the genipin ring-opening polymerization, decreasing the amount of genipin free to crosslink with chitosan [248]. At neutral and acidic conditions, genipin reacted with primary amino groups on chitosan to form heterocyclic amines, as discussed in Section 3.2.

\section{Conclusions and perspectives}

The mechanisms involved in major crosslinking reactions for polysaccharides and proteins were revisited and critically reviewed in this article, aiming at giving a facile way to choose the crosslinker that best fits the desired biopolymer and final applications.

Fabrication of hydrogel for biomaterials application requires a careful design and selection of the crosslinking process. It has an important role in the hydrogel's chemical and mechanical properties, which eventually affect the cellular responses of the hydrogel.

Although there is a plethora of crosslinkers commercially available [359]; the choice should consider the solubility, the reaction conditions ( $\mathrm{pH}$ and temperature), side reactions and the reactivity and there are still many challenges in application of these cross linkers. Depending on the final application, the cross linking speed, density, hydrogel integrity 
and biocompatibility of crosslinker and crosslinked biopolymers should be considered. Chemical crosslinkers with cell toxicity such as glutaraldehyde can result in cytocompatibility issues, while genipin is much less toxic. Hydrogels formed by physical cross linking methods, including host-guest interactions or hydrogen bonding, are of great interest for cell encapsulation in the hydrogel matrix. Nevertheless, the noncovalent cross-linking structure provides only weak mechanical properties. Further research is required to develop advanced selfhealing hydrogel materials by utilizing the reversibility and dynamic properties of these physical cross linking approaches.

A low degree of crosslinking can result in a hydrogel with weak mechanical and stability properties, and a high degree of crosslinking can result in low porosity, cell viability or biodegradation issues, however many aspects of hydrogels mechanical and rheological properties have not been evaluated or described in detail in the literature, and therefore it was not possible to critically assess and provide a guideline for the balance between the degree of crosslinking and chemical/mechanical properties of the hydrogel in different crosslinking methods. Nevertheless, we have covered major cross-linking reaction processes for proteins and polysaccharides which can guide the reader to select the suitable cross-linker and its concentration and treatment time for specific applications.

The increasing interest for 3D printing hydrogels probably will require alternative crosslinkers that allow controlling the rheological properties during the process and tuning the mechanical properties of the printed object through stimuli of light, magnetic or electric field. While there are several crosslinking methods, only some of these methods have been used for 3D bioprinting purposes. To learn more about the crosslinking strategies for $3 \mathrm{D}$ bioprinting, the authors are referred to [360]. Finally, if the hydrogel aims to encapsulate cells in its matrix, it is important to consider the role of cells in the hydrogel crosslinking process. Living cells may act as a physical barrier and reduce the contact and interaction between the functional groups involving in the crosslinking process.

\section{Uncited references}

$[169,201,217,264,265,358]$

\section{CRediT authorship contribution statement}

Alex Carvalho Alavarse: Data curation, Writing - original draft. Emilli Caroline Garcia Frachini: Data curation, Writing - original draft. Rafael Leonardo Cruz Gomes da Silva: Data curation, Writing - original draft. Vitoria Hashimoto Lima: Investigation. Amin Shavandi: Writing - review \& editing. Denise Freitas Siqueira Petri: Data curation, Writing - review \& editing, Funding acquisition, Supervision.

\section{Acknowledgements}

A.C.A., R.L.C.G.S and V.H.L. gratefully acknowledge São Paulo Research Foundation (FAPESP) for financial support, Grants 2020/01907$3,2020 / 05632-9$ and 2020/03248-7, respectively. DFSP gratefully acknowledges financial support from Conselho Nacional de Desenvolvimento Científico e Tecnológico (CNPq Grant 306848/2017 and 421014/2018) and São Paulo Research Foundation (FAPESP, Grants 2018/13492-2 and 2019/22671-0). E.C.G.F. gratefully acknowledges financial support from the Coordenação de Aperfeiçoamento de Pessoal de Nível Superior - Brasil (CAPES) - Finance Code 001 (Grant 88882.328247/2019-01). AS acknowledges financial support from FNRS-Fonds de la Recherche Scientifique for projets bilatéraux de mobilité (PINT-BILAT-M) R.M014.19 (35704283).

\section{References}

[1] IUPAC, Compendium of Chemical Terminology, 2nd ed., 2019, https://doi.org/ $10.1351 /$ goldbook.

[2] J. Kopecek, Polymer chemistry: swell gels, Nature. 417 (2002) 389-391, https://doi.org/10.1038/417388a.

[3] S. Chatterjee, P. Chi-leung Hui, Stimuli-Responsive Hydrogels: an Interdisciplinary Overview, 2018, https://doi.org/10.5772/intechopen.80536.

[4] E. Russo, C. Villa, Poloxamer hydrogels for biomedical applications, Pharmaceutics. 11 (2019) 1-17, https://doi.org/10.3390/ pharmaceutics11120671.

[5] S.C. Lee, G. Gillispie, P. Prim, S.J. Lee, Physical and chemical factors influencing the printability of hydrogel-based extrusion bioinks, Chem. Rev. 120 (2020) 10834-10886, https://doi.org/10.1021/acs.chemrev.0c00015.

[6] R.S. Dassanayake, S. Acharya, N. Abidi, Biopolymer-based materials from polysaccharides: properties, processing, characterization and sorption applications, in: Adv. Sorption Process Appl., 2018, https://doi.org/10.5772/ intechopen.80898.

[7] N. Reddy, R. Reddy, Q. Jiang, Crosslinking biopolymers for biomedical applications, Trends Biotechnol. 33 (2015) 362-369, https://doi.org/10.1016/ j.tibtech.2015.03.008.

[8] W. Hu, Z. Wang, Y. Xiao, S. Zhang, J. Wang, Advances in crosslinking strategies of biomedical hydrogels, Biomater. Sci. 7 (2019) 843-855, https://doi.org/ 10.1039/c8bm01246f.

[9] G. Thakur, F.C. Rodrigues, K. Singh, Crosslinking biopolymers for advanced drug delivery and tissue engineering applications, Adv. Exp. Med. Biol. 1078 (2018) 213-231, https://doi.org/10.1007/978-981-13-0950-2_11.

[10] PubMed database, in: https://pubmed.ncbi.nlm.nih.gov/, 2021.

[11] T. Takigawa, Y. Endo, Effects of glutaraldehyde exposure on human health, J. Occup. Health 48 (2006) 75-87, https://doi.org/10.1539/joh.48.75.

[12] J. Li, N. Ren, J. Qiu, H. Jiang, H. Zhao, G. Wang, R.I. Boughton, Y. Wang, H. Liu, Carbodiimide crosslinked collagen from porcine dermal matrix for high-strength tissue engineering scaffold, Int. J. Biol. Macromol. 61 (2013) 69-74, https:// doi.org/10.1016/j.ijbiomac.2013.06.038.

[13] P. Ma, Y. Wang, B. Li, H. Hou, Cross-linking effects of carbodiimide, oxidized chitosan oligosaccharide and glutaraldehyde on acellular dermal matrix of basa fish (Pangasius bocourti), Int. J. Biol. Macromol. 164 (2020) 677-686, https:// doi.org/10.1016/j.ijbiomac.2020.07.019.

[14] A. Oryan, A. Kamali, A. Moshiri, H. Baharvand, H. Daemi, Chemical crosslinking of biopolymeric scaffolds: current knowledge and future directions of crosslinked engineered bone scaffolds, Int. J. Biol. Macromol. 107 (2018) 678-688, https://doi.org/10.1016/j.ijbiomac.2017.08.184.

[15] T. Coviello, M. Grassi, R. Lapasin, A. Marino, F. Alhaique, Scleroglucan/borax: characterization of a novel hydrogel system suitable for drug delivery, Biomaterials. 24 (2003) 2789-2798, https://doi.org/10.1016/S0142-9612(03) 00087-5.

[16] B. Balakrishnan, N. Joshi, A. Jayakrishnan, R. Banerjee, Self-crosslinked oxidized alginate/gelatin hydrogel as injectable, adhesive biomimetic scaffolds for cartilage regeneration, Acta Biomater. 10 (2014) 3650-3663, https://doi.org/ 10.1016/j.actbio.2014.04.031.

[17] J.B. Tarigan, M. Ginting, F.M. Nainggolan, Synthesis and properties of new hydrogel from cross-linked galactomannan boric, J. Phys. Conf. Ser. 1116 (2018) 042041, https://doi.org/10.1088/1742-6596/1116/4/042041.

[18] T. Coviello, P. Matricardi, F. Alhaique, R. Farra, G. Tesei, S. Fiorentino, F. Asaro, G. Milcovich, M. Grassi, Guar gum/borax hydrogel: rheological, low field NMR and release characterizations, Express Polym Lett 7 (2013) 733-746, https://doi.org/10.3144/expresspolymlett.2013.71.

[19] R.V. Gadhave, P.S. Kasbe, P.A. Mahanwar, P.T. Gadekar, To study the effect of boric acid modification on starch-polyvinyl alcohol blend wood adhesive, J. Indian Acad. Wood Sci. 15 (2018) 190-198, https://doi.org/10.1007/s13196018-0225-2.

[20] S. Wang, H. Tang, J. Guo, K. Wang, Effect of $\mathrm{pH}$ on the rheological properties of borate crosslinked hydroxypropyl guar gum hydrogel and hydroxypropyl guar gum, Carbohydr. Polym. 147 (2016) 455-463, https://doi.org/10.1016/ j.carbpol.2016.04.029.

[21] C. Song, Y. Lv, K. Qian, Y. Chen, X. Qian, Preparation of konjac glucomannan-borax hydrogels with good self-healing property and $\mathrm{pH}$-responsive behavior, J. Polym. Res. 26 (2019) 52, https://doi.org/10.1007/s10965-0191702-z.

[22] F. Phoothong, A. Boonmahitthisud, S. Tanpichai, Using borax as a cross-linking agent in cellulose-based hydrogels, IOP Conf. Ser. Mater. Sci. Eng. 600 (2019) 012013, https://doi.org/10.1088/1757-899X/600/1/012013.

[23] N. Reddy, Y. Li, Y. Yang, Alkali-catalyzed low temperature wet crosslinking of plant proteins using carboxylic acids, Biotechnol. Prog. 25 (2009) 139-146, https://doi.org/10.1002/btpr.86.

[24] R.G. Andrade, L.T. Dalvi, J.M.C. Silva, G.K.B. Lopes, A. Alonso, M. HermesLima, The antioxidant effect of tannic acid on the in vitro copper-mediated formation of free radicals, Arch. Biochem. Biophys. 437 (2005) 1-9, https:// doi.org/10.1016/j.abb.2005.02.016.

[25] Z. Tashi, M. Zare, N. Parvin, Application of phytic-acid as an in-situ crosslinking agent in electrospun gelatin-based scaffolds for skin tissue engineering, Mater. Lett. 264 (2020) 127275, https://doi.org/10.1016/j.matlet.2019.127275.

[26] B. Tomadoni, A. Ponce, M. Pereda, M.R. Ansorena, Vanillin as a natural crosslinking agent in chitosan-based films: optimizing formulation by response surface methodology, Polym. Test. 78 (2019) 105935, https://doi.org/10.1016/ 
j.polymertesting.2019.105935.

[27] I. Migneault, C. Dartiguenave, M.J. Bertrand, K.C. Waldron, Glutaraldehyde: behavior in aqueous solution, reaction with proteins, and application to enzyme crosslinking, Biotechniques. 37 (2004) 790-802, https://doi.org/10.2144/ 04375RV01.

[28] H. Services, NIOSH Skin Notation Profiles, 2011, p. 8.

[29] D.D. Sabatini, K. Bensch, R.J. Barrnett, Cytochemistry and electron microscopy. The preservation of cellular ultrastructure and enzymatic activity by aldehyde fixation, J. Cell Biol. 17 (1963) 19-58, https://doi.org/10.1083/jcb.17.1.19.

[30] R.O. Beauchamp, M.B. Clair, T.R. Fennell, D.O. Clarke, K.T. Morgan, F.W. Kair, A critical review of the toxicology of glutaraldehyde, Gastroenterol. Nurs. 16 (1993) 42-43, https://doi.org/10.1097/00001610-199308000-00018.

[31] P.M. Hardy, A.C. Nicholls, H.N. Rydon, The nature of glutaraldehyde in aqueous solution, J. Chem. Soc. D. Chem. Commun. (1969) 565-566, https:// doi.org/10.1039/C29690000565.

[32] E.B. Whipple, M. Ruta, Structure of aqueous glutaraldehyde, J. Organomet. Chem. 39 (1974) 1666-1668, https://doi.org/10.1021/jo00925a015.

[33] A.H. Korn, S.H. Feairheller, E.M. Filachoine, Glutaraldehyde: nature of the reagent, J. Mol. Biol. 65 (1972) 525-529, https://doi.org/10.1016/0022-2836 (72)90206-9.

[34] F.M. Richards, J.R. Knowles, Glutaraldehyde as a protein cross-linking reagent, J. Mol. Biol. 37 (1968) 231-233, https://doi.org/10.1016/0022-2836(68)900867.

[35] C. Aso, Y. Aito, Intramolecular-intermolecular polymerization of glutaraldehyde, Bull. Chem. Soc. Jpn. 35 (1962) 1426, https://doi.org/10.1246/ bcsj.35.1426.

[36] T. Tashima, M. Imai, Y. Kuroda, S. Yagi, T. Nakagawa, Structure of a new oligomer of glutaraldehyde produced by aldol condensation reaction, $\mathrm{J}$. Organomet. Chem. 56 (1991) 694-697, https://doi.org/10.1021/jo00002a038.

[37] S. Margel, A. Rembaum, Synthesis and characterization of poly (glutaraldehyde). A potential reagent for protein immobilization and cell separation, Macromolecules 13 (1980) 19-24, https://doi.org/10.1021/ ma60073a004.

[38] K. Pal, A.T. Paulson, D. Rousseau, Biopolymers in Controlled-release Delivery Systems, 2013, https://doi.org/10.1016/B978-1-4557-2834-3.00014-8.

[39] E. Marin, J. Rojas, Y. Ciro, A review of polyvinyl alcohol derivatives: promising materials for pharmaceutical and biomedical applications, Afr. J. Pharm. Pharmacol 8 (2014) 674-684, https://doi.org/10.5897/AJPP2013.3906.

[40] R.V. Gadhave, P.A. Mahanwar, P.T. Gadekar, Effect of glutaraldehyde on thermal and mechanical properties of starch and polyvinyl alcohol blends, Des. Monomers Polym. 22 (2019) 164-170, https://doi.org/10.1080/ 15685551.2019 .1678222$.

[41] G.T. Hermanson, Bioconjugate Techniques, 3rd ed., 2013, https://doi.org/ 10.1016/C2009-0-64240-9.

[42] N.E. Hall, B.J. Smith, High-level ab initio molecular orbital calculations of imine formation, J. Phys. Chem. A 102 (1998) 4930-4938, https://doi.org/ 10.1021/jp9810825.

[43] E. Erdtman, E.A.C. Bushnell, J.W. Gauld, L.A. Eriksson, Computational studies on schiff-base formation: implications for the catalytic mechanism of porphobilinogen synthase, Comput.Theor. Chem. 963 (2011) 479-489, https:// doi.org/10.1016/j.comptc.2010.11.015.

[44] O. Barbosa, C. Ortiz, Á. Berenguer-Murcia, R. Torres, R.C. Rodrigues, R. Fernandez-Lafuente, Glutaraldehyde in bio-catalysts design: a useful crosslinker and a versatile tool in enzyme immobilization, RSC Adv. 4 (2014) 1583-1600, https://doi.org/10.1039/c3ra45991h.

[45] J.M. Ruijgrok, M.E. Boon, J.R. De Wijn, The effect of heating by microwave irradiation and by conventional heating on the aldehyde concentration in aqueous glutaraldehyde solutions, Histochem. J. 22 (1990) 389-393, https://doi.org/ 10.1007/BF01003175.

[46] M.B.B. Pereira, D.B. França, R.C. Araújo, E.C. Silva Filho, B. Rigaud, M.G. Fonseca, M. Jaber, Amino hydroxyapatite/chitosan hybrids reticulated with glutaraldehyde at different $\mathrm{pH}$ values and their use for diclofenac removal, Carbohydr. Polym. 236 (2020) 116036, https://doi.org/10.1016/ j.carbpol.2020.116036.

[47] Y. Wine, N. Cohen-Hadar, A. Freeman, F. Frolow, Elucidation of the mechanism and end products of glutaraldehyde crosslinking reaction by X-ray structure analysis, Biotechnol. Bioeng. 98 (2007) 711-718, https://doi.org/10.1002/ bit. 21459.

[48] A. Ou, I. Bo, Chitosan hydrogels and their glutaraldehyde-crosslinked counterparts as potential drug release and tissue engineering systems - synthesis, characterization, swelling kinetics and mechanism, J. Phys. Chem. Biophys. 7 (2017), https://doi.org/10.4172/2161-0398.1000256.

[49] Y. Liu, Z. Cai, L. Sheng, M. Ma, Q. Xu, Y. Jin, Structure-property of crosslinked chitosan/silica composite films modified by genipin and glutaraldehyde under alkaline conditions, Carbohydr. Polym. 215 (2019) 348-357, https://doi.org/ 10.1016/j.carbpol.2019.04.001.

[50] S. Yu, X. Zhang, G. Tan, L. Tian, D. Liu, Y. Liu, X. Yang, W. Pan, A novel pHinduced thermosensitive hydrogel composed of carboxymethyl chitosan and poloxamer cross-linked by glutaraldehyde for ophthalmic drug delivery, Carbohydr. Polym. 155 (2017) 208-217, https://doi.org/10.1016/ j.carbpol.2016.08.073.

[51] V.A. Reyna-Urrutia, V. Mata-Haro, J.V. Cauich-Rodriguez, W.A. Herrera-Kao, J.M. Cervantes-Uc, Effect of two crosslinking methods on the physicochemical and biological properties of the collagen-chitosan scaffolds, Eur. Polym. J. 117 (2019) 424-433, https://doi.org/10.1016/j.eurpolymj.2019.05.010.

[52] F.S. Al-Mubaddel, S. Haider, M.O. Aijaz, A. Haider, T. Kamal, W.A. Almasry, M.
Javid, S.U.D. Khan, Preparation of the chitosan/polyacrylonitrile semi-IPN hydrogel via glutaraldehyde vapors for the removal of Rhodamine B dye, Polym. Bull. 74 (2017) 1535-1551, https://doi.org/10.1007/s00289-016-1788-y.

[53] Z. Tian, W. Liu, G. Li, The microstructure and stability of collagen hydrogel cross-linked by glutaraldehyde, Polym. Degrad. Stab. 130 (2016) 264-270, https://doi.org/10.1016/j.polymdegradstab. 2016.06.015.

[54] S. Distantina, M. Rochmadi, Wiratni Fahrurrozi, Preparation and characterization of glutaraldehyde-crosslinked kappa carrageenan hydrogel, Engl. J. 17 (2013) 57-66, https://doi.org/10.4186/ej.2013.17.3.57.

[55] M. Pulat, G.O. Akalin, Preparation and characterization of gelatin hydrogel support for immobilization of Candida Rugosa lipase, Artif. Cells. Nanomedicine Biotechnol. 41 (2013) 145-151, https://doi.org/10.3109/ 10731199.2012.696070.

[56] J. Lin, D. Pan, Y. Sun, C. Ou, Y. Wang, J. Cao, The modification of gelatin films: based on various cross-linking mechanism of glutaraldehyde at acidic and alkaline conditions, Food Sci. Nutr. 7 (2019) 4140-4146, https://doi.org/10.1002/ fsn3.1282.

[57] J.S. Haima, S.N. Nair, S. Juliet, B.N. Nisha, Ayinikkattil R. Dhanushkrishna, Synthesis and characterisation of glutaraldehyde cross-linked $\kappa$-carrageenangelatin hydrogel, J. Pharmacogn. Phytochem. 10 (2021) 459-463 (doi:ISSN 22784136).

[58] S. Mohammadzadehmoghadam, Y. Dong, Fabrication and characterization of electrospun silk fibroin/gelatin scaffolds crosslinked with glutaraldehyde vapor, Front. Mater. 6 (2019) 1-12, https://doi.org/10.3389/fmats.2019.00091.

[59] X. Wu, L. Black, G. Santacana-Laffitte, C.W. Patrick Jr., Preparation and assessment of glutaraldehyde-crosslinked collagen-chitosan hydrogels for adipose tissue engineering, J. Biomed. Mater. Res. Part A. 81 (2006) 59-65, https:// doi.org/10.1002/jbm.a.31003.

[60] C.E. Campiglio, N.C. Negrini, S. Farè, L. Draghi, Cross-linking strategies for electrospun gelatin scaffolds, Materials (Basel). 12 (2019) 2476, https://doi.org/ $10.3390 / \mathrm{ma1} 2152476$.

[61] B. Zhu, W. Li, N. Chi, R.V. Lewis, J. Osamor, R. Wang, Optimization of glutaraldehyde vapor treatment for electrospun collagen/silk tissue engineering scaffolds, ACS Omega. 2 (2017) 2439-2450, https://doi.org/10.1021/ acsomega.7b00290.

[62] J.Y. Lai, Biocompatibility of chemically cross-linked gelatin hydrogels for ophthalmic use, J. Mater. Sci. Mater. Med. 21 (2010) 1899-1911, https://doi.org/ 10.1007/s10856-010-4035-3.

[63] J. Skopinska-Wisniewska, M. Tuszynska, E. Olewnik-Kruszkowska, Comparative study of gelatin hydrogels modified by various cross-linking agents, Materials (Basel). 14 (2021) 396, https://doi.org/10.3390/ma14020396.

[64] P.L. Lu, J.Y. Lai, D.H.K. Ma, G.H. Hsiue, Carbodiimide cross-linked hyaluronic acid hydrogels as cell sheet delivery vehicles: characterization and interaction with corneal endothelial cells, J. Biomater. Sci. Polym. Ed. 19 (2008) 1-18, https://doi.org/10.1163/156856208783227695.

[65] S. Gao, Z. Yuan, W. Guo, M. Chen, S. Liu, T. Xi, Q. Guo, Comparison of glutaraldehyde and carbodiimides to crosslink tissue engineering scaffolds fabricated by decellularized porcine menisci, Mater. Sci. Eng. C 71 (2017) 891-900, https://doi.org/10.1016/j.msec.2016.10.074.

[66] N. Nakajima, Y. Ikada, Mechanism of amide formation by carbodiimide for bioconjugation in aqueous media, Bioconjug. Chem. 6 (1995) 123-130, https:// doi.org/10.1021/bc00031a015.

[67] K. Tomihata, Y. Ikada, Crosslinking of hyaluronic acid with water-soluble carbodiimide, J. Biomed. Mater. Res. 37 (1997) 243-251, https://doi.org/ 10.1002/(SICI)1097-4636(199711)37:2 < 243::AID-JBM14 > 3.0.CO;2-F.

[68] J.B. Xu, J.P. Bartley, R.A. Johnson, Preparation and characterization of alginate hydrogel membranes crosslinked using a water-soluble carbodiimide, J. Appl. Polym. Sci. 90 (2003) 747-753, https://doi.org/10.1002/app.12713.

[69] A. Sannino, S. Pappadà, M. Madaghiele, A. Maffezzoli, L. Ambrosio, L. Nicolais, Crosslinking of cellulose derivatives and hyaluronic acid with water-soluble carbodiimide, Polymer (Guildf). 46 (2005) 11206-11212, https://doi.org/ 10.1016/j.polymer.2005.10.048.

[70] S. Khunmanee, Y. Jeong, H. Park, Crosslinking method of hyaluronic-based hydrogel for biomedical applications, J. Tissue Eng. 8 (2017), https://doi.org/ $10.1177 / 2041731417726464$

[71] M. Klein, E. Poverenov, Natural biopolymer-based hydrogels for use in food and agriculture, J. Sci. Food Agric. 100 (2020) 2337-2347, https://doi.org/10.1002/ jsfa.10274.

[72] D.H. Rich, J. Singh, The Carbodiimide Method, Academic Press, Inc., 1979 https://doi.org/10.1016/b978-0-12-304201-9.50011-4.

[73] H.C. Liang, W.H. Chang, H.F. Liang, M.H. Lee, H.W. Sung, Crosslinking structures of gelatin hydrogels crosslinked with genipin or a water-soluble carbodiimide, J. Appl. Polym. Sci. 91 (2004) 4017-4026, https://doi.org/ 10.1002/app.13563.

[74] C. Park, C.L.N. Vo, T. Kang, E. Oh, B.J. Lee, New method and characterization of self-assembled gelatin-oleic nanoparticles using a desolvation method via carbodiimide/N-hydroxysuccinimide (EDC/NHS) reaction, Eur. J. Pharm. Biopharm. 89 (2015) 365-373, https://doi.org/10.1016/j.ejpb.2014.12.002.

[75] P. Slusarewicz, K. Zhu, T. Hedman, Kinetic characterization and comparison of various protein crosslinking reagents for matrix modification, J. Mater. Sci. Mater. Med. 21 (2010) 1175-1181, https://doi.org/10.1007/s10856-010-3986-8.

[76] C.R. Cammarata, M.E. Hughes, C.M. Ofner III, Carbodiimide induced crosslinking, ligand addition, and degradation in gelatin, Mol. Pharm. 12 (2015) 783-793, https://doi.org/10.1021/mp5006118.

[77] S.A. Madison, J.O. Carnali, pH optimization of amidation via carbodiimides, Ind. Eng. Chem. Res. 52 (2013) 13547-13555, https://doi.org/10.1021/ 
ie $401724 \mathrm{~m}$.

[78] P. Bulpitt, D. Aeschlimann, New strategy for chemical modification of hyaluronic acid: Preparation of functionalized derivatives and their use in the formation of novel biocompatible hydrogels, J. Biomed. Mater. Res. 47 (1999) 152-169, https://doi.org/10.1002/(SICI)1097-4636(199911)47:2<152::AIDJBM5 > 3.0.CO;2-I.

[79] Y. Yang, Side Reactions Upon Amino Acid/Peptide Carboxyl Activation, 2016, https://doi.org/10.1016/b978-0-12-801009-9.00005-7.

[80] M. Jafari-Sabet, H. Nasiri, R. Ataee, The effect of cross-linking agents and collagen concentrations on properties of collagen scaffolds, J. Arch. Mil. Med. 4 (2016), https://doi.org/10.5812/jamm.42367.

[81] J.Y. Lai, Corneal stromal cell growth on gelatin/chondroitin sulfate scaffolds modified at different NHS/EDC molar ratios, Int. J. Mol. Sci. 14 (2013) 2036-2055, https://doi.org/10.3390/ijms14012036.

[82] D. Sehgal, I.K. Vijay, A method for the high efficiency of water-soluble carbodiimide-mediated amidation, Anal. Biochem. 218 (1994) 87-91, https:// doi.org/10.1006/abio.1994.1144.

[83] R. Zhang, M. Tang, A. Bowyer, R. Eisenthal, J. Hubble, A novel pH- and ionic strength-sensitive carboxy methyl dextran hydrogel, Biomaterials. 26 (2005) 4677-4683, https://doi.org/10.1016/j.biomaterials.2004.11.048.

[84] J. Li, A. He, J. Zheng, C.C. Han, Gelatin and gelatin - hyaluronic acid nanofibrous membranes produced by electrospinning of their aqueous solutions, Biomacromolecules. 7 (2006) 2243-2247, https://doi.org/10.1021/bm0603342.

[85] J. Ratanavaraporn, R. Rangkupan, H. Jeeratawatchai, S. Kanokpanont, S. Damrongsakkul, Influences of physical and chemical crosslinking techniques on electrospun type A and B gelatin fiber mats, Int. J. Biol. Macromol. 47 (2010) 431-438, https://doi.org/10.1016/j.ijbiomac.2010.06.008.

[86] M. do L.L.R. Menezes, H.L. Ribeiro, F. de O.M.d. S. Obreu, J.P. de A. Feitosa, M. de S.M. de S. Filho, Optimization of the collagen extraction from Nile tilapia skin (Oreochromis niloticus) and its hydrogel with hyaluronic acid, Colloids Surf. B: Biointerfaces 189 (2020) 110852, https://doi.org/10.1016/ j.colsurfb.2020.110852.

[87] I.A. Rodriguez, G. Saxena, K.R. Hixon, S.A. Sell, G.L. Bowlin, In vitro characterization of MG-63 osteoblast-like cells cultured on organic-inorganic lyophilized gelatin sponges for early bone healing, J. Biomed. Mater. Res. - Part A. 104 (2016) 2011-2019, https://doi.org/10.1002/jbm.a.35733.

[88] G. Apte, A. Repanas, C. Willems, A. Mujtaba, C.E.H. Schmelzer, A. Raichur, F. Syrowatka, T. Groth, Effect of different crosslinking strategies on physical properties and biocompatibility of freestanding multilayer films made of alginate and chitosan, Macromol. Biosci. 19 (2019), https://doi.org/10.1002/ mabi.201900181.

[89] S.F. Chou, L.J. Luo, J.Y. Lai, D.H.K. Ma, Role of solvent-mediated carbodiimide cross-linking in fabrication of electrospun gelatin nanofibrous membranes as ophthalmic biomaterials, Mater. Sci. Eng. C 71 (2017) 1145-1155, https:// doi.org/10.1016/j.msec.2016.11.105.

[90] S. Kondaveeti, P.V. de A. Bueno, A.M. Carmona-Ribeiro, F. Esposito, N Lincopan, M.R. Sierakowski, D.F.S. Petri, Microbicidal gentamicin-alginate hydrogels, Carbohydr. Polym. 186 (2018) 159-167, https://doi.org/10.1016/ j.carbpol.2018.01.044.

[91] C. Claaßen, L. Sewald, G. Tovar, K. Borchers, Controlled release of vascular endothelial growth factor from heparin-functionalized gelatin type A and albumin hydrogels, Gels. 3 (2017) 35, https://doi.org/10.3390/gels3040035.

[92] L.X. Lin, J.W. Luo, F. Yuan, H.H. Zhang, C.Q. Ye, P. Zhang, Y.L. Sun, In situ cross-linking carbodiimide-modified chitosan hydrogel for postoperative adhesion prevention in a rat model, Mater. Sci. Eng. C 81 (2017) 380-385, https://doi.org/10.1016/j.msec.2017.07.024.

[93] R. Curley, Borate mineral, Encycl. Br. (2017) 1-6. https:// www.britannica.com/science/borate-mineral.

[94] F.S. Kot, Boron in the environment, in: Boron Sep. Process., Elsevier B.V., 2015, pp. 1-33, https://doi.org/10.1016/B978-0-444-63454-2.00001-0.

[95] L.M.S. Ansaloni, E.M. de Souza, Boron nitride nanostructured: synthesis, characterization and potential use in cosmetics, Mater. Sci. Appl. 4 (2013) 1-7, https://doi.org/10.4236/msa.2013.41004.

[96] A. Lopalco, A.A. Lopedota, V. Laquintana, N. Denora, V.J. Stella, Boric acid, a Lewis acid with unique and unusual properties: formulation implications, $\mathrm{J}$. Pharm. Sci. 109 (2020) 2375-2386, https://doi.org/10.1016/ j.xphs.2020.04.015.

[97] D.M. Schubert, Boric oxide, boric acid, and borates, in: Ullmann's Encycl. Ind. Chem., 2015, pp. 1-32, https://doi.org/10.1002/14356007.a04_263.pub2.

[98] Z. Xu, Z. Chu, L. Yan, Enhancing the flame-retardant and smoke suppression properties of transparent intumescent fire-retardant coatings by introducing boric acid as synergistic agent, J. Therm. Anal. Calorim. 133 (2018) 1241-1252, https://doi.org/10.1007/s10973-018-7201-3.

[99] F.S. Kot, Boron sources, speciation and its potential impact on health, Rev. Environ. Sci. Biotechnol. 8 (2009) 3-28, https://doi.org/10.1007/s11157-0089140-0.

[100] E. Baysal, E.D. Tomak, E. Topaloglu, E. Pesman, Surface properties of bamboo and scots pine impregnated with boron and copper based wood preservatives after accelerated weathering, Maderas Cienc. y Tecnol. 18 (2016) 253-264, https:// doi.org/10.4067/S0718-221X2016005000023.

[101] U.C. Gupta, Boron and Its Role in Crop Production, 1993

[102] Z. Kızılay, H.A. Erken, N.K. Çetin, S. Aktaş, B.İ. Abas, A. Yılmaz, Boric acid reduces axonal and myelin damage in experimental sciatic nerve injury, Neural Regen. Res. 11 (2016) 1660-1665, https://doi.org/10.4103/1673-5374.193247.

[103] V.I. Zhuchkov, A.A. Akberdin, N.A. Vatolin, L.I. Leont'ev, O.V. Zayakin, A.S. Kim, U.K. Konurov, Application of boron-containing materials in metallurgy,
Russ. Metall. (2011) (2011) 1134-1137, https://doi.org/10.1134/ S003602951112024X.

[104] M. Rietjens, P.A. Steenbergen, Crosslinking mechanism of boric acid with diols revisited, Eur. J. Inorg. Chem. (2005) 1162-1174, https://doi.org/10.1002/ ejic.200400674.

[105] H. Kurokawa, M. Shibayama, T. Ishimaru, S. Nomura, W.li Wu, Phase behaviour and sol-gel transition of poly(vinyl alcohol)-borate complex in aqueous solution, Polymer (Guildf). 33 (1992) 2182-2188, https://doi.org/10.1016/0032-3861 (92)90886-2.

[106] S. Gao, J. Guo, K. Nishinari, Thermoreversible konjac glucomannan gel crosslinked by borax, Carbohydr. Polym. 72 (2008) 315-325, https://doi.org/ 10.1016/j.carbpol.2007.08.015.

[107] H. Awada, D. Montplaisir, C. Daneault, The development of a composite based on cellulose fibres and polyvinyl alcohol in the presence of boric acid, BioResources. 9 (2014) 2448-3439, https://doi.org/10.15376/biores.9.2.34393448.

[108] A.K. Priya, B.S. Kaith Sharma, Bhagyashree Simran, S. Arora, Synthesis of dextrin-polyacrylamide and boric acid based tough and transparent, self-healing, superabsorbent film, Int. J. Biol. Macromol. 182 (2021) 712-721, https://doi.org/ 10.1016/j.ijbiomac.2021.04.028.

[109] N. Thombare, U. Jha, S. Mishra, M.Z. Siddiqui, Borax cross-linked guar gum hydrogels as potential adsorbents for water purification, Carbohydr. Polym. 168 (2017) 274-281, https://doi.org/10.1016/j.carbpol.2017.03.086.

[110] K. Das, D. Ray, N.R. Bandyopadhyay, A. Gupta, S. Sengupta, S. Sahoo, A. Mohanty, M. Misra, Preparation and characterization of cross-linked starch/poly (vinyl alcohol) green films with low moisture absorption, Ind. Eng. Chem. Res. 49 (2010) 2176-2185, https://doi.org/10.1021/ie901092n.

[111] I. Colinet, L. Picton, G. Muller, D. Le Cerf, pH-dependent stability of scleroglucan borate gels, Carbohydr. Polym. 69 (2007) 65-71, https://doi.org/ 10.1016/j.carbpol.2006.09.002.

[112] S.H. Kim, K. Hyun, T.S. Moon, T. Mitsumata, J.S. Hong, K.H. Ahn, S.J. Lee, Morphology-rheology relationship in hyaluronate/poly(vinyl alcohol)/borax polymer blends, Polymer (Guildf). 46 (2005) 7156-7163, https://doi.org/ 10.1016/j.polymer.2005.05.089.

[113] Y. Yin, J. Li, Y. Liu, Z. Li, Starch crosslinked with poly(vinyl alcohol) by boric acid, J. Appl. Polym. Sci. 96 (2005) 1394-1397, https://doi.org/10.1002/ app. 21569 .

[114] P.C. Harris, Chemistry and rheology of borate-crosslinked fluids at temperatures to $300^{\circ} \mathrm{F}$, J. Pet. Technol. 45 (1993) 264-269, https://doi.org/ 10.2118/24339-PA.

[115] M. Grisel, G. Muller, Rheological properties of the schizophyllan-borax system, Macromolecules. 31 (1998) 4277-4281, https://doi.org/10.1021/ma970485k.

[116] C.J. Tsai, Y.R. Chang, M.L. Chen, Y.K. Lo, D.J. Lee, Stable poly(vinyl alcohol) and alginate cross-linked granules with immobilized ferric hexacyanoferrate for cesium removal from waters, J. Taiwan Inst. Chem. Eng. 95 (2019) 1-10, https:// doi.org/10.1016/j.jtice.2018.09.028.

[117] P.-H. Wang, Y.-R. Chang, D.-J. Lee, Shape stable poly(vinyl alcohol) and alginate cross-linked hydrogel with borate anions under dry-rewet cycles, J. Taiwan Inst. Chem. Eng. 103 (2019) 85-93, https://doi.org/10.1016/ j.jtice.2019.07.013.

[118] N. Aliasgharlou, F. Asghari Sana, S. Khoshbakht, P. Zolfaghari, H. Charkhian, Fabrication and characterization of boric acid-crosslinked ethyl cellulose and polyvinyl alcohol films as potential drug release systems for topical drug delivery, Turk. J. Chem. 44 (2020) 1723-1732, https://doi.org/10.3906/kim-2008-23.

[119] J. Han, T. Lei, Q. Wu, Facile preparation of mouldable polyvinyl alcohol-borax hydrogels reinforced by well-dispersed cellulose nanoparticles: physical, viscoelastic and mechanical properties, Cellulose. 20 (2013) 2947-2958, https:// doi.org/10.1007/s10570-013-0082-5.

[120] F. Seidi, Y. Jin, J. Han, M.R. Saeb, A. Akbari, S.H. Hosseini, M. Shabanian, H. Xiao, Self-healing polyol/borax hydrogels: fabrications, properties and applications, Chem. Rec. 20 (2020) 1142-1162, https://doi.org/10.1002/ tcr. 202000060

[121] H.M. Bolt, N. Başaran, Y. Duydu, Effects of boron compounds on human reproduction, Arch. Toxicol. 94 (2020) 717-724, https://doi.org/10.1007/ s00204-020-02700-x.

[122] N. Hadrup, M. Frederiksen, A.K. Sharma, Toxicity of boric acid, borax and other boron containing compounds: a review, Regul. Toxicol. Pharmacol. 121 (2021) 104873, https://doi.org/10.1016/j.yrtph.2021.104873.

[123] N. Başaran, Y. Duydu, A. Üstündağ, G. Taner, S. Aydin, H.G. Anlar, C.Ö. Yalçin, M. Bacanli, K. Aydos, C.S. Atabekoğlu, K. Golka, K. Ickstadt, T. Schwerdtle, M. Werner, S. Meyer, H.M. Bolt, Evaluation of the DNA damage in lymphocytes, sperm and buccal cells of workers under environmental and occupational boron exposure conditions, Mutat. Res. Genet. Toxicol. Environ. Mutagen. 843 (2019) 33-39, https://doi.org/10.1016/j.mrgentox.2018.12.013.

[124] J.T. Keeton, E.A. Foegeding, C. Patana-Anake, A comparison of nonmeat proteins, sodium tripolyphosphate and processing temperature effects on physical and sensory properties of frankfurters, J. Food Sci. 49 (1984) 1462-1465, https:// doi.org/10.1111/j.1365-2621.1984.tb12821.x.

[125] P. Stadtler, F. Muller-Bruckschwaiger, K. Schafer, E. Huntington, The effect of sodium trimetaphosphate on caries: a 3-year clinical toothpaste trial, Caries Res. 30 (1996) 418-422.

[126] L. Piani, A. Papo, Sodium tripolyphosphate and polyphosphate as dispersing agents for alumina suspensions: rheological characterization, Colloids Surfaces A Physicochem. Eng. Asp. 201 (2002) 219-230, https://doi.org/10.1016/S09277757(01)01024-X.

[127] Y.P. Lin, P.C. Singer, Inhibition of calcite crystal growth by polyphosphates, 
Water Res. 39 (2005) 4835-4843, https://doi.org/10.1016/ j.watres.2005.10.003.

[128] D. Pham Minh, J. Ramaroson, A. Nzihou, P. Sharrock, One-Step Synthesis of Sodium Trimetaphosphate (Na3P3O9) from Sodium Chloride and Orthophosphoric Acid One-Step Synthesis of Sodium Trimetaphosphate (Na 3 P 3 O 9) from Sodium Chloride and Orthophosphoric Acid, (n.d.). doi:https://doi.org/ 10.1021/ie201085bï.

[129] J.B. Hirsch, J.L. Kokini, Understanding the mechanism of cross-linking agents (POCl3, STMP, and EPI) through swelling behavior and pasting properties of cross-linked waxy maize starches, Cereal Chem. 79 (2002) 102-107, https:// doi.org/10.1094/CCHEM.2002.79.1.102.

[130] V. Dulong, S. Lack, D. Le Cerf, L. Picton, J.P. Vannier, G. Muller, Hyaluronanbased hydrogels particles prepared by crosslinking with trisodium trimetaphosphate. Synthesis and characterization, Carbohydr. Polym. 57 (2004) 1-6, https://doi.org/10.1016/j.carbpol.2003.12.006.

[131] F.M. Carbinatto, A.D. De Castro, B.S.F. Cury, A. Magalhães, R.C. Evangelista, Physical properties of pectin-high amylose starch mixtures cross-linked with sodium trimetaphosphate, Int. J. Pharm. 423 (2012) 281-288, https://doi.org/ 10.1016/j.ijpharm.2011.11.042.

[132] V. Wintgens, C. Lorthioir, P. Dubot, B. Sébille, C. Amiel, Cyclodextrin/dextran based hydrogels prepared by cross-linking with sodium trimetaphosphate, Carbohydr. Polym. 132 (2015) 80-88, https://doi.org/10.1016/ j.carbpol.2015.06.038.

[133] S. Lack, V. Dulong, L. Picton, D. Le Cerf, E. Condamine, High-resolution nuclear magnetic resonance spectroscopy studies of polysaccharides crosslinked by sodium trimetaphosphate: a proposal for the reaction mechanism, Carbohydr. Res. 342 (2007) 943-953, https://doi.org/10.1016/j.carres.2007.01.011.

[134] R. Zhang, Y. Tao, Q. Xu, N. Liu, P. Chen, Y. Zhou, Z. Bai, Rheological and ionconductive properties of injectable and self-healing hydrogels based on xanthan gum and silk fibroin, Int. J. Biol. Macromol. 144 (2020) 473-482, https://doi.org/ 10.1016/j.ijbiomac.2019.12.132.

[135] V. Sharma, M. Kaur, K.S. Sandhu, S.K. Godara, Effect of cross-linking on physico-chemical, thermal, pasting, in vitro digestibility and film forming properties of Faba bean (Vicia faba L.) starch, Int. J. Biol. Macromol. 159 (2020) 243-249, https://doi.org/10.1016/j.ijbiomac.2020.05.014.

[136] Y. Zhao, H. Sun, B. Yang, B. Fan, H. Zhang, Y. Weng, Enhancement of mechanical and barrier property of hemicellulose film via crosslinking with sodium trimetaphosphate, Polymers (Basel). 13 (2021) 927, https://doi.org/ 10.3390/polym13060927.

[137] G. Leone, A. Bidini, S. Lamponi, A. Magnani, States of water, surface and rheological characterisation of a new biohydrogel as articular cartilage substitute, Polym. Adv. Technol. 24 (2013) 824-833, https://doi.org/10.1002/pat.3150.

[138] S. Iswariya, A.V. Bhanukeerthi, P. Velswamy, T.S. Uma, P.T. Perumal, Design and development of a piscine collagen blended pullulan hydrogel for skin tissue engineering, RSC Adv. 6 (2016) 57863-57871, https://doi.org/10.1039/ c6ra03578g.

[139] S.P. Rowland, C.M. Welch, M.A.F. Brannan, D.M. Gallagher, Introduction of ester cross links into cotton cellulose by a rapid curing process, Text. Res. J. 37 (1967) 933-941, https://doi.org/10.1177/004051756703701105.

[140] C.Q. Yang, FT-IR spectroscopy study of the ester crosslinking mechanism of cotton cellulose, Text. Res. J. 61 (1991) 433-440, https://doi.org/10.1177/ 004051759106100801.

[141] E.L. Gillingham, D.M. Lewis, B. Voncina, An FTIR study of anhydride formation on heating butane tetracarboxylic acid in the presence of various catalysts, Text Res. J. 69 (1999) 949-955, https://doi.org/10.1177/004051759906901211.

[142] R.O. Brown, N.C. Reidsville, C. Tomasino, Catalysis of 1,2,3,4 butanetetracarboxylic acid in the durable press finishing of cotton textiles, Amer. Assoc. Text. Chem. Color Int. Conf. Exhib. (1991) 168-185.

[143] B. Ji, P. Tang, K. Yan, G. Sun, Catalytic actions of alkaline salts in reactions between 1,2,3,4-butanetetracarboxylic acid and cellulose: II. Esterification, Carbohydr. Polym. 132 (2015) 228-236, https://doi.org/10.1016/ j.carbpol.2015.06.070.

[144] C. Zhao, G. Sun, Catalytic actions of sodium salts in direct esterification of 3,3'4, 4'-benzophenone tetracarboxylic acid with cellulose, Ind. Eng. Chem. Res. 54 (2015) 10553-10559, https://doi.org/10.1021/acs.iecr.5b02308.

[145] V.B. Bueno, R. Bentini, L.H. Catalani, D.F.S. Petri, Synthesis and swelling behavior of xanthan-based hydrogels, Carbohydr. Polym. 92 (2013) 1091-1099, https://doi.org/10.1016/j.carbpol.2012.10.062.

[146] N. Reddy, Y. Yang, Citric acid cross-linking of starch films, Food Chem. 118 (2010) 702-711, https://doi.org/10.1016/j.foodchem.2009.05.050.

[147] P.L. Marani, G.D. Bloisi, D.F.S. Petri, Hydroxypropylmethyl cellulose films crosslinked with citric acid for control release of nicotine, Cellulose. 22 (2015) 3907-3918, https://doi.org/10.1007/s10570-015-0757-1.

[148] B. Ji, P. Tang, C. Hu, K. Yan, Catalytic and ionic cross-linking actions of Lglutamate salt for the modification of cellulose by 1,2,3,4-butanetetracarboxylic acid, Carbohydr. Polym. 207 (2018) 288-296, https://doi.org/10.1016/ j.carbpol.2018.11.090.

[149] Z. Huang, X. Zhou, Z. Xing, B. Wang, Improving application performance of in situ polymerization and crosslinking system of maleic acid/itaconic acid for cotton fabric, Fibers Polym. 19 (2018) 281-288, https://doi.org/10.1007/ s12221-018-7745-z.

[150] G. Priya, U. Narendrakumar, I. Manjubala, Thermal behavior of carboxymethyl cellulose in the presence of polycarboxylic acid crosslinkers, J. Therm. Anal. Calorim. 138 (2019) 89-95, https://doi.org/10.1007/s10973-019-08171-2.

[151] Y. Monroy, S. Rivero, M.A. García, Sustainable panels design based on modified cassava starch bioadhesives and wood processing byproducts, Ind. Crop. Prod.
137 (2019) 171-179, https://doi.org/10.1016/j.indcrop.2019.04.062.

[152] V.S. Ghorpade, A.V. Yadav, R.J. Dias, K.K. Mali, S.S. Pargaonkar, P.V. Shinde, N.S. Dhane, Citric acid crosslinked carboxymethylcellulose-poly(ethylene glycol) hydrogel films for delivery of poorly soluble drugs, Int. J. Biol. Macromol. 118 (2018) 783-791, https://doi.org/10.1016/j.ijbiomac.2018.06.142.

[153] B.M. Simões, C. Cagnin, F. Yamashita, J.B. Olivato, P.S. Garcia, S.M. de Oliveira, M.V. Eiras Grossmann, Citric acid as crosslinking agent in starch/ xanthan gum hydrogels produced by extrusion and thermopressing, Lwt-Food Sci. Technol. 125 (2020) 1-7, https://doi.org/10.1016/j.lwt.2019.108950.

[154] P.V.O. Toledo, O.D. Bernardinelli, E. Sabadini, D.F.S. Petri, The states of water in tryptophan grafted hydroxypropyl methylcellulose hydrogels and their effect on the adsorption of methylene blue and rhodamine B, Carbohydr. Polym. 248 (2020) 116765, https://doi.org/10.1016/j.carbpol.2020.116765.

[155] Í.F.T. de Souza, D.F.S. Petri, $\beta$-Cyclodextrin hydroxypropyl methylcellulose hydrogels for bisphenol A adsorption, J. Mol. Liq. 266 (2018) 640-648, https:// doi.org/10.1016/j.molliq.2018.06.117.

[156] M. Petitjean, F. Aussant, A. Vergara, J.R. Isasi, Solventless crosslinking of chitosan, xanthan, and locust bean gum networks functionalized with $\beta$ cyclodextrin, Gels. 6 (2020) 1-13, https://doi.org/10.3390/gels6040051.

[157] G. Sennakesavan, M. Mostakhdemin, L.K. Dkhar, A. Seyfoddin, S.J. Fatihhi, Acrylic acid/acrylamide based hydrogels and its properties - a review, Polym. Degrad. Stab. 180 (2020) 109308, https://doi.org/10.1016/j.polymdegradstab. 2020.109308.

[158] N. He, X. Chen, L. Wang, J. Wen, Y. Li, Q. Cao, Z. Liu, B. Li, Fabrication of composite hydrogels based on soy protein isolate and their controlled globular protein delivery, Glob. Challenges. 3 (2019) 1900030, https://doi.org/10.1002/ gch2.201900030.

[159] A.K. Sharma, B.S. Priya, N. Kaith, J.K. Sharma, V. Bhatia, S. Tanwar, S. Panchal, Bajaj, Selective removal of cationic dyes using response surface methodology optimized gum acacia-sodium alginate blended superadsorbent, Int. J. Biol. Macromol. 124 (2019) 331-345, https://doi.org/10.1016/ j.ijbiomac.2018.11.213.

[160] Priya, A.K. Sharma, B.S. Kaith, Vipula, K. Chandel, A. Singh, Isha, Chemically modified chitosan-sodium alginate as chemo-sensor adsorbent for the detection of picric acid and removal of biebrich scarlet, Int. J. Biol. Macromol. 147 (2020) 582-594, https://doi.org/10.1016/j.ijbiomac.2020.01.090.

[161] A.K. Priya, B.S. Sharma, K. Chandel Kaith, Isha Vipula, A. Singh, Bifunctional gelatin/dextrin hybrid backbone based fluorescent chemo-sensor for the detection of tannic acid and removal of eosin yellow dye, Mater. Chem. Phys. 254 (2020) 123304, https://doi.org/10.1016/j.matchemphys.2020.123304.

[162] M. Chen, M. Zhong, J.A. Johnson, Light-controlled radical polymerization: mechanisms, methods, and applications, Chem. Rev. 116 (2016) 10167-10211, https://doi.org/10.1021/acs.chemrev.5b00671.

[163] V.V. Lele, S. Kumari, H. Niju, Syntheses, Characterization and Applications of Graft Copolymers of Sago Starch - a Review, 70, Starch/Staerke, 2018, pp. 1-9, https://doi.org/10.1002/star.201700133.

[164] M.B. Thürmer, C.E. Diehl, F.J.B. Brum, L.A. Dos Santos, Preparation and characterization of hydrogels with potential for use as biomaterials, Mater. Res. 17 (2014) 109-113, https://doi.org/10.1590/1516-1439.223613.

[165] M. Kaur, A.K. Srivastava, Photopolymerization: a review, J. Macromol. Sci. Polym. Rev. 42 (2002) 481-512, https://doi.org/10.1081/MC-120015988.

[166] J. Wu, Z. Zhao, C.M. Hamel, X. Mu, X. Kuang, Z. Guo, H.J. Qi, Evolution of material properties during free radical photopolymerization, J. Mech. Phys. Solids. 112 (2018) 25-49, https://doi.org/10.1016/j.jmps.2017.11.018.

[167] S. Bashir, Y.Y. Teo, S. Ramesh, K. Ramesh, Synthesis and characterization of karaya gum-g- poly (acrylic acid) hydrogels and in vitro release of hydrophobic quercetin, Polymer (Guildf). 147 (2018) 108-120, https://doi.org/10.1016/ j.polymer.2018.05.071.

[168] A. Hajikarimi, M. Sadeghi, Free radical synthesis of cross-linking gelatin base poly NVP/acrylic acid hydrogel and nanoclay hydrogel as cephalexin drug deliver, J. Polym. Res. 27 (2020) 1-20, https://doi.org/10.1007/s10965-020 2020-1.

[169] G. Moad, D.H. Solomon, The Chemistry of Radical Polymerization, 2nd ed., Elsevier, 2006.

[170] W. Ruan, Y. Lian, T. Zhen, L. Huang, J. Qiao, pH-response superabsorbant hydrogel synthesized by ultraviolet photopolymerization, J. Appl. Polym. Sci. 103 (2007) 1847-1852, https://doi.org/10.1002/app.25409.

[171] A. Serafim, C. Tucureanu, D.G. Petre, D.M. Dragusin, A. Salageanu, S. Van Vlierberghe, P. Dubruel, I.C. Stancu, One-pot synthesis of superabsorbent hybrid hydrogels based on methacrylamide gelatin and polyacrylamide. Effortless control of hydrogel properties through composition design, New J. Chem. 38 (2014) 3112-3126, https://doi.org/10.1039/c4nj00161c.

[172] M.F. Attia, A.S. Montaser, M. Arifuzzaman, M. Pitz, K. Jlassi, A. AlexanderBryant, S.S. Kelly, F. Alexis, D.C. Whitehead, In situ photopolymerization of acrylamide hydrogel to coat cellulose acetate nanofibers for drug delivery system, Polymers (Basel). 13 (2021) 1863, https://doi.org/10.3390/polym13111863.

[173] S. Qavi, S. Pourmahdian, H. Eslami, Acrylamide hydrogels preparation via free radical crosslinking copolymerization: kinetic study and morphological investigation, J. Macromol. Sci. Part A Pure Appl. Chem. 51 (2014) 842-848, https://doi.org/10.1080/10601325.2014.937132.

[174] R. Singhal, R.S. Tomar, A.K. Nagpal, Effect of cross-linker and initiator concentration on the swelling behaviour and network parameters of superabsorbent hydrogels based on acrylamide and acrylic acid, Int. J. Plast. Technol. 13 (2009) 22-37, https://doi.org/10.1007/s12588-009-0004-4.

[175] H. Chavda, C. Patel, Effect of crosslinker concentration on characteristics of superporous hydrogel, Int. J. Pharm. Investig. 1 (2011) 17-21, https://doi.org/ 
$10.4103 / 2230-973 x .76724$

[176] J.H. Exon, A review of the toxicology of acrylamide, J. Toxicol. Environ. Heal. Part B. 9 (2006) 397-412, https://doi.org/10.1080/10937400600681430.

[177] R.R.B. Makarand, V. Risbud, Polyacrylamide-chitosan hydrogels: in vitro biocompatibility and sustained antibiotic release studies, Drug Deliv. 7 (2000) 69-75, https://doi.org/10.1080/107175400266623.

[178] R.P. Dumitriu, A.-M. Oprea, C. Natalia Cheaburu, M.-T. Nistor, O. Novac, C.M. Ghiciuc, L. Profire, C. Vasile, Biocompatible and biodegradable alginate/poly(Nisopropylacrylamide) hydrogels for sustained theophylline release, J. Appl. Polym. Sci. 131 (40733) (2014) 1-16, https://doi.org/10.1002/app.40733.

[179] R. Kouser, A. Vashist, M. Zafaryab, M.A. Rizvi, S. Ahmad, Biocompatible and mechanically robust nanocomposite hydrogels for potential applications in tissue engineering, Mater. Sci. Eng. C 84 (2018) 168-179, https://doi.org/10.1016/ J.MSEC.2017.11.018.

[180] B.-L. Guo, Q.-Y. Gao, Preparation and properties of a pH/temperatureresponsive carboxymethyl chitosan/poly(N-isopropylacrylamide)semi-IPN hydrogel for oral delivery of drugs, Carbohydr. Res. 342 (2007) 2416-2422, https://doi.org/10.1016/j.carres.2007.07.007.

[181] N.M. Ranjha, G. Ayub, S. Naseem, M.T. Ansari, Preparation and characterization of hybrid $\mathrm{pH}$-sensitive hydrogels of chitosan-co-acrylic acid for controlled release of verapamil, J. Mater. Sci. Mater. Med. 21 (2010) 2805-2816, https://doi.org/10.1007/s10856-010-4134-1.

[182] T. Heck, G. Faccio, M. Richter, L. Thöny-Meyer, Enzyme-catalyzed protein crosslinking, Appl. Microbiol. Biotechnol. 97 (2013) 461-475, https://doi.org/ 10.1007/s00253-012-4569-z.

[183] L.J. Eggermont, Z.J. Rogers, T. Colombani, A. Memic, S.A. Bencherif, Injectable cryogels for biomedical applications, Trends Biotechnol. 38 (2020) 418-431, https://doi.org/10.1016/j.tibtech.2019.09.008.

[184] W. Il Choi, Y. Hwang, A. Sahu, K. Min, D. Sung, G. Tae, J.H. Chang, An injectable and physical levan-based hydrogel as a dermal filler for soft tissue augmentation, Biomater. Sci. 6 (2018) 2627-2638, https://doi.org/10.1039/ c8bm00524a.

[185] X. Li, B. Cho, R. Martin, M. Seu, C. Zhang, Z. Zhou, J.S. Choi, X. Jiang, L. Chen, G. Walia, J. Yan, M. Callanan, H. Liu, K. Colbert, J. Morrissette-McAlmon, W. Grayson, S. Reddy, J.M. Sacks, H.-Q. Mao, Nanofiber-hydrogel composite-mediated angiogenesis for soft tissue reconstruction, Sci. Transl. Med. 11 (2019) eaau6210, https://doi.org/10.1126/scitranslmed.aau6210.

[186] J.M. Stukel, R.K. Willits, Mechanotransduction of neural cells through cellsubstrate interactions, Tissue Eng. - Part B Rev. (2016), https://doi.org/10.1089/ ten.teb.2015.0380.

[187] K. Song, A.M. Compaan, W. Chai, Y. Huang, Injectable gelatin microgel-based composite ink for 3D bioprinting in air, ACS Appl. Mater. Interfaces 12 (2020) 22453-22466, https://doi.org/10.1021/acsami.0c01497.

[188] S.H. Kim, S.H. Lee, J.E. Lee, S.J. Park, K. Kim, I.S. Kim, Y.S. Lee, N.S. Hwang, B.G. Kim, Tissue adhesive, rapid forming, and sprayable ECM hydrogel via recombinant tyrosinase crosslinking, Biomaterials. 178 (2018) 401-412, https:/ doi.org/10.1016/j.biomaterials.2018.04.057.

[189] S. Poveda-Reyes, V. Moulisova, E. Sanmartín-Masiá, L. Quintanilla-Sierra, M. Salmerón-Sánchez, G.G. Ferrer, Gelatin-hyaluronic acid hydrogels with tuned stiffness to counterbalance cellular forces and promote cell differentiation, Macromol. Biosci. 16 (2016) 1311-1324, https://doi.org/10.1002/ mabi.201500469.

[190] S. Amadori, P. Torricelli, K. Rubini, M. Fini, S. Panzavolta, A. Bigi, Effect of sterilization and crosslinking on gelatin films, J. Mater. Sci. Mater. Med. (2015), https://doi.org/10.1007/s10856-015-5396-4.

[191] S. Cheng, W. Wang, Y. Li, G. Gao, K. Zhang, J. Zhou, Z. Wu, Cross-linking and film-forming properties of transglutaminase-modified collagen fibers tailored by denaturation temperature, Food Chem. 271 (2019) 527-535, https://doi.org/ 10.1016/j.foodchem.2018.07.223.

[192] X. Cai, S. Hu, B. Yu, Y. Cai, J. Yang, F. Li, Y. Zheng, X. Shi, Transglutaminasecatalyzed preparation of crosslinked carboxymethyl chitosan/carboxymethyl cellulose/collagen composite membrane for postsurgical peritoneal adhesion prevention, Carbohydr. Polym. 201 (2018) 201-210, https://doi.org/10.1016/ j.carbpol.2018.08.065.

[193] A. Abaee, A. Madadlou, Niosome-loaded cold-set whey protein hydrogels, Food Chem. 196 (2016) 106-113, https://doi.org/10.1016/j.foodchem.2015.09.037.

[194] N.R. Raia, B.P. Partlow, M. McGill, E.P. Kimmerling, C.E. Ghezzi, D.L. Kaplan, Enzymatically crosslinked silk-hyaluronic acid hydrogels, Biomaterials. 131 (2017) 58-67, https://doi.org/10.1016/j.biomaterials.2017.03.046.

[195] J. Hou, C. Li, Y. Guan, Y. Zhang, X.X. Zhu, Enzymatically crosslinked alginate hydrogels with improved adhesion properties, Polym. Chem. 6 (2015) 2204-2213, https://doi.org/10.1039/c4py01757a.

[196] J. Carthew, J.E. Frith, J.S. Forsythe, V.X. Truong, Polyethylene glycol-gelatin hydrogels with tuneable stiffness prepared by horseradish peroxidase-activated tetrazine-norbornene ligation, J. Mater. Chem. B 6 (2018) 1394-1401, https:// doi.org/10.1039/c7tb02764h.

[197] J.K. Sahoo, J. Choi, O. Hasturk, I. Laubach, M.L. Descoteaux, S. Mosurkal, B. Wang, N. Zhang, D.L. Kaplan, Silk degumming time controls horseradish peroxidase-catalyzed hydrogel properties, Biomater. Sci. 8 (2020) 4176-4185, https://doi.org/10.1039/d0bm00512f

[198] M. Di Luca, M. Curcio, E. Valli, G. Cirillo, F. Voli, M.E. Butini, A. Farfalla, E. Pantuso, A. Leggio, F.P. Nicoletta, A. Tavanti, F. Iemma, O. Vittorio, Combining antioxidant hydrogels with self-assembled microparticles for multifunctional wound dressings, J. Mater. Chem. B 7 (2019) 4361-4370, https://doi.org/ 10.1039/c9tb00871c.

[199] A.L. Martínez-López, E. Carvajal-Millan, N. Sotelo-Cruz, V. Micard, A. Rascón-
Chu, Y.L. López-Franco, J. Lizardi-Mendoza, R. Canett-Romero, Enzymatically cross-linked arabinoxylan microspheres as oral insulin delivery system, Int. J. Biol. Macromol. 126 (2019) 952-959, https://doi.org/10.1016/ j.ijbiomac.2018.12.192.

[200] D. Huber, G. Tegl, M. Baumann, E. Sommer, E.G. Gorji, N. Borth, G. Schleining, G.S. Nyanhongo, G.M. Guebitz, Chitosan hydrogel formation using laccase activated phenolics as cross-linkers, Carbohydr. Polym. 157 (2017) 814-822, https://doi.org/10.1016/j.carbpol.2016.10.012.

[201] A. de A. Morandim-Giannetti, P. de O.Wecchi, P. de A. Silvério, R. Carlstron, P.A. Bersanetti, Attainment and characterization of carboxymethyl chitosan hydrogels by enzymatic cross-linking, J. Therm. Anal. Calorim. 138 (2019) 3635-3643, https://doi.org/10.1007/s10973-019-08571-4.

[202] J. Di, Q. Sun, X. Song, Laccase-TEMPO-mediated air oxidation of galactomannan for use as paper strengthening agent, Carbohydr. Polym. 184 (2018) 94-99, https://doi.org/10.1016/j.carbpol.2017.12.050.

[203] E. ztürk, T. Stauber, C. Levinson, E. Cavalli, O. Arlov, M. Zenobi-Wong, Tyrosinase-crosslinked, tissue adhesive and biomimetic alginate sulfate hydrogels for cartilage repair, Biomed. Mater. 15 (2020) 045019, https://doi.org/10.1088/ 1748-605X/ab8318.

[204] B.S. Kim, S.H. Kim, K. Kim, Y.H. An, K.H. So, B.G. Kim, N.S. Hwang, Enzymemediated one-pot synthesis of hydrogel with the polyphenol cross-linker for skin regeneration, Mater. Today Bio. 8 (2020) 100079, https://doi.org/10.1016/ j.mtbio.2020.100079.

[205] M.R. Arkenberg, D.M. Moore, C.C. Lin, Dynamic control of hydrogel crosslinking via sortase-mediated reversible transpeptidation, Acta Biomater. 83 (2019) 83-95, https://doi.org/10.1016/j.actbio.2018.11.011.

[206] N. Broguiere, F. Formica, G. Barreto, M. Zenobi-Wong, Sortase A as a crosslinking enzyme in tissue engineering, Acta Biomater. 77 (2018) 182-190, https:// doi.org/10.1016/j.actbio.2018.07.020.

[207] J.E. Folk, J.S. Finlayson, The $\varepsilon$-( $\gamma$-glutamyl)lysine crosslink and the catalytic role of transglutaminases, Adv. Protein Chem. 31 (1977) 1-133, https://doi.org/ 10.1016/S0065-3233(08)60217-X.

[208] A.L.C. Gaspar, S.P. De Góes-Favoni, Action of microbial transglutaminase (MTGase) in the modification of food proteins: a review, Food Chem. 171 (2015) 315-322, https://doi.org/10.1016/j.foodchem.2014.09.019.

[209] M. Kieliszek, A. Misiewicz, Microbial transglutaminase and its application in the food industry. a review, Folia Microbiol. (Praha). 59 (2014) 241-250, https:// doi.org/10.1007/s12223-013-0287-x.

[210] J.W. Keillor, C.M. Clouthier, K.Y.P. Apperley, A. Akbar, A. Mulani, Acyl transfer mechanisms of tissue transglutaminase, Bioorg. Chem. 57 (2014) 186-197, https://doi.org/10.1016/j.bioorg.2014.06.003.

[211] L.C. Huang, H.C. Wang, L.H. Chen, C.Y. Ho, P.H. Hsieh, M.Y. Huang, H.C. Wu, T.W. Wang, Bioinspired self-assembling peptide hydrogel with proteoglycanassisted growth factor delivery for therapeutic angiogenesis, Theranostics. 9 (2019) 7072-7087, https://doi.org/10.7150/thno.35803.

[212] W.J. Bradshaw, A.H. Davies, C.J. Chambers, A.K. Roberts, C.C. Shone, K.R. Acharya, Molecular features of the sortase enzyme family, FEBS J. 282 (2015) 2097-2114, https://doi.org/10.1111/febs.13288.

[213] S.M.A.G. Ulson de Souza, E. Forgiarini, A.A. Ulson de Souza, Toxicity of textile dyes and their degradation by the enzyme horseradish peroxidase (HRP), J. Hazard. Mater. 147 (2007) 1073-1078, https://doi.org/10.1016/ j.jhazmat.2007.06.003.

[214] H.J. Kim, Y. Suma, S.H. Lee, J.A. Kim, H.S. Kim, Immobilization of horseradish peroxidase onto clay minerals using soil organic matter for phenol removal, J. Mol. Catal. B Enzym. 83 (2012) 8-15, https://doi.org/10.1016/ j.molcatb.2012.06.012.

[215] M. Auriol, Y. Filali-Meknassi, C.D. Adams, R.D. Tyagi, Natural and synthetic hormone removal using the horseradish peroxidase enzyme: temperature and $\mathrm{pH}$ effects, Water Res. 40 (2006) 2847-2856, https://doi.org/10.1016/ j.watres.2006.05.032.

[216] A.F. Naves, A.M. Carmona-Ribeiro, R. Casarano, L.H. Catalani, Y. Kawano, D.F.S. Petri, Crystalline particles from self-assembled divinyl oligomers, Mater. Sci. Eng. C 29 (2009) 564-570, https://doi.org/10.1016/j.msec.2008.10.010.

[217] M. Kurisawa, J.E. Chung, Y.Y. Yang, S.J. Gao, H. Uyama, Injectable biodegradable hydrogels composed of hyaluronic acid-tyramine conjugates for drug delivery and tissue engineering, Chem. Commun. (2005) 4312-4314, https://doi.org/10.1039/b506989k.

[218] A. Darr, A. Calabro, Synthesis and characterization of tyramine-based hyaluronan hydrogels, J. Mater. Sci. Mater. Med. 20 (2009) 33-44, https:// doi.org/10.1007/s10856-008-3540-0.

[219] A. Schulz, M.M. Gepp, F. Stracke, H. von Briesen, J.C. Neubauer, H. Zimmermann, Tyramine-conjugated alginate hydrogels as a platform for bioactive scaffolds, J. Biomed. Mater. Res. Part A. 107 (2019) 114-121, https://doi.org/ 10.1002/jbm.a.36538.

[220] B. Bi, H. Liu, W. Kang, R. Zhuo, X. Jiang, An injectable enzymatically crosslinked tyramine-modified carboxymethyl chitin hydrogel for biomedical applications, Colloids Surf. B: Biointerfaces 175 (2019) 614-624, https://doi.org/ 10.1016/j.colsurfb.2018.12.029.

[221] R. Jin, C. Hiemstra, Z. Zhong, J. Feijen, Enzyme-mediated fast in situ formation of hydrogels from dextran-tyramine conjugates, Biomaterials. 28 (2007) 2791-2800, https://doi.org/10.1016/j.biomaterials.2007.02.032.

[222] I.M. Oliveira, C. Gonçalves, M.E. Shin, S. Lee, R.L. Reis, G. Khang, J.M. Oliveira, Enzymatically crosslinked tyramine-gellan gum hydrogels as drug delivery system for rheumatoid arthritis treatment, Drug Deliv. Transl. Res. (2020) 1-13, https:// doi.org/10.1007/s13346-020-00855-9.

[223] P. Le Thi, Y. Lee, D.L. Tran, T.T.H. Thi, J. Il Kang, K.M. Park, K.D. Park, In situ 
forming and reactive oxygen species-scavenging gelatin hydrogels for enhancing wound healing efficacy, Acta Biomater. 103 (2020) 142-152, https://doi.org/ 10.1016/j.actbio.2019.12.009.

[224] P.J. Strong, H. Claus, Laccase: A review of its past and its future in bioremediation, Crit. Rev. Environ. Sci. Technol. 41 (2011) 373-434, https:// doi.org/10.1080/10643380902945706.

[225] K. Brijwani, A. Rigdon, P.V. Vadlani, Fungal laccases: production, function, and applications in food processing, Enzyme Res. 2010 (2010) 1-10, https://doi.org/ $10.4061 / 2010 / 149748$.

[226] P. Baldrian, Fungal laccases-occurrence and properties, FEMS Microbiol. Rev. 30 (2006) 215-242, https://doi.org/10.1111/j.1574-4976.2005.00010.x.

[227] T. Kudanga, B. Nemadziva, M. Le Roes-Hill, Laccase catalysis for the synthesis of bioactive compounds, Appl. Microbiol. Biotechnol. (n.d.). doi:https://doi.org/ 10.1007/s00253-016-7987-5.

[228] A.I. Yaropolov, O.V. Skorobogat'ko, S.S. Vartanov, S.D. Varfolomeyev, Laccase properties, catalytic mechanism, and applicability, Appl. Biochem. Biotechnol. 49 (1994) 257-280, https://doi.org/10.1007/BF02783061.

[229] C.A. Ramsden, P.A. Riley, Tyrosinase: The four oxidation states of the active site and their relevance to enzymatic activation, oxidation and inactivation, Bioorg. Med. Chem. 22 (2014) 2388-2395, https://doi.org/10.1016/j.bmc.2014.02.048.

[230] O.S. Ilesanmi, I.O. Adewale, Physicochemical properties of free and immobilized tyrosinase from different species of yam (Dioscorea spp.), Biotechnol. Reports. 27 (2020) e00499, https://doi.org/10.1016/j.btre.2020.e00499.

[231] A. Aljawish, I. Chevalot, B. Piffaut, C. Rondeau-Mouro, M. Girardin, J. Jasniewski, J. Scher, L. Muniglia, Functionalization of chitosan by laccasecatalyzed oxidation of ferulic acid and ethyl ferulate under heterogeneous reaction conditions, Carbohydr. Polym. 87 (2012) 537-544, https://doi.org/ 10.1016/j.carbpol.2011.08.016.

[232] G. Kumar, P.J. Smith, G.F. Payne, Enzymatic grafting of a natural product onto chitosan to confer water solubility under basic conditions, Biotechnol. Bioeng. 63 (1999) 154-165, https://doi.org/10.1002/(SICI)1097-0290(19990420)63:2 $<154:$ :AID-BIT4 > 3.0.CO;2-R.

[233] Y. Li, L. Li, M.N. Lund, B. Li, Y. Hu, X. Zhang, Kinetic investigation of the trapping of $\mathrm{N} \varepsilon$-(carboxymethyl)lysine by 4-methylbenzoquinone: a new mechanism to control Ne-(carboxymethyl)lysine levels in foods, Food Chem. 244 (2018) 25-28, https://doi.org/10.1016/j.foodchem.2017.09.144.

[234] S. Sampaio, P. Taddei, P. Monti, J. Buchert, G. Freddi, Enzymatic grafting of chitosan onto Bombyx mori silk fibroin: kinetic and IR vibrational studies, J. Biotechnol. 116 (2005) 21-33, https://doi.org/10.1016/j.jbiotec.2004.10.003.

[235] V.-H. Nguyen, Thang Phan Nguyen, Quang Vinh Nguyen, T.-H. Le, V.Q.N. Huynh, D.-V.N. Vo, Q.T. Trinh, S.Y. Kim, Q. Van Le, Silk fibroin-based biomaterials for biomedical applications: a review, Polymers (Basel) 11 (1933) (2019), https://doi.org/10.3390/polym11121933.

[236] L. Wang, B. Xu, Y. Nong, P. Wang, Y. Yu, C. Deng, J. Yuan, Q. Wang, Laccasemediated construction of flexible double-network hydrogels based on silk fibroin and tyramine-modified hyaluronic acid, Int. J. Biol. Macromol. 160 (2020) 795-805, https://doi.org/10.1016/j.ijbiomac.2020.05.258.

[237] B. Tavsanli, O. Okay, Mechanically robust and stretchable silk/hyaluronic acid hydrogels, Carbohydr. Polym. 208 (2019) 413-420, https://doi.org/10.1016/ j.carbpol.2018.12.088.

[238] H.Y. Liu, T. Greene, T.Y. Lin, C.S. Dawes, M. Korc, C.C. Lin, Enzyme-mediated stiffening hydrogels for probing activation of pancreatic stellate cells, Acta Biomater. 48 (2017) 258-269, https://doi.org/10.1016/j.actbio.2016.10.027.

[239] J.E. Brauch, Underutilized Fruits and Vegetables as Potential Novel Pigment Sources, Elsevier Ltd., 2016, https://doi.org/10.1016/B978-0-08-100371 8.00015-4.

[240] R.A.A. Muzzarelli, Genipin-crosslinked chitosan hydrogels as biomedical and pharmaceutical aids, Carbohydr. Polym. 77 (2009) 1-9, https://doi.org/10.1016/ j.carbpol.2009.01.016.

[241] M. Xu, Q. Sun, J. Su, J. Wang, C. Xu, T. Zhang, Q. Sun, Microbial transformation of geniposide in Gardenia jasminoides Ellis into genipin by Penicillium nigricans, Enzym. Microb. Technol. 42 (2008) 440-444, https://doi.org/10.1016/ j.enzmictec.2008.01.003.

[242] S. Ilkar Erdagi, F. Asabuwa Ngwabebhoh, U. Yildiz, Genipin crosslinked gelatindiosgenin-nanocellulose hydrogels for potential wound dressing and healing applications, Int. J. Biol. Macromol. 149 (2020) 651-663, https://doi.org/ 10.1016/j.ijbiomac.2020.01.279.

[243] S. Dimida, C. Demitri, V.M. De Benedictis, F. Scalera, F. Gervaso, A. Sannino, Genipin-cross-linked chitosan-based hydrogels: reaction kinetics and structurerelated characteristics, J. Appl. Polym. Sci. 132 (2015) 1-8, https://doi.org/ 10.1002/app.42256.

[244] Y. Wang, F. Bamdad, Y. Song, L. Chen, Hydrogel Particles and Other Novel Protein-based Methods for Food Ingredient and Nutraceutical Delivery Systems, Elsevier Masson SAS, 2012, https://doi.org/10.1533/9780857095909.3.412.

[245] A. Bigi, G. Cojazzi, S. Panzavolta, N. Roveri, K. Rubini, Stabilization of gelatin films by crosslinking with genipin, Biomaterials. 23 (2002) 4827-4832, https:// doi.org/10.1016/S0142-9612(02)00235-1.

[246] F. Oustadi, R. Imani, M. Haghbin Nazarpak, A.M. Sharifi, Genipin-crosslinked gelatin hydrogel incorporated with PLLA-nanocylinders as a bone scaffold: synthesis, characterization, and mechanical properties evaluation, Polym. Adv. Technol. 31 (2020) 1783-1792, https://doi.org/10.1002/pat.4905.

[247] D.M. Kirchmajer, C.A. Watson, M. Ranson, M. In Het Panhuis, Gelapin, a degradable genipin cross-linked gelatin hydrogel, RSC Adv. 3 (2013) 1073-1081, https://doi.org/10.1039/c2ra22859a.

[248] F.L. Mi, S.S. Shyu, C.K. Peng, Characterization of ring-opening polymerization of genipin and $\mathrm{pH}$-dependent cross-linking reactions between chitosan and genipin, J. Polym. Sci. Part A Polym. Chem. 43 (2005) 1985-2000, https:// doi.org/10.1002/pola.20669.

[249] Y.J. Cho, S.Y. Kim, J. Kim, E.K. Choe, S.I. Kim, H.J. Shin, One-step enzymatic synthesis of blue pigments from geniposide for fabric dyeing, Biotechnol. Bioprocess Eng. 11 (2006) 230-234, https://doi.org/10.1007/BF02932035.

[250] C. Xu, W. Zhan, X. Tang, F. Mo, L. Fu, B. Lin, Self-healing chitosan/vanillin hydrogels based on Schiff-base bond/hydrogen bond hybrid linkages, Polym. Test. 66 (2018) 155-163, https://doi.org/10.1016/j.polymertesting.2018.01.016.

[251] M. Hunger, P. Domalik-pyzik, Double crosslinking of chitosan/vanillin hydrogels as a basis for mechanically strong gradient scaffolds for tissue engineering, Eng. Biomater. 155 (2020) 2-11, https://doi.org/10.34821/ eng.biomat.155.2020.2-11.

[252] Q. Zou, J. Li, Y. Li, Preparation and characterization of vanillin-crosslinked chitosan therapeutic bioactive microcarriers, Int. J. Biol. Macromol. 79 (2015) 736-747, https://doi.org/10.1016/j.ijbiomac.2015.05.037.

[253] Z.H. Zhang, Z. Han, X.A. Zeng, X.Y. Xiong, Y.J. Liu, Enhancing mechanical properties of chitosan films via modification with vanillin, Int. J. Biol. Macromol. 81 (2015) 638-643, https://doi.org/10.1016/j.ijbiomac.2015.08.042.

[254] H. Robles, Tannic Acid, Third ed., Elsevier, 2014, https://doi.org/10.1016/ B978-0-12-386454-3.00542-X.

[255] M. Popa, B.C. Ciobanu, L. Ochiuz, J. Desbrieres, C.S. Stan, C.A. Peptu, Controlling the release kinetics of calcein loaded liposomes from chitosan/tannic acid and chitosan/poly(vinyl alcohol)/tannic acid hydrogels, Cellul. Chem. Technol. 52 (2018) 353-370.

[256] G. Ghigo, S. Berto, M. Minella, D. Vione, E. Alladio, V.M. Nurchi, J. Lachowicz P.G. Daniele, New insights into the protogenic and spectroscopic properties of commercial tannic acid: the role of gallic acid impurities, New J. Chem. 42 (2018) 7703-7712, https://doi.org/10.1039/C7NJ04903J.

[257] V. Natarajan, N. Krithica, B. Madhan, P.K. Sehgal, Preparation and properties of tannic acid cross-linked collagen scaffold and its application in wound healing, J. Biomed. Mater. Res. - Part B Appl. Biomater. 101 (2013) 560-567, https:// doi.org/10.1002/jbm.b.32856.

[258] X. Zhang, M.D. Do, P. Casey, A. Sulistio, G.G. Qiao, L. Lundin, P. Lillford, S. Kosaraju, Chemical cross-linking gelatin with natural phenolic compounds as studied by high-resolution NMR spectroscopy, Biomacromolecules. 11 (2010) 1125-1132, https://doi.org/10.1021/bm1001284.

[259] J. Wu, W. Liao, J. Zhang, W. Chen, Microwave-assisted reaction of gelatin with tannic acid: non-thermal effect on the crosslinking process, Chem. Eng. Commun. 206 (2019) 1152-1158, https://doi.org/10.1080/00986445.2018.1550394.

[260] M. Anvari, D. Chung, Dynamic rheological and structural characterization of fish gelatin - Gum arabic coacervate gels cross-linked by tannic acid, Food Hydrocoll. 60 (2016) 516-524, https://doi.org/10.1016/j.foodhyd.2016.04.028.

[261] S. Bahmanzadeh, T. Ruzgas, J. Sotres, Proteolytic degradation of gelatin-tannic acid multilayers, J. Colloid Interface Sci. 526 (2018) 244-252, https://doi.org/ 10.1016/j.jcis.2018.04.112.

[262] N. Cao, Y. Fu, J. He, Mechanical properties of gelatin films cross-linked, respectively, by ferulic acid and tannin acid, Food Hydrocoll. 21 (2007) 575-584, https://doi.org/10.1016/j.foodhyd.2006.07.001.

[263] G. Strauss, S.M. Gibson, Plant phenolics as cross-linkers of gelatin gels and gelatin-based coacervates for use as food ingredients, Food Hydrocoll. 18 (2004) 81-89, https://doi.org/10.1016/S0268-005X(03)00045-6.

[264] S. Bittner, When quinones meet amino acids: chemical, physical and biological consequences, Amino Acids 30 (2006) 205-224, https://doi.org/10.1007/ s00726-005-0298-2.

[265] H. Singh, Modification of food proteins by covalent crosslinking, Trends Food Sci. Technol. 2 (1991) 196-200, https://doi.org/10.1016/0924-2244(91)90683A.

[266] R.D. Kale, V.G. Gorade, O. Parmaj, R.D. Kale, V.G. Gorade, Waste medical cotton reinforced chitosan biocomposite film using tannic acid as the crosslinking agent waste medical cotton reinforced chitosan biocomposite film using tannic acid as the crosslinking agent, J. Nat. Fibers. 0 (2018) 1-8, https://doi.org/ $10.1080 / 15440478.2018 .1558156$.

[267] S. Rivero, M.A. García, A. Pinotti, Crosslinking capacity of tannic acid in plasticized chitosan films, Carbohydr. Polym. 82 (2010) 270-276, https:// doi.org/10.1016/j.carbpol.2010.04.048.

[268] Q. Li, Z. Liao, X. Fang, D. Wang, J. Xie, X. Sun, L. Wang, Tannic acidpolyethyleneimine crosslinked loose nano fi ltration membrane for dye/salt mixture separation, J. Membr. Sci. 584 (2019) 324-332, https://doi.org/ 10.1016/j.memsci.2019.05.002.

[269] R. Ravichandran, V. Seitz, J. Reddy Venugopal, R. Sridhar, S. Sundarrajan, S. Mukherjee, E. Wintermantel, S. Ramakrishna, Mimicking native extracellular matrix with phytic acid-crosslinked protein nanofibers for cardiac tissue engineering, Macromol. Biosci. 13 (2013) 366-375, https://doi.org/10.1002/ mabi.201200391.

[270] A.J.R. Costello, T. Glonek, T.C. Myers, 31P Nuclear magnetic resonance pH titrations of myo-inositol hexaphosphate, Carbohydr. Res. 46 (1976) 159-171, https://doi.org/10.1016/S0008-6215(00)84287-1.

[271] T. Zhang, H. Yan, L. Shen, Z. Fang, X. Zhang, J. Wang, B. Zhang, Chitosan/ phytic acid polyelectrolyte complex: a green and renewable intumescent flame retardant system for ethylene-vinyl acetate copolymer, Ind. Eng. Chem. Res. 53 (2014) 19199-19207, https://doi.org/10.1021/ie503421f.

[272] J.U. Kim, B. Kim, H.M. Shahbaz, S.H. Lee, D. Park, J. Park, Encapsulation of probiotic Lactobacillus acidophilus by ionic gelation with electrostatic extrusion for enhancement of survival under simulated gastric conditions and during refrigerated storage, Int. J. Food Sci. Technol. 52 (2017) 519-530, https:// doi.org/10.1111/ijfs.13308. 
[273] J. Yang, H. Lu, M. Li, J. Liu, S. Zhang, L. Xiong, Q. Sun, Development of chitosan-sodium phytate nanoparticles as a potent antibacterial agent, Carbohydr. Polym. 178 (2017) 311-321, https://doi.org/10.1016/j.carbpol.2017.09.053.

[274] T. Kim, J.U. Kim, K. Yang, K. Nam, D. Choe, E. Kim, I.H. Hong, M. Song, H. Lee J. Park, Y.H. Roh, Nanoparticle-patterned multicompartmental chitosan capsules for oral delivery of oligonucleotides, ACS Biomater. Sci. Eng. (2018), https:// doi.org/10.1021/acsbiomaterials.8b00806.

[275] G. Liu, Z. Liu, J. Li, M. Zeng, Z. Li, L. He, F. Li, Chitosan/phytic acid hydrogel as a platform for facile synthesis of heteroatom-doped porous carbon frameworks for electrocatalytic oxygen reduction, Carbon N. Y. 137 (2018) 68-77, https:// doi.org/10.1016/j.carbon.2018.05.027.

[276] J.U. Kim, H.M. Shahbaz, H. Lee, T. Kim, K. Yang, Y.H. Roh, J. Park, Optimization of phytic acid-crosslinked chitosan microspheres for oral insulin delivery using response surface methodology, Int. J. Pharm. 588 (2020) 119736, https://doi.org/10.1016/j.ijpharm.2020.119736.

[277] M. Amidi, E. Mastrobattista, W. Jiskoot, W.E. Hennink, Chitosan-based delivery systems for protein therapeutics and antigens, Adv. Drug Deliv. Rev. 62 (2010) 59-82, https://doi.org/10.1016/j.addr.2009.11.009.

[278] J.R. Veraart, Y. Schouten, C. Gooijer, H. Lingeman, Evaluation of phytic acid as a buffer additive for the separation of proteins in capillary electrophoresis, J. Chromatogr. A 768 (1997) 307-313, https://doi.org/10.1016/S0021-9673(96) 01099-0.

[279] H. Lee, C. Jeong, K. Ghafoor, S. Cho, J. Park, Oral delivery of insulin using chitosan capsules cross-linked with phytic acid, Biomed. Mater. Eng. 21 (2011) 25-36, https://doi.org/10.3233/BME-2011-0654.

[280] C. Aral, J. Akbuga, S. Ozbas-Turan, Controlled release of Interleukin-2 from chitosan microspheres, J. Pharm. Sci. 91 (2002) 1245-1251.

[281] R.D. Kale, V.G. Gorade, O. Parmaj, R.D. Kale, V.G. Gorade, Waste medical cotton reinforced chitosan biocomposite film using tannic acid as the crosslinking agent waste medical cotton reinforced chitosan biocomposite film using tannic acid as the crosslinking agent, J. Nat. Fibers. 0 (2018) 1-8, https://doi.org/ $10.1080 / 15440478.2018 .1558156$

[282] S. Rivero, M.A. García, A. Pinotti, Crosslinking capacity of tannic acid in plasticized chitosan films, Carbohydr. Polym. 82 (2010) 270-276, https:// doi.org/10.1016/j.carbpol.2010.04.048.

[283] Q. Li, Z. Liao, X. Fang, D. Wang, J. Xie, X. Sun, L. Wang, Tannic acidpolyethyleneimine crosslinked loose nano fi ltration membrane for dye/salt mixture separation, J. Membr. Sci. 584 (2019) 324-332, https://doi.org/ 10.1016/j.memsci.2019.05.002.

[284] H.C. Kolb, M.G. Finn, K.B. Sharpless, Click chemistry: diverse chemical function from a few good reactions, Angew. Chem. Int. Ed. Eng. 40 (2001) 2004-2021, https://doi.org/10.1002/1521-3773(20010601)40:11 < 2004::aid-anie2004> 3.3.co; $2-\mathrm{x}$.

[285] Y. Zou, L. Zhang, L. Yang, F. Zhu, M. Ding, F. Lin, Z. Wang, Y. Li, “Click" chemistry in polymeric scaffolds: bioactive materials for tissue engineering, $\mathrm{J}$. Control. Release 273 (2018) 160-179, https://doi.org/10.1016/ j.jconrel.2018.01.023.

[286] Z. Xu, K.M. Bratlie, Click chemistry and material selection for in situ fabrication of hydrogels in tissue engineering applications, ACS Biomater. Sci. Eng. 4 (2018) 2276-2291, https://doi.org/10.1021/acsbiomaterials.8b00230.

[287] Y. Li, X. Wang, Y. Han, H.-Y. Sun, J. Hilborn, L. Shi, Click chemistry-based biopolymeric hydrogels for regenerative medicine, Biomed. Mater. 16 (2021) 22003, https://doi.org/10.1088/1748-605x/abc0b3.

[288] J. Gopinathan, I. Noh, Click chemistry-based injectable hydrogels and bioprinting inks for tissue engineering applications, Tissue Eng. Regen. Med. 15 (2018) 531-546, https://doi.org/10.1007/s13770-018-0152-8.

[289] H.J. Lee, G.M. Fernandes-Cunha, K.-S. Na, S.M. Hull, D. Myung, Bioorthogonally crosslinked, in situ forming corneal stromal tissue substitute, Adv. Healthc. Mater. 7 (2018) 1800560, https://doi.org/10.1002/adhm.201800560.

[290] X. Feng, X. Zhang, S. Li, Y. Zheng, X. Shi, F. Li, S. Guo, J. Yang, Preparation of aminated fish scale collagen and oxidized sodium alginate hybrid hydrogel for enhanced full-thickness wound healing, Int. J. Biol. Macromol. 164 (2020) 626-637, https://doi.org/10.1016/j.ijbiomac.2020.07.058.

[291] J.G. Hardy, P. Lin, C.E. Schmidt, Biodegradable hydrogels composed of oxime crosslinked poly(ethylene glycol), hyaluronic acid and collagen: a tunable platform for soft tissue engineering, J. Biomater. Sci. Polym. Ed. 26 (2015) 143-161, https://doi.org/10.1080/09205063.2014.975393.

[292] N.B. Hentzen, L.E.J. Smeenk, J. Witek, S. Riniker, H. Wennemers, Cross-linked collagen triple helices by oxime ligation, J. Am. Chem. Soc. 139 (2017) 12815-12820, https://doi.org/10.1021/jacs.7b07498.

[293] S.-B. Park, E. Lih, K.-S. Park, Y.K. Joung, D.K. Han, Biopolymer-based functional composites for medical applications, Prog. Polym. Sci. 68 (2017) 77-105, https:// doi.org/10.1016/j.progpolymsci.2016.12.003.

[294] S. Piluso, R. Vukićević, U. Nöchel, S. Braune, A. Lendlein, A.T. Neffe, Sequential alkyne-azide cycloadditions for functionalized gelatin hydrogel formation, Eur. Polym. J. 100 (2018) 77-85, https://doi.org/10.1016/j.eurpolymj.2018.01.017.

[295] C. García-Astrain, A. Gandini, C. Peña, I. Algar, A. Eceiza, M. Corcuera, N. Gabilondo, Diels-Alder "click" chemistry for the cross-linking of furfuryl-gelatinpolyetheramine hydrogels, RSC Adv. 4 (2014) 35578-35587, https://doi.org/ 10.1039/C4RA06122E.

[296] L. Tytgat, L. Van Damme, J. Van Hoorick, H. Declercq, H. Thienpont, H. Ottevaere, P. Blondeel, P. Dubruel, S. Van Vlierberghe, Additive manufacturing of photo-crosslinked gelatin scaffolds for adipose tissue engineering, Acta Biomater. 94 (2019) 340-350, https://doi.org/10.1016/j.actbio.2019.05.062.

[297] X. Hu, D. Li, F. Zhou, C. Gao, Biological hydrogel synthesized from hyaluronic acid, gelatin and chondroitin sulfate by click chemistry, Acta Biomater. 7 (2011)
1618-1626, https://doi.org/10.1016/j.actbio.2010.12.005.

[298] J.L. Vanderhooft, M. Alcoutlabi, J.J. Magda, G.D. Prestwich, Rheological properties of cross-linked hyaluronan-gelatin hydrogels for tissue engineering, Macromol. Biosci. 9 (2009) 20-28, https://doi.org/10.1002/mabi.200800141.

[299] T. Hozumi, T. Kageyama, S. Ohta, J. Fukuda, T. Ito, Injectable hydrogel with slow degradability composed of gelatin and hyaluronic acid cross-linked by Schiff's base formation, Biomacromolecules. 19 (2018) 288-297, https://doi.org/ 10.1021/acs.biomac.7b01133.

[300] X. Bi, A. Liang, Y. Tan, P. Maturavongsadit, A. Higginbothem, T. Gado, A. Gramling, H. Bahn, Q. Wang, Thiol-ene crosslinking polyamidoamine dendrimerhyaluronic acid hydrogel system for biomedical applications, J. Biomater. Sci. Polym. Ed. 27 (2016) 743-757, https://doi.org/10.1080/ 09205063.2016 .1159473$.

[301] F. Yu, X. Cao, Y. Li, L. Zeng, B. Yuan, X. Chen, An injectable hyaluronic acid/ PEG hydrogel for cartilage tissue engineering formed by integrating enzymatic crosslinking and Diels-Alder "click chemistry", Polym. Chem. 5 (2014) 1082-1090, https://doi.org/10.1039/C3PY00869J.

[302] X. Li, S. A., Q. Xu, F. Alshehri, M. Zeng, D. Zhou, J. Li, G. Zhou, W. Wang, Cartilage-derived progenitor cell-laden injectable hydrogel—an approach for cartilage tissue regeneration, ACS Appl. Bio Mater. 3 (2020) 4756-4765, https:// doi.org/10.1021/acsabm.0c00294.

[303] L. Ma, W. Su, Y. Ran, X. Ma, Z. Yi, G. Chen, X. Chen, Z. Deng, Q. Tong, X. Wang, $\mathrm{X}$. Li, Synthesis and characterization of injectable self-healing hydrogels based on oxidized alginate-hybrid-hydroxyapatite nanoparticles and carboxymethyl chitosan, Int. J. Biol. Macromol. 165 (2020) 1164-1174, https://doi.org/ 10.1016/j.ijbiomac.2020.10.004.

[304] H. Sánchez-Morán, A. Ahmadi, B. Vogler, K.-H. Roh, Oxime cross-linked alginate hydrogels with tunable stress relaxation, Biomacromolecules. 20 (2019) 4419-4429, https://doi.org/10.1021/acs.biomac.9b01100.

[305] A. Lueckgen, D.S. Garske, A. Ellinghaus, D.J. Mooney, G.N. Duda, A. Cipitria, Enzymatically-degradable alginate hydrogels promote cell spreading and in vivo tissue infiltration, Biomaterials. 217 (2019) 119294, https://doi.org/10.1016/ j.biomaterials.2019.119294.

[306] G. Wang, J. Zhu, X. Chen, H. Dong, Q. Li, L. Zeng, X. Cao, Alginate based antimicrobial hydrogels formed by integrating Diels-Alder "click chemistry" and the thiol-ene reaction, RSC Adv. 8 (2018) 11036-11042, https://doi.org/ 10.1039/C8RA00668G.

[307] O. Guaresti, C. García-Astrain, T. Palomares, A. Alonso-Varona, A. Eceiza, N. Gabilondo, Synthesis and characterization of a biocompatible chitosan-based hydrogel cross-linked via 'click' chemistry for controlled drug release, Int. J. Biol. Macromol. 102 (2017) 1-9, https://doi.org/10.1016/j.ijbiomac.2017.04.003.

[308] Z. Jia, F. Zhu, X. Li, Q. Liang, Z. Zhuo, J. Huang, L. Duan, J. Xiong, D. Wang, Repair of osteochondral defects using injectable chitosan-based hydrogel encapsulated synovial fluid-derived mesenchymal stem cells in a rabbit model, Mater. Sci. Eng. C 99 (2019) 541-551, https://doi.org/10.1016/ j.msec.2019.01.115

[309] ThermoFisher, Bioconjugation Technical Handbook Download, 2021. https:// www.thermofisher.com/br/en/home/global/forms/life-science/bioconjugationtechnical-handbook-download.html. (Accessed 12 December 2021).

[310] Sigma Aldrich, 2021. in: https://www.sigmaaldrich.com/BR/pt. (Accessed 12 December 2021).

[311] I. Myrgorodska, M. Jenkinson-Finch, R.O. Moreno-Tortolero, S. Mann, P. Gobbo, A novel acid-degradable PEG crosslinker for the fabrication of $\mathrm{pH}$ responsive soft materials, Macromol. Rapid Commun. 42 (2021) 2100102, https://doi.org/10.1002/marc.202100102.

[312] X. Huang, M. Li, D.C. Green, D.S. Williams, A.J. Patil, S. Mann, Interfacial assembly of protein-polymer nano-conjugates into stimulus-responsive biomimetic protocells, Nat. Commun. 4 (2013) 1-9, https://doi.org/10.1038/ ncomms3239.

[313] X. Huang, A.J. Patil, M. Li, S. Mann, Design and construction of higher-order structure and function in proteinosome-based protocells, J. Am. Chem. Soc. 136 (2014) 9225-9234, https://doi.org/10.1021/ja504213m.

[314] C. Zhao, M. Zhu, Y. Fang, X. Liu, L. Wang, D. Chen, X. Huang, Engineering proteinosomes with renewable predatory behaviour towards living organism, Mater. Horizons. 7 (2019) 157-163, https://doi.org/10.1039/C9MH00976K.

[315] W. Muangsiri, L.E. Kirsch, The protein-binding and drug release properties of macromolecular conjugates containing daptomycin and dextran, Int. J. Pharm. 315 (2006) 30-43, https://doi.org/10.1016/j.ijpharm.2006.02.016.

[316] N.J. Rodriguez, O. Hu, Y. Luo, Oxidized dextran as a macromolecular crosslinker stabilizes the Zein/Caseinate nanocomplex for the potential oral delivery of curcumin, Molecules. 24 (2019) 4061, https://doi.org/10.3390/ molecules24224061.

[317] C. Dispenza, D. Giacomazza, M. Jonsson, Micro-to nanoscale bio-hybrid hydrogels engineered by ionizing radiation, Biomolecules. 11 (2021) 1-19, https://doi.org/10.3390/biom11010047.

[318] Electromagnetic Spectrum, (n.d.). https://astronomy.swin.edu.au/cosmos/e/ electromagnetic + spectrum.

[319] K.A. da Silva Aquino, Sterilization by gamma irradiation, in: Gamma Radiat, 2012, pp. 172-202, https://doi.org/10.5772/34901.

[320] M.E. Dzaugis, A.J. Spivack, S. D'Hondt, A quantitative model of water radiolysis and chemical production rates near radionuclide-containing solids, Radiat. Phys. Chem. 115 (2015) 127-134, https://doi.org/10.1016/ j.radphyschem.2015.06.011.

[321] B. Fei, R.A. Wach, H. Mitomo, F. Yoshii, T. Kume, Hydrogel of biodegradable cellulose derivatives. I. Radiation-induced crosslinking of CMC, J. Appl. Polym. Sci. 78 (2000) 278-283. doi:10.1002/1097-4628(20001010)78:2<278::AID- 
APP60 > 3.0.CO;2-9.

[322] T. Fekete, J. Borsa, E. Takács, L. Wojnárovits, Synthesis of carboxymethylcellulose/starch superabsorbent hydrogels by gamma-irradiation, Chem. Cent. J. 11 (2017) 1-10, https://doi.org/10.1186/s13065-017-0273-5.

[323] M.M. Bhuyan, N.C. Dafader, K. Hara, H. Okabe, Y. Hidaka, M.M. Rahman, M.M.R. Khan, N. Rahman, Synthesis of potato starch-acrylic-acid hydrogels by gamma radiation and their application in dye adsorption, Int. J. Polym. Sci. 2016 (2016), https://doi.org/10.1155/2016/9867859.

[324] A.A. El-Naggar, Radiation synthesis of superabsorbent hydrogels based on carboxymethyl cellulose/sodium alginate for absorbent of heavy metal ions from waste water, J. Thermoplast. Compos. Mater. 29 (2016) 16-27, https://doi.org/ $10.1177 / 0892705713518786$.

[325] L. Zhao, H.J. Gwon, Y.M. Lim, Y.C. Nho, S.Y. Kim, Hyaluronic acid/chondroitin sulfate-based hydrogel prepared by gamma irradiation technique, Carbohydr. Polym. 102 (2014) 598-605, https://doi.org/10.1016/j.carbpol.2013.11.048.

[326] R.A. Wach, A. Adamus-Wlodarczyk, A.K. Olejnik, M. Matusiak, C. TranquilanAranilla, P. Ulanski, Carboxymethylchitosan hydrogel manufactured by radiationinduced crosslinking as potential nerve regeneration guide scaffold, React. Funct. Polym. 152 (2020) 104588, https://doi.org/10.1016/ j.reactfunctpolym.2020.104588.

[327] R.A. Wach, H. Mitomo, N. Nagasawa, F. Yoshii, Radiation crosslinking of carboxymethylcellulose of various degree of substitution at high concentration in aqueous solutions of natural pH, Radiat. Phys. Chem. 68 (2003) 771-779, https:// doi.org/10.1016/S0969-806X(03)00403-1.

[328] T. Fekete, J. Borsa, E. Takács, L. Wojnárovits, Synthesis of cellulose derivative based superabsorbent hydrogels by radiation induced crosslinking, Cellulose. 21 (2014) 4157-4165, https://doi.org/10.1007/s10570-014-0445-6.

[329] A.I. Van Den Bulcke, B. Bogdanov, N. De Rooze, E.H. Schacht, M. Cornelissen, H. Berghmans, Structural and rheological properties of methacrylamide modified gelatin hydrogels, Biomacromolecules. 1 (2000) 31-38.

[330] M. Zhu, Y. Wang, G. Ferracci, J. Zheng, N.J. Cho, B.H. Lee, Gelatin methacryloyl and its hydrogels with an exceptional degree of controllability and batch-to-batch consistency, Sci. Rep. 9 (2019) 1-13, https://doi.org/10.1038/s41598-01942186-X.

[331] X.H. Qin, A. Ovsianikov, J. Stampfl, R. Liska, Additive manufacturing of photosensitive hydrogels for tissue engineering applications, BioNanoMaterials. 15 (2014) 49-70, https://doi.org/10.1515/bnm-2014-0008.

[332] H. Ding, N.P. Illsley, R.C. Chang, 3D bioprinted GelMA based models for the study of trophoblast cell invasion, Sci. Rep. 9 (2019) 1-13, https://doi.org/ 10.1038/s41598-019-55052-7.

[333] P.A. Levett, F.P.W. Melchels, K. Schrobback, D.W. Hutmacher, J. Malda, T.J. Klein, A biomimetic extracellular matrix for cartilage tissue engineering centered on photocurable gelatin, hyaluronic acid and chondroitin sulfate, Acta Biomater. 10 (2014) 214-223, https://doi.org/10.1016/j.actbio.2013.10.005.

[334] S.M. Saraiva, S.P. Miguel, M.P. Ribeiro, P. Coutinho, I.J. Correia, Synthesis and characterization of a photocrosslinkable chitosan-gelatin hydrogel aimed for tissue regeneration, RSC Adv. 5 (2015) 63478-63488, https://doi.org/10.1039/ c5ra10638a.

[335] O. Jeon, K.H. Bouhadir, J.M. Mansour, E. Alsberg, Photocrosslinked alginate hydrogels with tunable biodegradation rates and mechanical properties, Biomaterials. 30 (2009) 2724-2734, https://doi.org/10.1016/ j.biomaterials.2009.01.034.

[336] S.H. Kim, C.C. Chu, Synthesis and characterization of dextran-methacrylate hydrogels and structural study by SEM, J. Biomed. Mater. Res. 49 (2000) 517-527, https://doi.org/10.1002/(SICI)1097-4636(20000315)49:4<517::AIDJBM10 > 3.0.CO;2-8.

[337] N.A. Peppas, Hydrogels in Medicine and Pharmacy, 1986.

[338] K.F. Arndt, F. Krahl, S. Richter, G. Steiner, Swelling-related processes in hydrogels, in: Hydrogel Sensors and Actuators, Springer, Berlin, Heidelberg, 2009, pp. 69-136, https://doi.org/10.1007/978-3-540-75645-3_3.

[339] H.A. Barnes, J.F. Hutton, K. Walters, An Introduction to Rheology, Elsevier, 1989.

[340] M.J. Moura, M.M. Figueiredo, M.H. Gil, Rheological study of genipin crosslinked chitosan hydrogels, Biomacromolecules. 8 (2007) 3823-3829, https:// doi.org/10.1021/bm700762w.

[341] R. Sun Han Chang, J.C.W. Lee, S. Pedron, B.A.C. Harley, S.A. Rogers, Rheological analysis of the gelation kinetics of an enzyme cross-linked PEG hydrogel, Biomacromolecules. 20 (2019) 2198-2206, https://doi.org/10.1021/ acs.biomac.9b00116.
[342] F.M. Ruzengwe, E.O. Amonsou, T. Kudanga, Transglutaminase-mediated crosslinking of Bambara groundnut protein hydrogels: Implications on rheological, textural and microstructural properties, Food Res. Int. 137 (2020) 109734, https://doi.org/10.1016/j.foodres.2020.109734.

[343] M. Rahimnejad, T. Labonté-Dupuis, N.R. Demarquette, S. Lerouge, A rheological approach to assess the printability of thermosensitive chitosan-based biomaterial inks, Biomed. Mater. 16 (2020) 015003, https://doi.org/10.1088/ 1748-605X/abb2d8.

[344] M. Petitjean, J.R. Isasi, Chitosan, xanthan and locust bean gum matrices crosslinked with $\beta$-cyclodextrin as green sorbents of aromatic compounds, Int. J. Biol. Macromol. 180 (2021) 570-577, https://doi.org/10.1016/ j.ijbiomac.2021.03.098.

[345] R.M. Silverstein, F.X. Webster, D.J. Kiemle, Spectrometric Identification of Organic Compounds, 7th ed., John Wiley \& Sons, New Jersey, 2005.

[346] Libretexts, Infrared Spectroscopy Absorption Table, 2021. https:// chem.libretexts.org/Ancillary_Materials/Reference/Reference_Tables/ Spectroscopic_Parameters/Infrared_Spectroscopy_Absorption_Table. (Accessed 10 October 2021).

[347] J.N.I. Balitaan, C. Der Hsiao, J.M. Yeh, K.S. Santiago, Innovation inspired by nature: biocompatible self-healing injectable hydrogels based on modified- $\beta$ chitin for wound healing, Int. J. Biol. Macromol. 162 (2020) 723-736, https:// doi.org/10.1016/j.ijbiomac.2020.06.129.

[348] Y. Zhang, C.Y. Pham, R. Yu, E. Petit, S. Li, M. Barboiu, Dynamic hydrogels based on double imine connections and application for delivery of fluorouracil, Front. Chem. 8 (2020) 1-8, https://doi.org/10.3389/fchem.2020.00739.

[349] X. He, X. Liu, J. Yang, H. Du, N. Chai, Z. Sha, M. Geng, X. Zhou, C. He, Tannic acid-reinforced methacrylated chitosan/methacrylated silk fibroin hydrogels with multifunctionality for accelerating wound healing, Carbohydr. Polym. 247 (2020) 116689, https://doi.org/10.1016/j.carbpol.2020.116689.

[350] W. Ge, S. Cao, F. Shen, Y. Wang, J. Ren, X. Wang, Rapid self-healing, stretchable, moldable, antioxidant and antibacterial tannic acid-cellulose nanofibril composite hydrogels, Carbohydr. Polym. 224 (2019) 115147, https:// doi.org/10.1016/j.carbpol.2019.115147.

[351] S. Yang, Y. Zhang, T. Wang, W. Sun, Z. Tong, Ultrafast and programmable shape memory hydrogel of gelatin soaked in tannic acid solution, ACS Appl. Mater. Interfaces 12 (2020) 46701-46709, https://doi.org/10.1021/acsami.0c13531.

[352] J.W. Fischer, L.H. Merwin, R.A. Nissan, NMR investigation of the thermolysis of citric acid, Appl. Spectrosc. 49 (1995) 120-126, https://doi.org/10.1366/ 0003702953963229.

[353] V. Sampatrao Ghorpade, A. Vyankatrao Yadav, R. Jacky Dias, K. Krishnat Mali, Fabrication of citric acid crosslinked $\beta$-cyclodextrin/hydroxyethylcellulose hydrogel films for controlled delivery of poorly soluble drugs, J. Appl. Polym. Sci. 135 (2018) 46452, https://doi.org/10.1002/app.46452.

[354] X. He, F. Luzi, W. Yang, Z. Xiao, L. Torre, Y. Xie, D. Puglia, Citric Acid as Green Modifier for Tuned Hydrophilicity of Surface Modified Cellulose and Lignin Nanoparticles, 2018, https://doi.org/10.1021/acssuschemeng.8b01202.

[355] V.S. Ghorpade, R.J. Dias, K.K. Mali, S.I. Mulla, Citric acid crosslinked carboxymethylcellulose-polyvinyl alcohol hydrogel films for extended release of water soluble basic drugs, J. Drug Deliv. Sci. Technol. 52 (2019) 421-430, https://doi.org/10.1016/j.jddst.2019.05.013.

[356] N. Zhang, H. Zhang, R. Li, Y. Xing, Preparation and adsorption properties of citrate-crosslinked chitosan salt microspheres by microwave assisted method, Int. J. Biol. Macromol. 152 (2020) 1146-1156, https://doi.org/10.1016/ j.ijbiomac.2019.10.203.

[357] K.K. Mali, S.C. Dhawale, R.J. Dias, Synthesis and characterization of hydrogel films of carboxymethyl tamarind gum using citric acid, Int. J. Biol. Macromol. 105 (2017) 463-470, https://doi.org/10.1016/j.ijbiomac.2017.07.058.

[358] Y. Tsuchido, Y. Sasaki, S. Sawada, K. Akiyoshi, Protein nanogelation using vitamin B6-bearing pullulan: effect of zinc ions, Polym. J. 47 (2015) 201-205, https://doi.org/10.1038/pj.2014.120.

[359] Thermo Fisher, Crosslinking Technical Handbook, 2012, pp. 1-53, https:// tools.thermofisher.com/content/sfs/brochures/1602163-Crosslinking-ReagentsHandbook.pdf.

[360] A. GhavamiNejad, N. Ashammakhi, X.Y. Wu, A. Khademhosseini, Crosslinking strategies for 3D bioprinting of polymeric hydrogels, Small. 16 (2020) 1-30, https://doi.org/10.1002/smll.202002931. 